\title{
Marco Antonio Cianciarullo
}

\section{Estudo da homeostase dos mediadores pró-inflamatórios e antiinflamatórios na sepse neonatal}

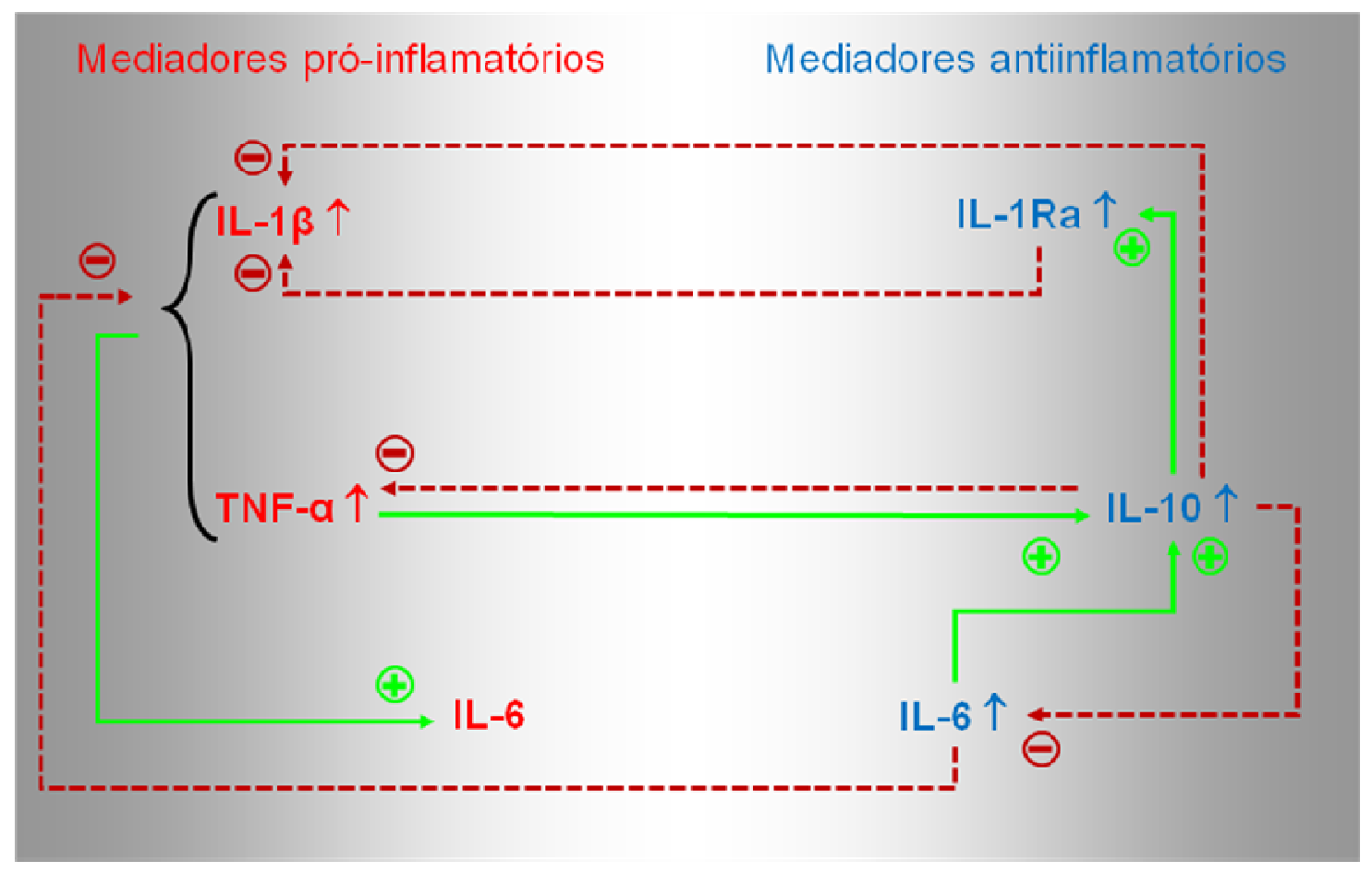

Tese apresentada à Faculdade de Medicina da Universidade de São Paulo, para obtenção do Título de Doutor em Medicina

Área de concentração: Pediatria

Orientadora: Prof. Dra. Maria Esther Jurfest Rivero Ceccon

São Paulo

2008 


\title{
Dados Internacionais de Catalogação na Publicação (CIP)
}

\author{
Preparada pela Biblioteca da
}

Faculdade de Medicina da Universidade de São Paulo

Creprodução autorizada pelo autor

\section{Cianciarullo, Marco Antonio}

Estudo da homeostase dos mediadores pró-inflamatórios e antiinflamatórios na sepse neonatal / Marco Antonio Cianciarullo. -- São Paulo, 2008.

Tese(doutorado)--Faculdade de Medicina da Universidade de São Paulo. Departamento de Pediatria.

Área de concentração: Pediatria.

Orientadora: Maria Esther Jurfest Rivero Ceccon.

Descritores: 1.Mediadores pró-inflamatórios e antiinflamatórios 2.Sepse 3.Recémnascido 4.Fator de necrose tumoral alfa 5.Interleucina-1-beta 6.Interleucina-6 7.Interleucina-10 8.Antagonista do receptor da interleucina-1 9.Proteína C-reativa 10.Diagnóstico clínico 11.Homeostase 12.Prognóstico 


\section{Dedicatórias}

À minha esposa Andréa,

Eterna namorada,

Pelo dom de compartithar a lizz do amor

Guiando nossos caminhos

Pelo dom de ser mãe,

Sempre presente, paciente, compreensiva e

educando nossas fithas,

Pelo carinho, compreensão, paciência, incentivoe colaboração para a reatização deste trabatho,

Comoébom estar ao seu lado

Amote amar. 


\author{
À minha fitha Gabriela \\ Pelos seus ensinamentos \\ Por resgatar a chama da infância onde a \\ inocência ensina a perdoar sem mágoas \\ Por ser uma bênção em nossas vidas \\ Pelo orgulho que sinto \\ Por ser seu fã no 1 \\ Pelo poder da Graça de ser pai \\ E constituir uma Sagrada Famítia
}


À minha fitha Rafaela

Pelos novos ensinamentos:

O Amor não se divide, multiplica-se

Por uma nova bênção em nossas vidas

E a Graça de ser pai novamente

Aumentando a Sagrada Família 


$$
\begin{gathered}
\text { Ao meu sogro Cláudio } \\
\text { À minha Sogra Maritena } \\
\text { Pelo carinho, apoio e dedicação } \\
\text { Que tão bem me acolheram } \\
\text { Por serem exemplos de um porto seguroe } \\
\text { compartithar a vívência e sapiência } \\
\text { No dia a dia }
\end{gathered}
$$


À minha mãe Áurea (in memorüm)

Que não mediw esforços para oferecer precioso amor, justiça e felicidade 


\section{Agradecimentos}

A Dra. Maria Esther Jurfest Rivero Ceccon, pela grandiosidade de nossa amizade, pela sempre presença, estimulo, orientação e realização deste trabalho. Sua arte de ensinar vai muito além do ensinamento médico científico, porque mostra a autêntica riqueza da experiência humana e todos os degraus de limitaçöes a serem superados.

À Dra Edna Maria de Albuquerque Diniz, pela amizade, incentivo e ensinamentos do dia a dia, contribuindo na minha formação universitáría.

À Adriana Sañudo, pela amizade, pela orientação, elaboração, sugestóes e ensinamentos no estudo estatistico deste trabalho.

À Dra Telma Suely Okay, chefe do laboratório de Investigação Médica (LIM-36) e Karina Kawasato pela atenção sempre prestada, organização e reatização dos exames laboratoriais que fazem parte desta pesquisa. 
À Dra Marina B Martinez, chefe do Serviço de Laboratório Clínico do Hospital Universitário da FMUSP e aos profissionais Lígia Maria Giondo Fedeli e Marilice Friedrich pela atenção sempre prestada e auxítio na preparação e armazenamentos dos exames laboratoriais que fazem parte desta pesquisa.

Às colegas da UCINE, Dra Meire Nagaiassu, Dra Cristina Erico, Dra Renata Amato Vieira, pela amizade e colaboração durante a reatização desta tese.

À Dra Silvia Maria Ibidi e equipe neonatal do Hospital Universitário pelo coleguismo na colaboração para que pudesse reatizar este trabalho.

Aos residentes do $1^{\circ}, 2^{\circ}$ e $3^{\circ}$ anos que prestaram sua colaboração durante a reatização deste trabalho.

A Srta Mariza Kazue Umetsu, bibliotecária do Instituto da Criança pela preocupação e profissionatismo na correção das referências bibliográficas. 
Aor colegas do Hospital e Maternidade de Vita Nova Cachoeirinha, Dr. Alcyr Tsuguiyoshi Hamassaki, Dr. Amarildo Aparecido de Souza, Dr. Eduardo José Prado, Dra. Mônica Tilli Reis e Dra Wania Bichara de Freitas, pelo companheirismo e amizade colaborando para a realização deste trabalho. Pelo compartithamento do aprendizado do dia a dia e por serem modelos de companheirismo, postura e respeito dentro da equipe neonatal de sábado.

Ao Sr. Flávio Aoki Camargo e Sra. Tatiana Tuchiya pela grande amizade, companheirismo e preocupação na impressão da tese.

Ao Sr. Nivaldo L. Rocha e Sra. Múlene Aparecida, pela amizade, preocupação e profissionatismo na elaboração dos exemplares.

Às mães e pais que aceitaram participar deste estudo e cumpriram o compromisso até o final.

Aos recém-nascidos, que tornaram possiveis e são a razão desta pesquisa. 


\section{Normatização adotada}

Esta tese está de acordo com as seguintes normas, em vigor no momento desta publicação:

Referências: adaptado de International Committee of Medical Journals Editors (Vancouver)

Universidade de São Paulo. Faculdade de Medicina. Serviço de Biblioteca e Documentação. Guia de apresentação de dissertações, teses e monografias.

Elaborado por Anneliese Carneiro da Cunha, Maria Júlia de A. L. Freddi, Maria Fazanelli Crestana, Marinalva de Souza Aragão, Suely Campos Cardoso, Valéria Vilhena. $2 a$ ed.

São Paulo: Serviço de Biblioteca e Documentação; 2005.

Abreviaturas dos títulos dos periódicos de acordo com List of Journals Indexed in Index Medicus. 
Este trabalho teve auxílio da Fundação de Amparo a Pesquisa do Estado de São Paulo (FAPESP), processo $n^{\circ} 2004$ / $02789-1$ 


\section{Sumário}

Lista de abreviaturas

Resumo

Summary

1. INTRODUÇÃO

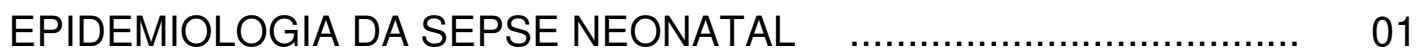

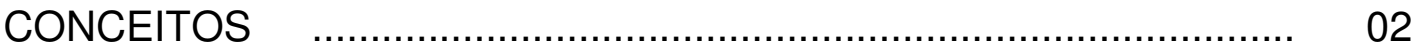

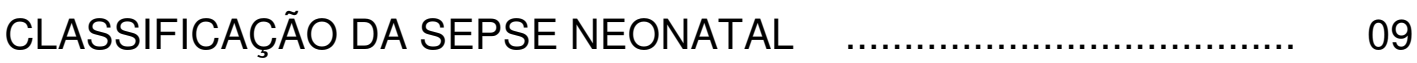

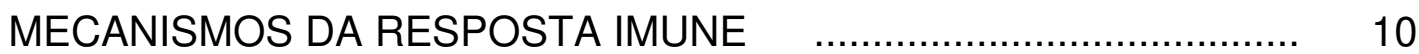

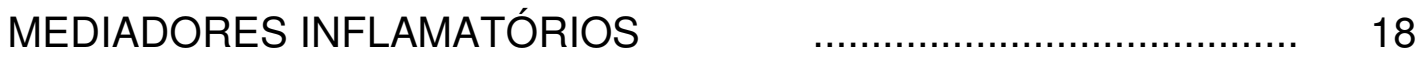

MEDIADORES INFLAMATÓRIOS NA GÊNESE DA SEPSE $\quad \ldots \ldots \ldots \ldots . . . .24$

CITOCINAS PRÓ-INFLAMATÓRIAS (TNF- $\alpha$; IL-1 $\beta$ E IL-6) $\quad . . . . . . . . . . .228$

CITOCINAS ANTIINFLAMATÓRIAS (IL-10 E IL-1Ra) ................ 32

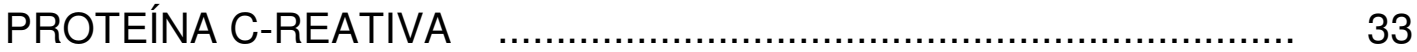

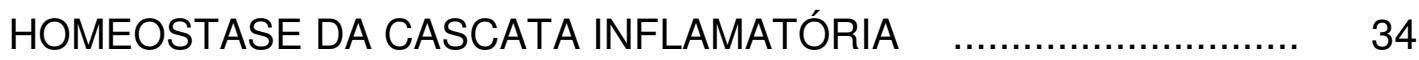

CINÉTICA DA HOMEOSTASE DOS MEDIADORES INFLAMATÓRIOS.. $\quad 37$

PAPEL DAS CITOCINAS NA SEPSE $\quad$....................................... 38

MODELO DO ESTUDO PROPOSTO $\quad$..................................... 41

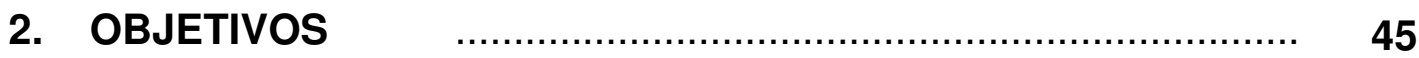

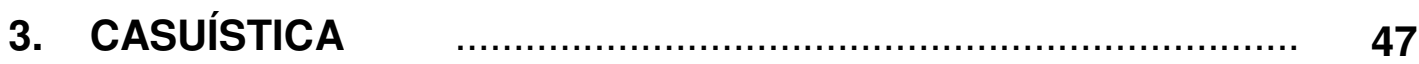

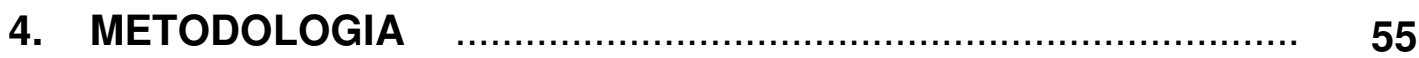

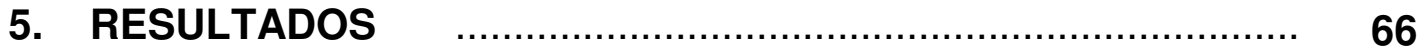

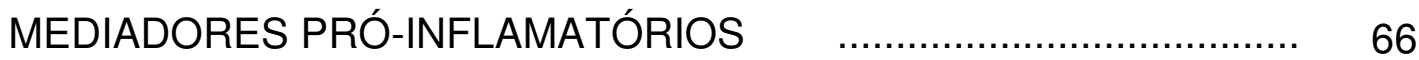

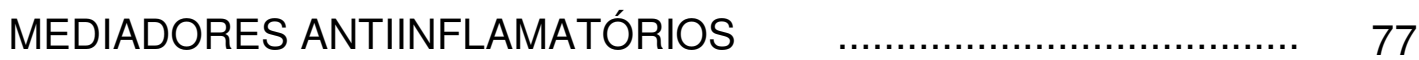

RELAÇÃO: MEDIADORES PRÓ / ANTIINFLAMATÓRIOS................. 84

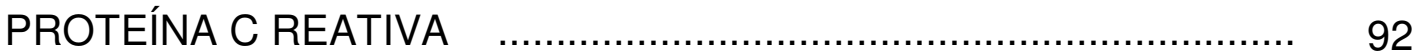

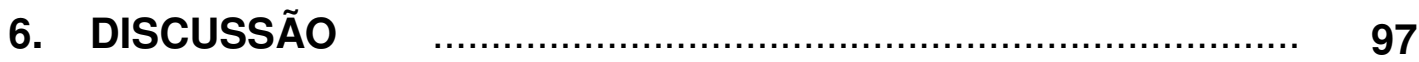

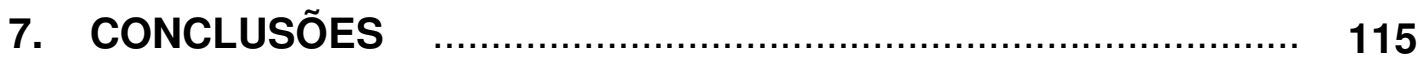

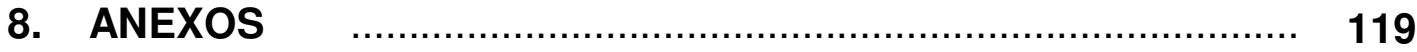

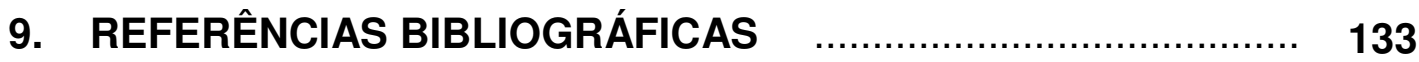




\section{Lista de Abreviaturas}

$\begin{array}{ll}\text { ACCP } & \text { Colégio Americano de Patologia Torácica } \\ \text { ANOVA } & \text { Análise de variância } \\ \text { AP } & \text { Análise paramétrica } \\ \text { ANP } & \text { Análise não paramétrica } \\ \text { CARS } & \text { Síndrome da Resposta Compensatória } \\ \text { CIVD } & \text { Coagulação Intravascular Disseminada } \\ \text { COX-2 } & \text { Ciclooxigenase 2 } \\ \text { DNA-CpG } & \text { DNA fosfato-guanosina bacteriana } \\ \text { ELISA } & \text { Enzyme-linked immunosorbent assay } \\ \text { E } & \text { Especificidade } \\ \text { GPI } & \text { Glicosilfosfatidilinositol } \\ \text { IFN- } \gamma & \text { Interferon } \gamma \\ \text { I-KB } & \text { Fator inibidor kappa B } \\ \text { IN } & \text { Índice neutrofílico } \\ \text { iNOS } & \text { Óxido nítrico sintetase } \\ \text { IL-1Ra } & \text { Antagonista do receptor da Interleucina 1 } \\ \text { IRAK } & \text { Receptor quinase da interleucina 1 } \\ \text { LBP } & \text { Lipopolysaccharide binding protein } \\ \text { LP } & \text { Lipoproteínas } \\ \text { LPS } & \text { Lipopolissacáride } \\ \text { LTA } & \text { Ácido lipoteicóico } \\ \text { MCP-1 } & \text { Proteína 1 monocitária } \\ \text { MHC } & \text { Complexo de histocompatibilidade principal } \\ \text { MyD88 } & \text { Fator 88 diferenciador do mielóide } \\ \text { NF- } \text { B } & \text { Fator nuclear kappa B } \\ \text { NIK } & \text { Fator nuclear quinase } \\ \text { PAMP } & \text { Pathogen-specific molecular patterns } \\ \text { PLA-2 } & \text { Fosfolipase A 2 } \\ \text { PCR } & \text { Proteína C reativa } \\ \text { PG } & \text { Peptideoglicanos }\end{array}$




$\begin{array}{ll}\text { RNI } & \text { Espécie reativa de nitrogênio } \\ \text { ROI } & \text { Espécie reativa de oxigênio } \\ \text { S } & \text { Sensibilidade } \\ \text { SCCM } & \text { Sociedade Americana de Terapia Intensiva } \\ \text { SIRS } & \text { Síndrome da Resposta Inflamatória Sistêmica } \\ \text { TGF } \beta & \text { Fator transformador de crescimento } \\ \text { TLRs } & \text { Toll-like receptors } \\ \text { TRAF-6 } & \text { Receptor TNF associado ao fator } 6 \\ \text { VPP } & \text { Valor preditivo positivo } \\ \text { VPN } & \text { Valor preditivo negativo }\end{array}$




\section{Resumo}

CIANCIARULLO, M. A. Estudo da homeostase dos mediadores próinflamatórios e antiinflamatórios na sepse neonatal. São Paulo 2008. Tese de Doutorado - Faculdade de Medicina da Universidade de São Paulo

Objetivos: Avaliar a utilidade dos mediadores pró-inflamatórios (TNF- $\alpha$, IL-1 $\beta$ e IL6), dos mediadores antiinflamatórios (IL-10 e IL-1Ra) e da Proteína $C$ reativa (PCR) para o diagnóstico na sepse neonatal; verificar se os valores séricos isolados ou a relação entre IL-6 e IL-1Ra têm valor preditivo de gravidade, na evolução clínica da doença; determinar se a homeostase entre os mediadores pró-inflamatórios e antiinflamatórios e a PCR definem o prognóstico da doença. Casuística e métodos: Foram incluídos no estudo 31 recém-nascidos $(\mathrm{RN})$ internados na UCINE ou no Hospital Universitário com diagnóstico de sepse, baseado em critérios clínicos e laboratoriais. Os RN com diagnóstico de sepse foram subdivididos em dois grupos de acordo com a evolução clínica: grupo sepse: os que tiveram boa evolução e grupo sepse grave, os que tiveram evolução complicada por choque séptico e/ou CIVD e/ou FMOS e/ou óbito. Além dos exames de rotina para sepse, forma mensurados nos dias 0,3 e 7 de evolução a partir do diagnóstico, os níveis séricos de TNF- $\alpha$, IL-1 $\beta$, IL-6, IL-10 e IL-1Ra. Resultados: Na análise evolutiva geral, todos os mediadores inflamatórios apresentaram mensuração elevada no dia do diagnóstico (dia 0), com decréscimo dos valores no decorrer do tempo. Entre os mediadores pró-inflamatórios, a TNF- $\alpha$, a IL- 6 e a IL-1 $\beta$ se mostraram adequados para o diagnóstico, no entanto para o seguimento, a melhor foi a IL-6. Entre os mediadores antiinflamatórios a IL-10 seguiu os padrões dos mediadores próinflamatórios acompanhando a resolução do processo séptico, enquanto a IL-1Ra apresentou decréscimos até $03^{\circ}$ dia e permaneceu estável até $07^{0}$ dia caracterizando a perpetuação da ação antiinflamatória desta citocina. Quanto às relações entre mediadores pró-inflamatórios e antiinflamatórios (relação IL-6/IL-1Ra e IL-6/(IL-6 + IL-1Ra) observamos que a IL-6/IL-1Ra apresentou relação com a evolução do processo séptico, mostrando inicialmente predomínio da ação próinflamatória no dia 0 e antiinflamatória no dia 7. A PCR acompanhou de forma muito semelhante as curvas da TNF- $\alpha$, L-6 e IL-10. Quando se subdividiu a casuística em grupos, sepse e sepse grave, observamos que os RN com sepse com boa evolução apresentaram níveis séricos médios de TNF- $\alpha$, IL-1 beta e IL-10 próximos aos níveis mínimos detectáveis e estas citocinas nos $\mathrm{RN}$ com sepse grave 
apresentaram valores bem acima, o que mostra que a gravidade do quadro está relacionada com níveis mais elevados destes mediadores. As IL-6 e IL-1Ra mostraram-se bons marcadores da evolução da doença, pois seus níveis séricos médios estiveram sempre elevados e maiores na sepse grave em relação à sepse com boa evolução. Estas duas citocinas na sepse, apresentaram curvas com o mesmo padrão, enquanto na sepse grave, a IL-1Ra acompanhou o declínio da IL-6 até o $3^{\circ}$ dia para depois, elevar-se até o $7^{\circ}$ dia, caracterizando um desequilíbrio homeostático. Quanto às relações IL-6/IL-1Ra e IL-6/(IL-6 + IL-1Ra), ambas seguiram o mesmo padrão de curva, porém na sepse grave, a relação IL-6/IL-1Ra foi superior a um nos dias 0 e 3 e inferior a 1 no dia 7, enquanto na sepse sem complicações foi superior a 1 no dia 0 e inferior nos dias 3 e 7 , demonstrando que a gravidade do processo séptico (com evolução para cura do processo séptico) retarda a inversão da relação pró-inflamatória/antiinflamatória. Quanto a PCR, observamos que no grupo sepse com boa evolução no dia 0 seu nível sérico foi superior ao do grupo sepse grave, mas nos dias 3 e 7 estes diminuíram de forma mais acentuada, enquanto no grupo sepse houve elevação no dia 3 e posteriormente diminuição paulatina até o dia 7. Conclusões: Os mediadores analisados nesta casuística foram efetivos para o diagnóstico de sepse neonatal e preditivos de gravidade, principalmente as citocinas IL-6 e IL-1Ra. O equilíbrio e/ou desequilíbrio homeostático entre estes, esteve relacionado com o tipo de evolução da doença, sepse sem complicações e sepse grave.

Descritores: 1.Mediadores pró-inflamatórios e antiinflamatórios 2.Sepse 3.Recémnascidos 4.Fator de necrose tumoral alfa 5.Interleucina 1 beta 6.Interleucina 6 7.Interleucina 10 8.Antagonista do receptor da interleucina 1 9.Proteína C-reativa 10.Diagnóstico clínico 11. Homeostase 12.Prognóstico 
Summary

CIANCIARULLO, M.A. - A Study of the homeostasis of the pro-inflammatory and anti-inflammatory mediators in neonatal sepsis. - São Paulo - 2008. Thesis - Doctorate degree - University of São Paulo Medical Scholl.

Objectives - To evaluate the utility of the pro-inflammatory mediators (TNF- $\alpha$, IL1$\beta$, and IL-6), the anti-inflammatory mediators (IL-10 and IL-1Ra) and C-Reactive Protein (CRP) for the diagnosis of neonatal sepsis; to verify whether the isolated seric values or the relation between IL- 6 and IL-1Ra have predictive values for severity regarding the clinical outcome, and to ascertain if the homeostasis between the pro-inflammatory and anti-inflammatory mediators and CPR can define the prognosis of the disease.

Patients and Methods - The study included 31 newborns (NB) admitted to the UCINE (External Neonatal Unit) or to Hospital Universitário (São Paulo University Hospital) with diagnosis of sepsis based upon clinical and laboratorial parameters. The NB with diagnosis of sepsis were further subdivided into 2 groups according to the clinical outcome: sepsis group: containing those NB who evolved to a positive outcome, and severe sepsis group, in turn composed of the NB with unsatisfactory outcomes due to complications caused by septic shock and/or DIVC and/or FMOS and/or death. On days 0,3 , and 7 following diagnosis the seric levels of TNF- $\alpha$, IL$1 \beta$, IL-6, IL-10, and IL-1Ra were measured in addition to the routine sepsis workup.

Results - The general follow-up analysis revealed that all the inflammatory mediators presented elevated levels at diagnosis (day 0 ) with a decrease of these values over time. Regarding the pro-inflammatory mediators, TNF- $\alpha$, IL- 6 and IL- $1 \beta$ were satisfactory for diagnosis, whereas IL-6 was more accurate for follow-up. In relation to the anti-inflammatory mediators, IL-10 revealed the same pattern of the pro-inflammatory mediators following the septic process resolution, whereas IL-1Ra gradually decreased until the $3^{\text {rd }}$ day but hence remained stable until the $7^{\text {th }}$ day, thus characterizing the continuity of the anti-inflammatory action of this cytokine. Concerning the inter-relation between the pro and anti-inflammatory mediators (IL-6/IL-1Ra relation and IL-6/(IL6+IL-1Ra)) we observed that the IL-6/IL-1Ra correlated with the septic process evolution with predominance of the proinflammatory action on day 0 and of the anti-inflammatory action on day 7 . The CRP 
levels behaved similarly to the curves of TNF- $\alpha$, IL-6 and IL-10. When the patients were sub-divided into 2 groups: sepsis and severe sepsis, we observed that the NB with satisfactory outcomes presented with average seric values of TNF- $\alpha$, IL- $1 \beta$ and IL-10 very close to the minimum detected levels of these cytokines, whilst in the NB with severe sepsis had significantly higher values, thus revealing that the severity of the condition was directly correlated to higher levels of these mediators. IL-6 and IL$1 \mathrm{Ra}$ were good disease outcome indicators as their average seric values were always high and even higher in the severe sepsis group when compared to sepsis with satisfactory outcome. During sepsis the two cytokines presented curves with the same pattern, while in severe sepsis the IL-1 Ra followed the decline of IL-6 until the $3^{\text {rd }}$ day but then rose again until the $7^{\text {th }}$ day, thus characterizing a homeostatic imbalance. Both IL-6/IL-1Ra and IL-6/(IL-6+IL-1Ra) followed the same curve patterns, however, in the severe sepsis group the IL-6/IL-1Ra relation was higher than one during days 0 to 3 and lower than one on day 7, while in the sepsis group with no complications (sepsis) the relation was higher than 1 on day 0 and lower than 1 on days 3 and 7 , thus demonstrating that the severity of the septic process (with an outcome towards healing) slows the inversion of the pro-inflammatory/antiinflammatory relation. Regarding the CRP levels, we observed that in the sepsis group with satisfactory outcome on day 0 the seric values were higher than in the severe sepsis group, although on days 3 and 7 these values decreased more substantially, while in the sepsis group they increased on day 3 followed by a gradual decrease until day 7 .

Conclusions - The analyzed mediators were effective in the diagnosis of neonatal sepsis and also predictive of the degree of severity, mainly with regards to cytokines IL-6 and IL-1Ra. The homeostatic equilibrium/disequilibrium was correlated to the type of disease outcome: sepsis with no complications versus severe sepsis.

Keywords: 1 .Inflammation mediators 2.Sepsis 3.Infant newborn 4.Tumor Necrosis Factoralpha 5.Interleukin-1 beta 6.Interleukin-6 7.Interleukin-10 8.Interleukin-1 receptor antagonist 9.C reactive protein 10.Diagnosis clinical 11.Homeostasis 12.Prognosis 
01

INTRODUÇÃO 


\section{INTRODUÇÃO}

\section{EPIDEMIOLOGIA DA SEPSE NEONATAL}

A sepse no período neonatal ainda é causa de elevada morbidade e mortalidade. Segundo a Organização Mundial de Saúde - OMS — em estimativa do ano 2.000, dos 130 milhões de recém-nascidos que nascem, 4 milhões morrem anualmente (Zupan e Aahman, 2005; Lawn et al., 2005), sendo que $99 \%$ destes óbitos ocorrem em países em desenvolvimento. Cerca de 25 a $45 \%$ nas primeiras 24 horas de vida e $75 \%$, na primeira semana de vida (Lawn et al., 2005).

Os processos infecciosos são os mais freqüentes como causa de óbito neonatal $(36 \%)$. Outras causas são prematuridade (28\%) e asfixia (23\%) (Lawn et al., 2005).

As taxas de incidência desta doença variam consideravelmente e dependem principalmente da forma da apresentação (precoce ou tardia), do conceito adotado (clínico ou bacteriológico), do local de estudo (berçários de recém-nascidos normais ou unidade de terapia intensiva neonatal), da idade gestacional e do peso de nascimento do recém-nascido (recém-nascido com muito baixo peso tem maior incidência).

Palazzi et al. (2006) citam uma incidência de 1 a 8,1 casos por 1.000 nascidos vivos. No entanto, Stoll et al., em 2005, analisando recém-nascidos 
com sepse precoce e peso de nascimento variando de 401 a 1.500 gramas, que nasceram em centros do NICHD (National Institute of Child Health and Human Development) durante três períodos: 1.991 a 1.993; 1.998 a 2.000 e 2.002 a 2.003, observaram uma incidência de sepse neonatal precoce de 19,3; 15,4 e 17,0 casos por 1.000 nascidos vivos, respectivamente, ou seja, o dobro da encontrada na população geral. A letalidade na sepse neonatal precoce varia entre 3 a 50\%, na sepse tardia entre 2 a $40 \%$ (Palazzi et al., 2006).

\section{CONCEITOS}

A Conferência Internacional de Definição de Sepse, em 2001, recomendou a incorporação dos critérios da Síndrome da Resposta Inflamatória Sistêmica na categoria de sinais e sintomas, com intuito de melhorar a identificação e definição da síndrome séptica (Levy et al., 2003; Cunneen e Cartwrith, 2004).

Uma visão nova da fisiopatologia da sepse vem aflorando. Historicamente, os sintomas da resposta séptica são decorrentes da resposta imune. Entretanto, estudos recentes sugerem uma complexa interação entre inflamação, coagulação e diminuição da fibrinólise que ocorrem em resposta a um "gatilho" imune, por exemplo, a infecção bacteriana (Opal e Esmon, 2003). O início simultâneo desses três processos tem papel central na fisiopatologia da sepse e o prosseguimento destes pode desencadear disfunção endotelial e falência múltipla de órgãos culminando, se não houver tratamento, com o óbito do paciente (figura 1). 


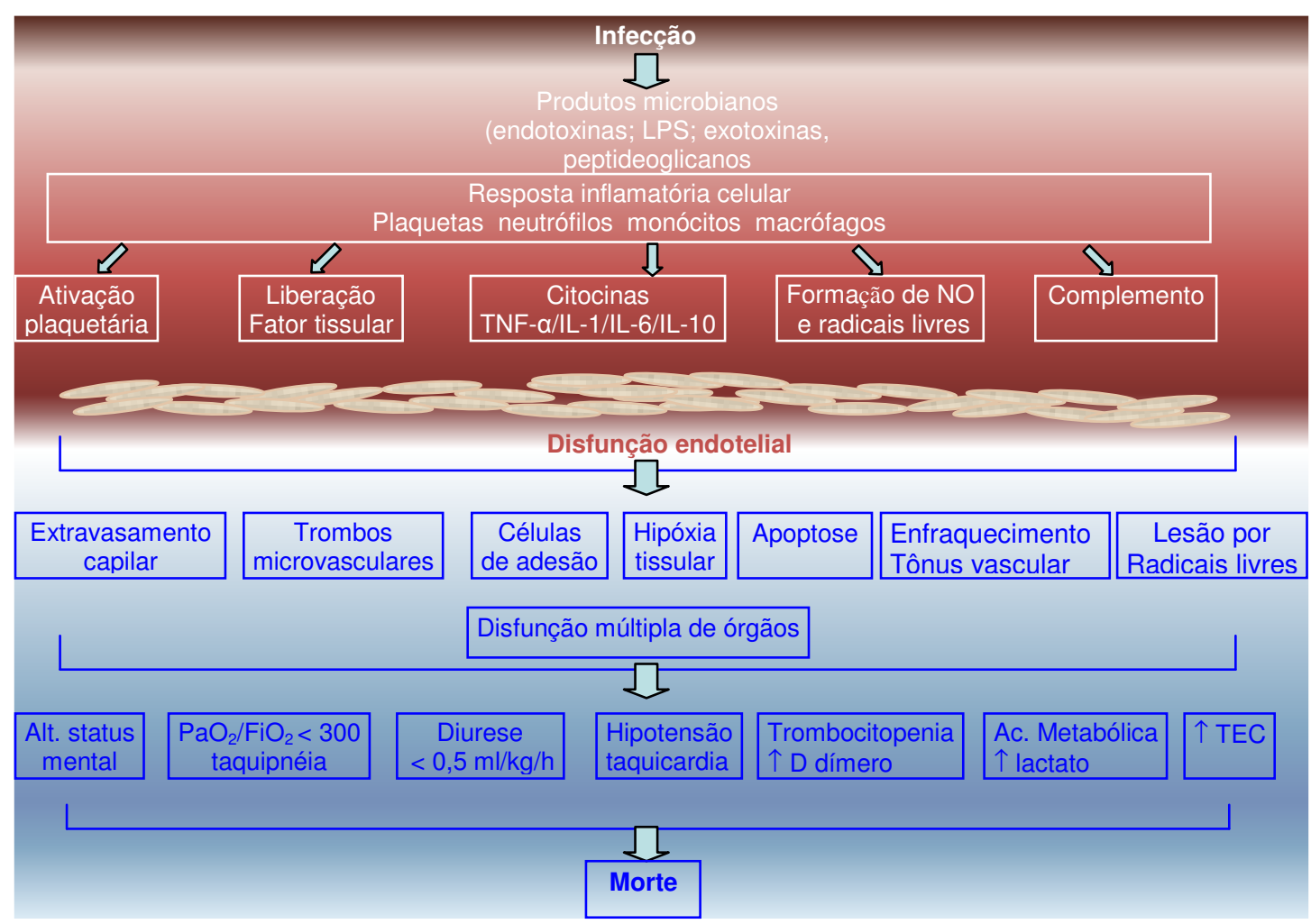

Figura 1: Resumo da patologia da sepse

Fonte: Cunneen e Cartwright, 2004.

Foi discutido na Conferência de 2001 que a disfunção da sepse pediátrica, sobretudo neonatal, necessitava de refinamento e requeria uma série de consensos baseados em evidências. Estes novos conceitos, ainda que não tão elucidativos, buscam uniformizar as condutas médicas e investigação para estudos e diagnósticos.

Em 2002, em outra Conferência realizada em Santo Antonio (Texas), um novo consenso apresentado por Goldstein et al., foi submetido à apreciação e aprovação pela Seção pediátrica da Sociedade de Medicina Intensiva (SCCM), do Colégio Americano de Medicina Intensiva e pela Seção de Medicina Intensiva da Academia Americana de Pediatria e que leva muito em conta as várias faixas etárias: 


\section{a) Delineamento da sepse de acordo com a faixa etária}

As variáveis clínicas usadas como critérios clínicos para o diagnóstico de sepse são bastante afetadas com as mudanças fisiológicas que ocorrem no decorrer da idade da criança. Como a definição de sepse depende dos valores de normalidade dos sinais vitais e laboratoriais de cada faixa etária foram propostos seis grupos de faixa etária (Tabela 1), e com esta a classificação dos novos conceitos:

\begin{tabular}{lc}
\hline \hline Tabela 1: Grupo de idade pediátrica para definição de sepse grave \\
\hline Recém-nascido & 0 dia -1 semana \\
Neonato & 1 semana - 1 mês \\
Lactente & 1 mês - 1 ano \\
Pré-escolar & $2-5$ anos \\
Escolar & $6-12$ anos \\
Adolescentes e adulto jovem & $13-<18$ anos \\
\hline \hline
\end{tabular}

b) Bacteremia / Infecção

Processo patológico causado pela invasão por organismos patogênicos de tecido, fluido ou cavidade normalmente estéril. A cultura de sangue é considerada como exame "Gold Standard", entretanto a positividade da hemocultura em coletas simples não tem boa apreciação, principalmente em recém-nascidos. Fisher et al., em 2003, estimaram que 1 $\mathrm{ml}$ de sangue enviado para cultura tem sensibilidade ao redor de 30 a $40 \%$ e que se eleva para 70 a $80 \%$ quando a amostra é de $3 \mathrm{ml}$. Culturas seriadas não melhoram a sensibilidade do teste (Wiswell e Hachey, 1991). 
b.1) Categorias de infecção na circulação sangüínea em recémnascidos

i) Infecção comprovada: Hemocultura positiva ou reação em cadeia de polimerase positiva na presença de sinais e sintomas clínicos de infecção.

iii) infecção provável: Presença de sinais e sintomas clínicos de infecção e pelo menos dois exames laboratoriais alterados (hemograma e proteína $C$ reativa $(P C R))$ quando a hemocultura é negativa.

iii) Infecção possível: Presença de sinais e sintomas clínicos, aumento da proteína C reativa ou aumento dos níveis de interleucinas - IL-6 e IL-8, quando a hemocultura é negativa.

iv) Ausência de infecção: Ausência de sinais e sintomas clínicos e de exames laboratoriais alterados.

c) Síndrome da Resposta Inflamatória Sistêmica (SRIS)

É definida pela manifestação de pelo menos dois dos seguintes condições:

- Hipotermia $\left(\mathrm{T}^{\circ} \mathrm{C}<36^{\circ} \mathrm{C}\right)$ ou Hipertermia $\left(\mathrm{T}^{\circ} \mathrm{C}>37,9^{\circ} \mathrm{C}\right)$

- Taquicardia, definida com a freqüência cardíaca média > dois desvios padrão para a faixa etária ( $R N$ e neonato $F C>180$ bpm), na ausência de estímulo externo, drogas de uso crônico, estímulo doloroso ou elevação persistente inexplicável por período de 30 minutos a 4 horas.

- Bradicardia: definida com a freqüência cardíaca média inferior ao percentil 10 para idade, ( $\mathrm{RN}$ e neonato $\mathrm{FC}<100 \mathrm{bpm}$ ), na ausência de 
estímulo vagal externo, drogas $\beta$ bloqueadores, cardiopatia congênita ou depressão persistente inexplicável por período superior a 30 minutos.

- Taquipnéia: definida com a freqüência respiratória média superior em duas vezes o desvio padrão para idade (RN FR > 50 irpm e neonato FR > 40 irpm) ou ventilação mecânica em processos agudos não relacionados à doença neuromuscular ou submetidos à anestesia geral.

- Anormalidade de leucócitos no hemograma: contagem de leucócitos elevadas ou diminuídas para idade (não secundária a quimioterapia) ou superior a 10\% de neutrófilos imaturos.

\section{1) Leucocitose:}

RN (0 dia -1 semana): $\quad$ Leucócitos $>34.000 / \mathrm{mm}^{3}$

Neonato: (1 semana -1 mês): $\quad$ Leucócitos $>19.500 / \mathrm{mm}^{3}$

\section{2) Leucopenia:}

RN (0 dia -1 semana): $\quad$ Leucócitos $<5.000 / \mathrm{mm}^{3}$

Neonato: (1 semana -1 mês): $\quad$ Leucócitos $<4.000 / \mathrm{mm}^{3}$

3) Índice Neutrofílico: $\quad$ Índice $>0,2$

4) Plaquetopenia: $\quad$ Plaquetas $<100.000 / \mathrm{mm}^{3}$

\section{d) Sepse}

Definida como a SIRS na presença de infecção ou como resultado de infecção provável ou suspeita. 


\section{e) Sepse Grave}

É a sepse associada à disfunção cardiovascular ou disfunção respiratória ou duas ou mais disfunções de outros órgãos (tabela 2).

\section{f) Choque Séptico}

Sepse e disfunção cardiovascular caracterizada por:

- Taquicardia: FC > 180 bpm em associação a sinais de má perfusão periférica:

a) Tempo de enchimento capilar $>3$ segundos

b) Hipotensão $\geq$ dois desvios padrão abaixo para a idade

c) Requerendo reposição volêmica e suporte vasopressor

\section{g) Síndrome da Disfunção de Múltiplos Órgãos}

Presença de falência múltipla de órgão a despeito do tratamento de suporte. 
Tabela 2: Critérios de disfunção orgânica

Disfunção cardiovascular

- Hipotensão: $\downarrow$ PA < p\% 5 para idade e sistólica < 2DP abaixo para idade

ou

- Necessidade de drogas vasoativas para manter PA (dopamina > $5 \mu \mathrm{g} / \mathrm{kg} / \mathrm{min}$ ou dobutamina ou adrenalina ou noradrenalina em alguma dose

ou

- Duas das seguintes condições:

$\circ$ Acidose metabólica inexplicável: $B E>5,0 \mathrm{mEq} / \mathrm{L}$

- $\uparrow$ Lactato arterial: $2 x$ o limite superior

$\circ$ Oligúria: Diurese $<0,5 \mathrm{ml} / \mathbf{k g} /$ hora

TEC $>>5$ segundos

- Diferença de $\mathbf{T}^{\circ} \mathrm{C}$ central* e periférica $>3^{\circ} \mathrm{C}$

\section{Respiratória}

- $\mathrm{PaO}_{2} / \mathrm{FiO}_{2}<300$ na ausência de cardiopatia congênita ou doença pulmonar pré-existente

ou

- $\mathrm{Pa} \mathrm{CO}_{2}>65$ Torr ou $20 \mathrm{mmHg}$ acima da linha de base

ou

- Necessidade de $\mathrm{FiO}_{2}>50 \%$ para manter $\mathrm{SatO}_{2}>92 \%$

ou

- Necessidade de ventilação mecânica invasiva não eletiva ou não invasiva

\section{Neurológico}

- Escore de Glasgow $\leq 11$

ou

- Mudança aguda do status mental com decréscimo do escore de Glasgow $\geq 3$ pontos da base normal

Hematológica

- Plaquetopenia < $80.000 / \mathrm{mm}^{3}$ ou declínio de $50 \%$ da contagem do valor mais alto dos últimos 3 dias (pacientes crônicos e oncológicos)

ou

- Taxa internacional normalidade $>2$

Renal

- Creatinina sérica $\geq 2$ vezes o limite normal para idade

Hepático

- Bilirrubina Total $\geq 4$ mg/dl (não aplicável em RN)

- Alanina transaminase (ALT) 2 vezes o limite da normalidade

Fonte: Goldstein, B et al., 2005

* Pode ser mensurada: via retal, vesical, oral ou cateter central. 


\section{CLASSIFICAÇÃO DA SEPSE NEONATAL}

A sepse neonatal pode ser classificada de acordo com o tempo de início da sintomatologia e os microorganismos envolvidos.

\section{a) Início precoce}

Quando os sintomas se manifestam nas primeiras 72 horas de vida e a infecção multissistêmica é adquirida por transmissão vertical da mãe correspondendo à infecção ascendente do canal de parto (corioamnionite) ou extensão hematogênica da infecção materna e os microorganismos responsáveis são aqueles do canal de parto.

\section{b) Inicio tardio}

Quando os sintomas se manifestam a partir do quarto dia de vida até três meses de vida, podendo ainda estar associado a complicações obstétricas, porém com intensidade bem menor em relação ao início precoce e os microorganismos, ainda que possam ser adquiridos no canal de parto, na maioria são procedentes de contaminação pós-natal no berçário, através da equipe de saúde, equipamentos ou procedimentos invasivos.

\section{c) Início muito tardio}

Quando os sintomas ocorrem após três meses de vida em recémnascidos de muito baixo peso que se encontram internados em unidades de terapia intensiva. Os microorganismos mais freqüentes são Cândida $s p$, organismos comensais, como os Staphylococcus coagulase negativo. Essas 
infecções são usualmente associadas a equipamentos, tais como cateteres intravasculares, drenos ou cânulas endotraqueais.

\section{MECANISMOS DA RESPOSTA IMUNE}

Em indivíduos saudáveis a proteção contra a invasão de microorganismos ocorre através da ativação simultânea e inter-relacionada do sistema imune. Este compreende:

Resposta natural, também denominada inata ou inespecífica

Resposta adquirida, também denominada adaptativa ou específica

A imunidade adquirida, mediada por linfócitos $T$ e B, reconhece com alta afinidade microorganismos através da combinação de receptores com estruturas da parede celular do microorganismo. No entanto, esta imunidade é caracteristicamente bastante lenta para a erradicação do microorganismo. Por isso, a resposta imune inata, que tem uma resposta mais rápida é de grande importância na defesa do hospedeiro durante os estágios precoces da infecção (Kaisho e Akira, 2002). A resposta imune adquirida além da ativação de fatores de transcrição e de promover a secreção de citocinas junto às células $T$, promove 0 aumento da síntese de citocinas antiinflamatórias (IL-4, IL-10, IL-13), a diminuição dos receptores das citocinas e a liberação de receptores solúveis e antagonistas (Sikora et al., 2001).

A resposta imunológica inata é inespecífica e indiferente a natureza antigênica do microorganismo. Não representa apenas a primeira linha de defesa contra infecções, mas é peça chave na sensibilidade em detectar o 
risco de infecção (Heeg e Dalpke, 2003). É ativada quando microorganismos atravessam a barreira física formada pela pele e pelas membranas mucosas, que podem ser penetradas na colocação de cateteres, intubação endotraqueal, sondas vesicais entre outros, propiciando a entrada de bactérias em tecidos subepiteliais levando a bacteremia por invasão tecidual e necrose (Balagtus et al., 1971; Harris et al., 1976; Storm, 1980) e a barreira química formada por enzimas digestivas, por ácidos graxos bacteriostáticos da pele.

O sistema imune inato é compreendido por substâncias solúveis resposta humoral (inclui sistema complemento, proteínas da fase aguda e citocinas) e por elementos celulares - resposta celular (inclui monócitos, macrófagos, neutrófilos, células dendríticas, células natural "killer") e deflagram a resposta imune adquirida (Bochud e Calandra, 2003).

Agindo de forma integrada e auto-regulada as respostas imunes, inata e adquirida, promovem não apenas o combate à invasão de microorganismos, mas também a limpeza de restos teciduais, a diminuição da lesão celular na tentativa de evitar a sua morte, orquestrando a remodelagem tecidual com proliferação celular e ação angiogênica para o restabelecimento da matriz lesada, promovendo a recuperação do hospedeiro, reduzindo a probabilidade de infecção secundária ou oportunista conforme pode se observar na tabela 3 (Oberholzer et al., 2000; Ayala et al., 2003). 
Tabela 3: Funções do sistema imune inato

- "1ํㅡㄴ linha de defesa"

- Combater à invasão microbiana

- Diminuir a lesão e morte celular

- Promover recuperação do hospedeiro

- Reduzir a probabilidade de infecção $2^{\text {aria }}$ ou oportunista

- Definir a resposta imune adquirida

Fonte: Oberholzer et al., 2000

A resposta imune inata libera diferentes mediadores humorais com função de conter a patogênese microbiana até a definição e o desenvolvimento da resposta imune adquirida, mais definitiva (Brown et al., 1994; Fearon e Locksley, 1996).

A inabilidade na auto-regulação ou desequilíbrio da reação inflamatória ou imune pode resultar em crescimento bacteriano incontrolável promovendo episódios de infecções recorrentes ou resposta inflamatória intensa com lesão tecidual, colapso vascular e falência múltipla de órgãos ou resposta hipoinflamatória promovendo a supressão imunológica (Ayala et al., 2003)

$\mathrm{Na}$ imunidade inata o reconhecimento da invasão de microorganismo é mediado por receptores que reconhecem por afinidade modelos moleculares partilhados por grande grupo de microorganismos. Esses modelos moleculares são estruturas essenciais da parede do microorganismo e os receptores - Toll-like - sinalizam a indução de citocinas pró-inflamatórias e regulação da expressão de moléculas coestimuladoras, ativando desse modo não apenas a resposta imune inata, 
mas também a imunidade adquirida (Heeg e Dalpke, 2003; Werling e Jungi, 2003).

a) Receptores "toll-like" como sensores de patógenos e desencadeadores da resposta imune inata

O que determina a iniciação da resposta imune inata contra microorganismos patogênicos é a presença de componentes da parede celular destes microorganismos em contato com a superfície das células imunológicas e seu reconhecimento como constituinte estrutural não próprio ao hospedeiro (Hallman et al., 2001; Werling e Jungi, 2003). Esta identificação inicial é pré-requisito e principal alicerce da resposta imune inata. Entre os componentes da parede celular de microorganismos patogênicos que envolvem a ativação do sistema imune, temos lipopolissacárides (LPS), peptideoglicanos (PG), ácido lipoteicóico (LTA), Lipoproteínas (LP) e DNA Citosina fosfato-guanosina bacteriana (DNA-CpG). Como fazem parte da estrutura da membrana da parede celular de microorganismos patogênicos são essenciais para a sua sobrevivência e patogenicidade e são freqüentemente denominados como modelo molecular associado ao patógeno - PAMP (pathogen-specific molecular patterns) (Lien e Ingalle, 2002; Kaisho e Akira, 2002, Lakhani e Bogue, 2003).

Os PAMPs são normalmente repetitivos na natureza e são distintos das moléculas do hospedeiro e, quando reconhecidos desencadeiam toda a resposta imune (Brightbill e Modlin, 2000). 
Os receptores envolvidos na identificação dos PAMPs são denominados Toll-like receptors (TLRs). A chave da resposta imune inata é baseada na família destes receptores Toll-like. São receptores do sistema imune inato expressos preferencialmente em monócitos e macrófagos, mas também em células dendríticas, células $B$ e até em outras células não consideradas tradicionalmente como de defesa (Hallman et al., 2001).

O número de receptores envolvidos na resposta imune inata é limitado a aproximadamente 100. Contudo, microorganismos patogênicos são extremamente heterogêneos com altas taxas de mutação. Mas a resposta imune inata tem sido centrada em estruturas essenciais presentes na parede celular destes microorganismos (Hallman et al., 2001; Lakhani e Bogue, 2003).

A funcionalidade do sistema imune está no mecanismo de reconhecimento de microorganismos patogênicos, constituindo a base na diferenciação do que é próprio ou não ao hospedeiro. A sensibilidade e especificidade deste reconhecimento são definidas, pelo menos em parte, pela habilidade dos receptores Toll-like em reconhecer modelos microbianos específicos (Lien e Ingalls, 2002).

Em seres humanos, foram identificados 10 receptores Toll-like (TLR1 a TLR10), sendo sete com interação a microorganismos patogênicos (tabela 4) (Kaisho e Akira, 2002; Bochud e Calandra, 2003). 


\begin{tabular}{|c|c|c|}
\hline Receptor & Agente etiológico & Moléculas de ligação \\
\hline TLR1 & Bactéria Gram positiva & Modulin, Lipopeptideos \\
\hline \multirow{8}{*}{ TLR2 } & Bactéria Gram positiva & $\begin{array}{l}\text { Lipoproteínas, Ácido lipoteicóico } \\
\text { Peptideoglicanos (TLR2/6 ou TLR2/X) }\end{array}$ \\
\hline & Pseudomonas aeruginosa & Polímero do ácido manurônico \\
\hline & Staphylococcus & Modulin (TLR2/6) \\
\hline & Mycobacteriae, Mycoplasmae & $\begin{array}{l}\text { Lipoproteínas, Lipopeptídeos } \\
\text { Lipoarabinomanan }\end{array}$ \\
\hline & Listeria & Bactéria heat-killed \\
\hline & Leveduras & Zymosano (TLR2/6) \\
\hline & Trypanosoma cruzei & Proteínas ancoradas no GPI \\
\hline & Spirochetae & LPS \\
\hline TLR3 & Vírus & dsRNA \\
\hline \multirow[t]{4}{*}{ TLR4 } & Bactéria Gram negativa & LPS \\
\hline & Bactéria Gram positiva & $\begin{array}{l}\text { Ácido lipoteicóico } \\
\text { Polímero do ácido manurônico }\end{array}$ \\
\hline & Plantas & Taxol \\
\hline & Vírus Sincicial Respiratório & Proteína F \\
\hline \multirow[t]{2}{*}{ TLR5 } & Bactéria Gram negativa & Flagelin \\
\hline & Bactéria Gram positiva & Flagelin \\
\hline TLR6 & Bactéria Gram positiva & $\begin{array}{l}\text { Modulin, Lipoproteína } \\
\text { Fator STFsolúvel tuberculosis }\end{array}$ \\
\hline TLR7 & & Pequenos componentes antivirais \\
\hline TLR8 & & Pequenos componentes antivirais \\
\hline TLR9 & Bactéria & ummetilado CpG-DNA \\
\hline
\end{tabular}

Fonte: Werling e Jungi, 2003

Quando a estrutura de algum microorganismo patogênico carboidratos, lípides, proteínas, DNA, RNA - é reconhecida pelos receptores Toll-like na superfície celular, por sua interação, determina a resposta imune inata e evoca a resposta inflamatória aguda com infiltração celular precoce no local da infecção. O sistema imune inato envolve complexa rede de receptores que identifica rapidamente microorganismos patogênicos baseado nas estruturas moleculares que são parte de uma 
variedade de microorganismos (Oberholzer et al., 2000; Bochud e Calandra, 2003; Cook, 2003). São ativadas várias vias de transmissão de sinais resultando na ativação de fatores de transcrição. São estes que controlam a expressão da resposta imune dos genes e a liberação de numerosas moléculas de efeito, como as citocinas. É neste momento que as citocinas têm papel essencial em orquestrar as respostas imunes, tanto inata quanto adquirida, indicando a resposta inflamatória e definindo a magnitude e a natureza da resposta imune adquirida (Figura 2) (Oberholzer et al., 2000; Bochud e Calandra, 2003). 


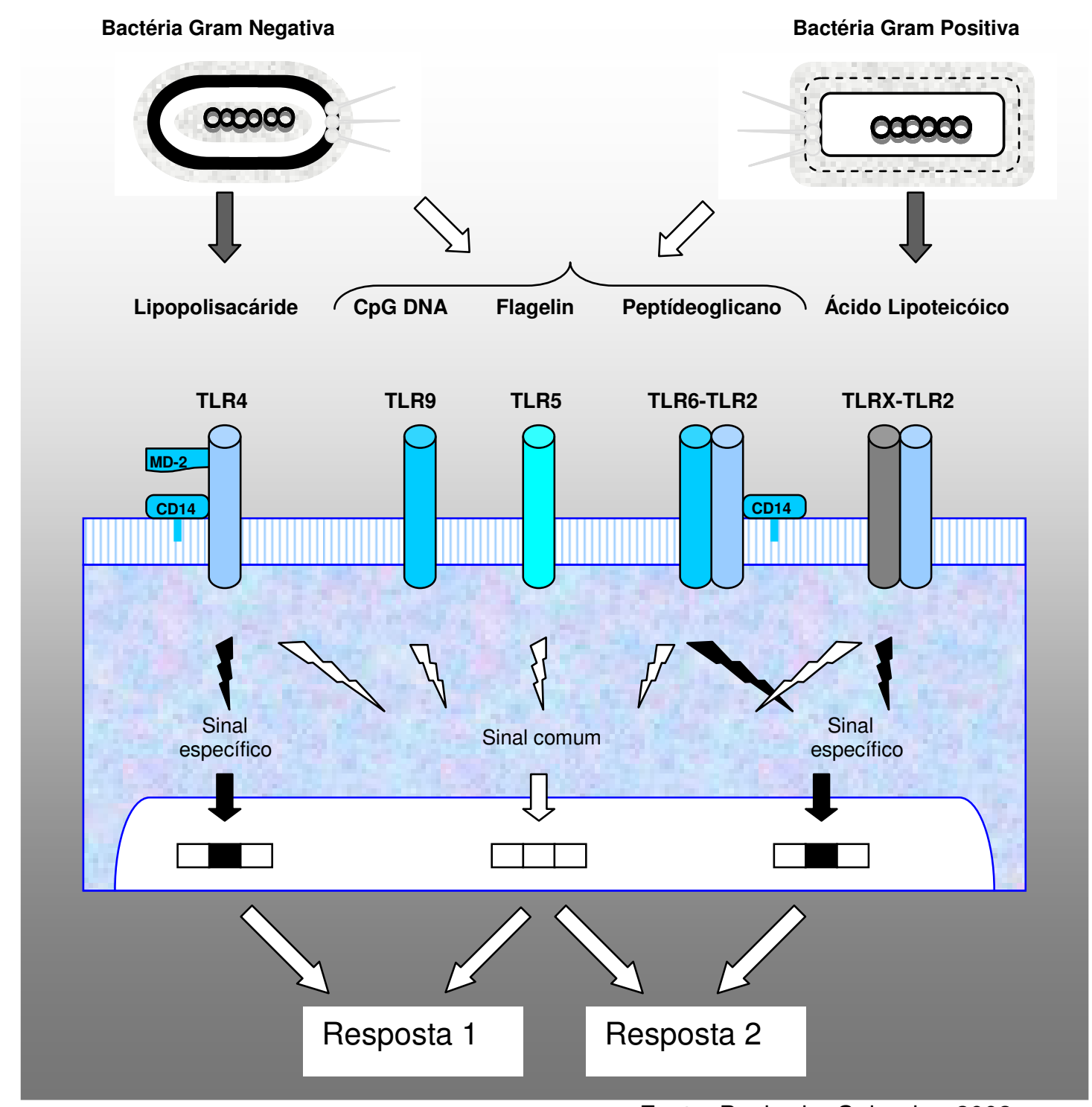

Fonte: Bochud e Calandra, 2003.

Figura 2: Interação entre produtos bacterianos e 0 modelo de reconhecimento da expressão dos receptores na célula imune. Componentes da parede da célula bacteriana (como lipopolissacárides, peptideoglicanos, acido lipoteicóico, flagelin e CpG DNA) interagem com os receptores Toll-like (TLR) expressos na célula imune. Os receptores de identificação ativam várias vias de transmissão de sinais resultando na ativação de fatores de transcrição. Estes controlam a expressão da resposta imune dos genes e a liberação de numerosas moléculas de efeito como as citocinas. 


\section{MEDIADORES INFLAMATÓRIOS}

O conceito de resposta pró e antiinflamatória é baseada na codificação de genes para a síntese de pequenas moléculas mediadoras que se auto-regulam durante a inflamação (Dinarello, 2000).

Após o reconhecimento da estrutura molecular da membrana do microorganismo patogênico invasor pelo receptor Toll-like são desencadeadas respostas imunes subseqüentes pela via NF Kappa B, com ativação e transcrição de vários genes promovendo cascata de eventos (Dinarello, 2000; Senftleben e Karin, 2002; Wright e Christman, 2003):

- Indução enzimática: Óxido-nítrico sintetase (iNOs), Fosfolipase A 2 (PLA-2), Ciclooxigenase-2 (COX-2).

- Ativação da transcrição da proteína ligada a LPS - LBP (lipopolysaccharide binding protein).

- $\quad$ Síntese de citocinas pró-inflamatórias: TNF- $\alpha$; IL-1; IL-6; IL-8; IL-12; IL-18.

- Síntese de: Fator ativador de plaquetas, Leucotrienos, Prostanóides, Quimocinas.

As citocinas têm papel importante nesta fase, pois compartilha os sinais intracelulares com receptores distribuindo informações sobre o tipo de infecção e recrutando células efetivas para a defesa do organismo (Heeg e Dalpke, 2003). Por exemplo, IL-1 e TNF-a recrutam neutrófilos e induzem a formação de moléculas de adesão endotelial, mecanismo essencial para a 
adesão dos leucócitos na superfície endotelial e posterior migração para o tecido (Dinarello, 2000; Brigthbill e Modlin, 2000; Senftleben e Karin, 2002).

\section{a) Ativação das citocinas pró-inflamatórias e antiinflamatórias}

Quando o hospedeiro é invadido por patógeno intracelular, macrófagos, entre outras células são ativados a secretar TNF- $\alpha$, IL-1 $\beta$, IL-12

e IL-18. As interleucinas IL-12 e IL-18 ativam as células T e natural "killer" a produzir interferon- $\gamma($ IFN- $\gamma)$.

O IFN- $\gamma$ e IL-12 induzem a diferenciação das células CD4 ao fenótipo Th1 (células Th1) induzindo a produção de IFN- $\gamma$ e IL-2 e linfotoxina- $\alpha$ (LTa). Além disso, o IFN- $\gamma$ apresenta habilidade para inibir a diferenciação das células CD4 em fenótipo Th2, o qual irá guiar a síntese de interleucinas IL-4, IL-5 e IL-10, potentes inibidores das citocinas tipo Th1.

O IFN- $\gamma$ também induz a atividade macrofágica microbicida através da inativação de TNF- $\alpha$ e da produção de espécies reativas de oxigênio $(\mathrm{ROI})$ e nitrogênio (RNI), e expressão de MHC (figura 3 - Netea et al., 2003). 


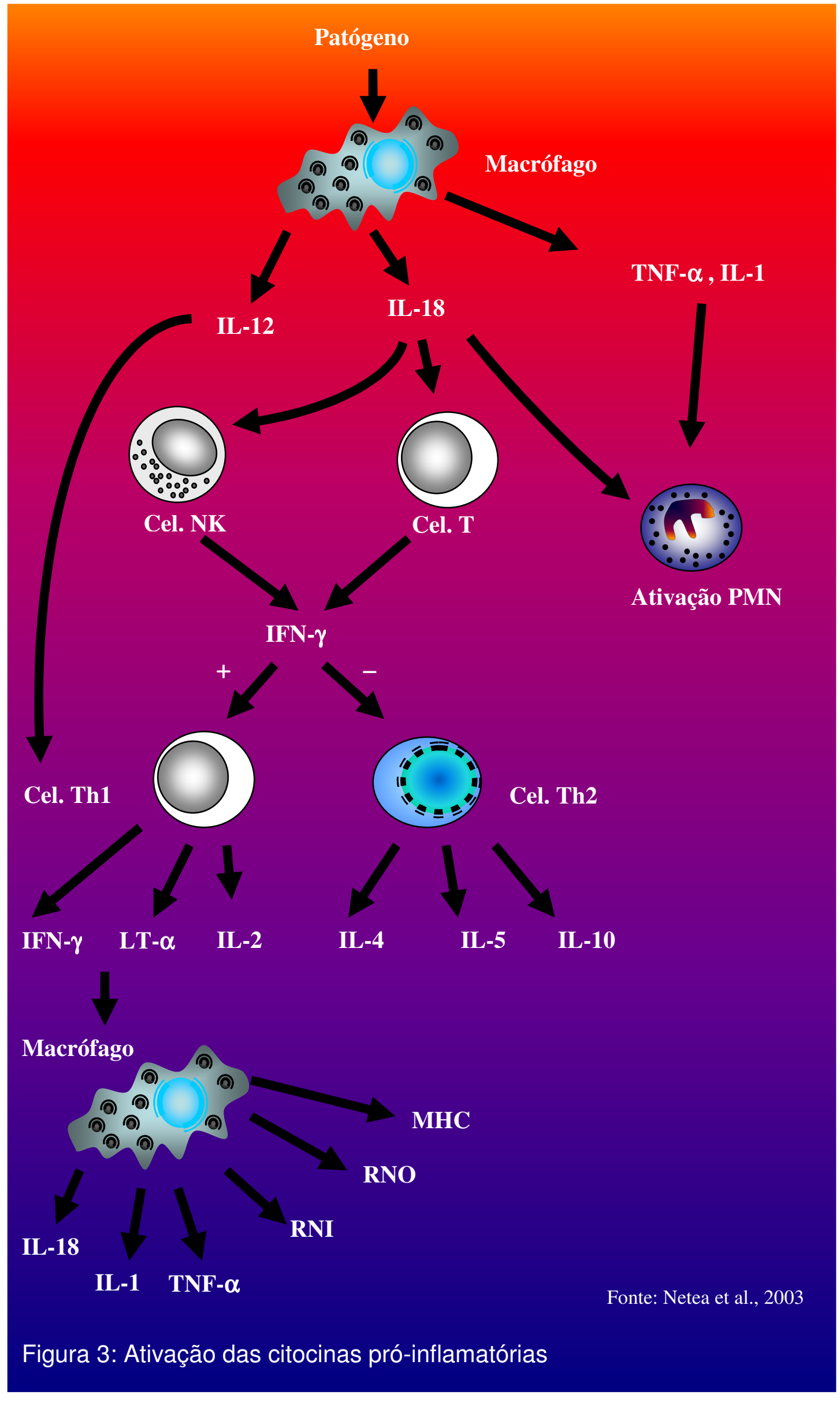




\section{b) Sepse bacteriana}

Bacilos Gram negativos, principalmente Escherichia coli, Klebsiella sp, Pseudomonas aeruginosa e Cocos Gram positivos, principalmente Streptococcus e Staphylococcus são os microorganismos mais freqüentemente isolados em pacientes com sepse grave ou choque séptico.

Lipopolissacáride (LPS) é um componente da membrana externa da bactéria gram negativa e tem papel importante na gênese da sepse por esta bactéria. Sua molécula contém uma cadeia lateral de lipopolissacarídeo, denominada antígeno O, ligada ao oligossacarídeo "core" que, por sua vez, está ligado à molécula lipídica denominada lipídio $\mathrm{A}$ - componente ativo e tóxico da endotoxina (Beutler et al., 1985; Zivot e Hoffman, 1995; Girior, 1993).

Quantidades pequenas de LPS são suficientes para deflagrar o estado de choque. O ser humano infectado por bactéria gram negativa está em contato tanto com a LPS ligada à bactéria como o LPS livre, representado por fragmentos da parede da bactéria liberados durante a replicação do microorganismo.

Uma proteína que apresenta papel crítico na função do receptor Tolllike é o CD14. Ela foi à primeira proteína a ser identificada como receptora de LPS. Esta proteína recruta moléculas com conteúdo lipídico que inclui a própria LPS, lipoproteínas microbianas, parede celular de Streptococcus e lipoarabinomana da M. tuberculosis (Brightbill e Modlin, 2000).

A LPS ligada à bactéria ou livre tem alta afinidade ao CD14, pela âncora glicosilfosfatidilinositol (GPI) ligado à proteína expressa nos 
macrófagos e na proteína TLR2. Entretanto quando o CD14 é co-expresso tanto com TLR2 como TLR4 a ativação por conteúdo lipídico é aumentado.

O complexo formado por CD14, TLR2 e LPS desencadeia o início da cascata intracelular de sinais para a regulação da transcrição do complexo fator nuclear kappa B (NF-k B) e fator inibidor kappa B (I-k B).

Inicialmente o complexo formado por CD14, TLR2 e LPS desencadeia o recrutamento dos fatores de transcrição denominado MyD88 (fator 88 diferenciador do mielóide) e IRAK (receptor quinase da interleucina 1) que agem na adaptação do receptor TRAF-6 (receptor TNF associado ao fator 6) induzindo a ativação da enzima NF-quinase (NIK). Esta quinase promove a fosforilação da porção inibitória kappa B (I-k B) causando sua rápida degradação com liberação de NF-k B. As duas subunidades de NF-k B adentram no núcleo e regulam a transcrição de vários genes promovendo seqüência específica de citocinas e moléculas co-estimuladoras, que são essenciais para a indução da resposta imune adaptativa.

As moléculas co-estimuladoras, chamadas B7.1 (CD80) e B7.2 (CD82) são proteínas da superfície celular que são expressas tanto por macrófagos quanto por células dendríticas em resposta ao LPS sinalizando pelo TLR4. É a presença destas moléculas junto aos antígenos microbianos apresentados pelo macrófago e pelas células dendríticas que ativam as células T CD4 necessárias para o início da maioria das respostas imunes adaptativas. Para encontrar uma célula T CD4, a célula dendrítica apresentadora de antígeno migra para um linfonodo próximo, através do qual passam células $T$ circulantes, e esta migração é estimulada por 
citocinas tais como TNF-a que também é induzida pela sinalização do TLR4. Assim a ativação da imunidade adaptativa depende de moléculas induzidas como conseqüência do reconhecimento imune inato e da sinalização (Janeway et al., 2002) Assim, estes produtos agem nas células T e B iniciando a resposta imune adaptativa (figura 4), que envolve células de proliferação, diferenciação, apoptose e inflamação (Modlin et al., 1999; Brightbill e Modlin, 2000; Beutler e Poltorak, 2001; Senftleben e Karin, 2002; Wright e Christman, 2003; Lakhani e Bogue, 2003).

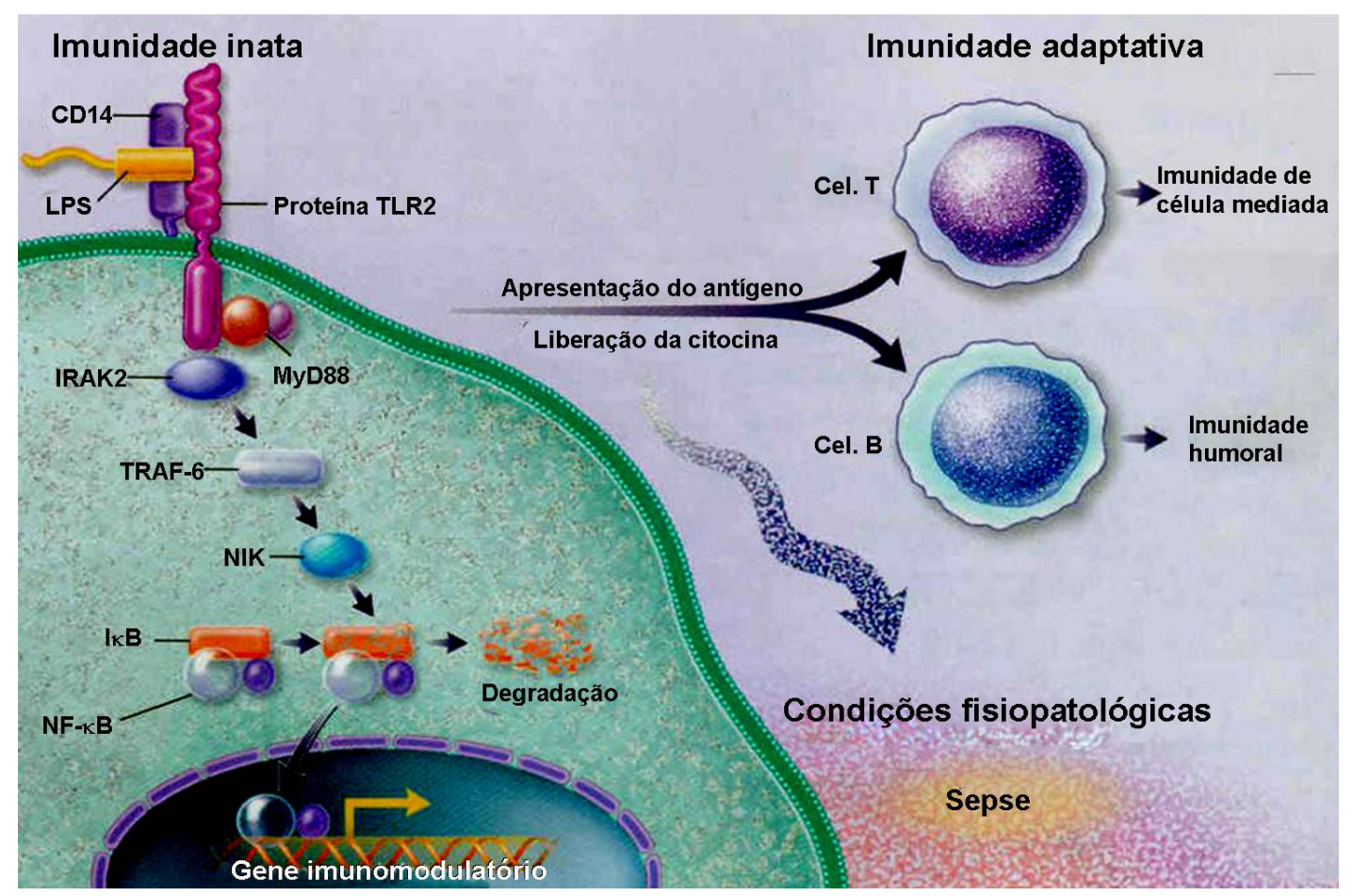

Fonte: Modlin et al., 1999

Figura 4: Mecanismo da resposta imune 


\section{MEDIADORES INFLAMATÓRIOS NA GÊNESE DA SEPSE}

Os mediadores inflamatórios liberados durante processos infecciosos são conhecidos como citocinas. O termo citocina, "células em movimento" (Cunneen e Cartwright, 2004) é aplicado para um número de proteínas (ou glicoproteínas) solúveis liberadas por células do sistema imune e, que servem como mensageiros químicos entre elas, agindo como regulador das funções celulares não enzimáticas (Hageman e Caplan, 1995) e da resposta imune (Oberholzer et al., 2000).

A concentração sérica de mediadores inflamatórios é baixa ou indetectável em indivíduos saudáveis, mas sua produção é estimulada durante a invasão ao hospedeiro por microorganismos patogênicos (Netea et al., 2003).

\section{a) Síntese das citocinas}

São sintetizadas a partir de células primárias mediante ativação da imunidade inata e adquirida constituindo-se no principal meio de comunicação intercelular contra a invasão de microorganismos (Oberholzer et al., 2000).

Entre as células produtoras de citocinas, citamos linfócitos, macrófagos, monócitos, células endoteliais, fibroblastos, hepatócitos, células da micróglia, astrócitos e células do músculo liso (Kilpatrick e Harris, 1998; Goldman et al., 1998).

Esses mediadores não são estocados permanentemente, sua síntese e secreção só ocorrem em resposta a um estímulo. Uma vez liberados, por ter meia vida curta, sua função se limita à atividade biológica que possuem, 
sendo que uma das principais é a comunicação entre as células. (Bellanti et al., 1994; Anderson e Blumer, 1997).

\section{b) Características gerais das citocinas}

As citocinas são proteínas multifuncionais, com papel importante em vários processos biológicos que inclui hematopoiese, imunidade inflamação e ação em fatores de crescimento.

Suas principais características são descritas a seguir (Abbas e Lichtman, 2005):

$1^{\text {a }) ~ S u a ~ s i ́ n t e s e ~ e ́ ~ u m ~ e v e n t o ~ b r e v e ~ e ~ a u t o-l i m i t a d o, ~ o u ~ s e j a, ~ n a ̃ o ~}$ são estocadas e, portanto são transitórias. Em resposta a estímulo ativador, como, por exemplo, infecção, as citocinas são sintetizadas e rapidamente liberadas em "surtos" e após a resolução do processo desencadeador a concentração sérica diminui a níveis baixos ou indetectáveis;

$2^{a}$ ) Cada citocina pode ser sintetizada por tipos celulares distintos;

$3^{\text {a }}$ ) Cada citocina tem habilidade em agir em diferentes tipos de células (pleiotropismo)

$4^{a}$ ) Têm efeitos redundantes, ou seja, várias citocinas produzem o mesmo efeito funcional;

5ª) Desencadeiam efeito "em cascata", onde uma citocina estimula a produção de outras citocinas em seqüências;

6ª ) Têm efeito sinérgico com potencialização do efeito final;

$\left.7^{\text {a }}\right)$ Efeitos hormonais: 
a) autócrino: afetando o comportamento das células que liberam as citocinas;

b) parácrino: afetando o comportamento das células adjacentes;

c) endócrino: afetando o comportamento das células distantes, na dependência de sua $1 / 2$ vida e de entrar na circulação sangüínea.

c) Resposta inflamatória: citocinas pró e antiinflamatórias e PCR

As citocinas são sintetizadas e liberadas por diversos tipos de células, imunes ou não, em resposta a diferentes estímulos ou sob influência de outras células (Kilpatrick e Harris, 1998).

Coordenam grande variedade de reações inflamatórias a nível tecidual. Interagem entre si formando rede complexa com influência na atividade e produção de sua própria e de outras citocinas (Van der Poll, 2001). Esta rede de citocinas é dividida em pró e antiinflamatórias.

Atualmente são conhecidos seus locais cromossômicos, sua massa molecular, o tamanho do gene, o número de exons, a quantidade de aminoácidos que possuem as células que as originam e as funções na resposta imune (Tabelas 5A e 5B) (Mire-Sluis e Thorpe, 1998). 
Tabela 5A: Propriedades estruturais das citocinas

\begin{tabular}{|c|c|c|c|c|c|}
\hline & $\begin{array}{c}\text { Localização } \\
\text { cromossômica }\end{array}$ & $\begin{array}{c}\text { Massa molecular } \\
(\mathrm{KDa})\end{array}$ & $\begin{array}{l}\text { Tamanho do } \\
\text { gene (kb) }\end{array}$ & $\begin{array}{l}\text { № de } \\
\text { exons } \\
\end{array}$ & $\begin{array}{c}\text { № de } \\
\text { aminoácidos } \\
\end{array}$ \\
\hline TNF & $6 \mathrm{p} 21$ & 174 & $\sim 3$ & 4 & 157 \\
\hline IL-1 $\beta$ & $2 q 13-q 21$ & 17,3 & 7 & 7 & 153 \\
\hline 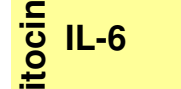 & $7 p 15-p 21$ & $\begin{array}{l}\text { Variável } \\
19-28\end{array}$ & 5 & 5 & 186 \\
\hline IL-10 & $1 q$ & 17,0 & 4,7 & 5 & 160 \\
\hline IL-1Ra & $2 q$ & 17,7 & & & 152 \\
\hline
\end{tabular}

Fonte: Mire-Sluis e Thorpe, 1998

Tabela 5B: Propriedades funcionais das citocinas: células de origem

\begin{tabular}{|c|c|c|c|}
\hline & & Células de origem & Funções \\
\hline \multirow{5}{*}{ 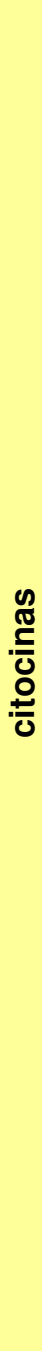 } & TNF & $\begin{array}{l}\text { 1.Macrófagos } \\
\text { 2.Células T } \\
\text { 3. Outras }\end{array}$ & $\begin{array}{l}\text { 1. Citotóxica para células tumorais } \\
\text { 2. Atividade antiviral, antibacteriana, antiparasitária } \\
\text { 3. Imuno-modulação } \\
\text { 4. Ação pró-inflamatória }\end{array}$ \\
\hline & IL-1 $\beta$ & $\begin{array}{l}\text { 1.Monócitos } \\
\text { 2.Linfócitos } \\
\text { 3.Endotélio } \\
\text { 4.Queratinócitos } \\
\text { 5.Epitélio } \\
\text { 6.Micróglia } \\
\text { 7.Condrócitos }\end{array}$ & $\begin{array}{l}\text { 1. Indução de outras citocinas } \\
\text { 2. Hematopoiese } \\
\text { 3. Co-estimuladores das células } T \\
\text { 4. Ativação do endotélio } \\
\text { 5. Resposta inflamatória na fase aguda } \\
\text { 6. Ação pirogênica } \\
\text { 7. Proliferação fibroblástica }\end{array}$ \\
\hline & IL-6 & $\begin{array}{l}\text { 1. Monócitos } \\
\text { 2. Macrófagos } \\
\text { 3. Fibroblastos } \\
\text { 4. Linfócitos T } \\
\text { 5. Células endoteliais } \\
\text { 6. Células epiteliais } \\
\text { 7. Queratinócitos } \\
\text { 8. Astrócitos } \\
\text { 9. Micróglia } \\
\text { 10. Estroma medular } \\
\text { ósseo } \\
\text { 11. Mastócitos }\end{array}$ & $\begin{array}{l}\text { 1. Produção de anticorpos células B } \\
\text { 2. Crescimento e diferenciação linfócitos T citotóxico } \\
\text { 3. Hematopoiese } \\
\text { 4. Estímulo hepático na produção de proteínas da fase } \\
\text { aguda }\end{array}$ \\
\hline & IL-10 & $\begin{array}{l}\text { 1. Monócitos } \\
\text { 2. Células T } \\
\text { 3. Células B } \\
\text { 4. Células epiteliais }\end{array}$ & $\begin{array}{l}\text { 1. Inibição citocinas pró-inflamatórias } \\
\text { 2. Inibição produção de IL-2 pelas células T } \\
\text { 3. Inibição da ativação antígeno específicas das células } \\
\text { T e produção de citocinas } \\
\text { 4. Inibição da produção de NO por monócitos e } \\
\text { macrófagos }\end{array}$ \\
\hline & IL-1Ra & $\begin{array}{l}\text { 1. Monócitos } \\
\text { 2. Macrófagos } \\
\text { 3. Células PMN } \\
\text { 4. Fibroblastos }\end{array}$ & $\begin{array}{l}\text { 1. Liga-se, mas não estimula o receptor IL } \\
\text { 2. Atua como antagonista natural da IL-1 }\end{array}$ \\
\hline
\end{tabular}

Fonte: Mire-Sluis e Thorpe, 1998; Colotta et al., 1998; Janeway et al., 2002 
A resposta imune humana a infecções graves é mediada principalmente por citocinas pró-inflamatórias primárias - TNF- $\alpha$ e IL-1 $\beta-$ e secundariamente por IL-6. No entanto, resposta antiinflamatória envolvendo a citocina antiinflamatória - IL-10 e citocina antagonista do receptor da IL-1 - IL-1Ra ocorre paralelamente à produção de citocinas próinflamatórias podendo induzir estado de imunossupressão, em resposta exacerbada, em pacientes com sepse (Gogos et al., 2000).

\section{CITOCINAS PRÓ-INFLAMATÓRIAS (TNF- $\alpha$; IL-1 $\beta$ e IL-6)}

As citocinas TNF- $\alpha$; IL-1 $\beta$ e IL-6 têm amplo espectro de atividades biológicas que auxiliam a coordenar as respostas do organismo contra a infecção.

Ativam os hepatócitos para sintetizar as proteínas da fase aguda (proteína C-reativa, proteína amilóide sérica e lecitina ligadora da manose) que vão ativar o sistema complemento e promover a opsonização.

Ativam o endotélio da medula óssea para liberar neutrófilos promovendo leucocitose e fagocitose. As proteínas da fase aguda atuam como opsoninas, enquanto a eliminação de patógenos opsonizados é aumentada pelo recrutamento reforçado dos neutrófilos da medula óssea.

Ativam as células endoteliais que induzem a expressão de moléculas de adesão (ICAM-1— molécula de adesão intercelular tipo 1; ELAM-1 molécula de adesão endotelial tipo 1; VCAM-1 - molécula de adesão vascular tipo 1), além de selectina E da família das selectinas, iniciando-se a 
interação dos leucócitos com as células endoteliais (Dinarello,1991; McKay, 1993; Strieter et al., 1993, Janeway et al, 2002).

Atuam também sobre o hipotálamo, como pirógeno endógeno, e sobre células musculares e adiposas promovendo a mobilização de energia para aumentar a temperatura corporal. Em temperaturas elevadas a replicação bacteriana e viral é reduzida e a resposta imune específica é aumentada (Janeway et al., 2002).

Atuam sobre os linfócitos B induzindo a se proliferar e se diferenciar em células plasmáticas secretando anticorpos.

O TNF- $\alpha$ estimula a migração das células dendríticas aos linfonodos e a maturação promovendo o início da resposta imune adaptativa.

A fração alfa do TNF é considerada a mediadora primária na patogênese da sepse (Beutler e Cerami, 1987; Bone, 1991) e a forma predominante produzida na sepse. Há evidências de que este mediador é detectável livre no plasma, após injeção de endotoxina em humanos saudáveis, com concomitante aparecimento de sinais e sintomas de infecção por gram negativo (Bone, 1991 e 1996). O TNF- $\alpha$ liberado guia a ativação de outras citocinas, tais como IL-1 $\beta$ e IL-6, associadas à lesão celular (Bone, 1991 e 1996).

Níveis elevados de TNF- $\alpha$ geralmente estão associados à gravidade da doença, embora estudos não confirmem (Waage et al., 1987; Pinsky et al., 1993; Martin et al., 1994; Goldie et al., 1995).

O TNF- $\alpha$ é uma citocina importante que ativa a contenção da infecção local, mas também induz o choque se liberado sistemicamente. 
Em infecção localizada há liberação local de TNF- $\alpha$. Esta citocina atua nos vasos sangüíneos, especialmente nas vênulas, promovendo aumento do fluxo sangüíneo, aumento da permeabilidade a líquidos, proteínas e células (com aumento da migração de fagócitos e linfócitos com conseqüente fagocitose bacteriana), estimulando a adesividade de leucócitos e plaquetas. Há formação de coágulos em pequenos vasos, promovendo a oclusão vascular local, prevenindo a disseminação da infecção para a circulação sangüínea e o plasma e células drenam para os linfonodos locais, onde se inicia a resposta imune inata (Janeway et al, 2002). Porém, se a infecção se dissemina para a corrente sangüínea, os mesmos mecanismos dos quais o TNF- $\alpha$ reprime infecção local com tanta eficiência, não ocorrem.

A liberação sistêmica de TNF- $\alpha$ causa vasodilatação, aumento da permeabilidade levando a edema sistêmico, com diminuição da volemia, hipoproteinemia conduzindo ao choque. Há estímulo para adesividade leucocitária e plaquetária, com formação de coágulos nos pequenos vasos e consumo de proteínas da coagulação, levando a perda da capacidade de coagular o sangue de maneira apropriada, guiando para a coagulação vascular disseminada. Esta condição leva freqüentemente à falência de órgãos vitais, como rins, fígado, coração e pulmões, que são rapidamente comprometidos pela insuficiência de perfusão normal e freqüentemente morte (Janeway et al, 2002).

Os níveis de IL-1 $1 \beta$ são freqüentemente indetectáveis na sepse e têm pobre correlação com a gravidade da doença (Damas et al., 1992; Pinsky et 
al., 1993; Casey et al., 1993; Goldie et al., 1995), no entanto, quando níveis séricos são detectáveis é significante a correlação com a mortalidade (Casey et al., 1993).

A IL-1 $\beta$ tem efeito fugaz porque concomitante ao estímulo de sua produção há estímulo para síntese de IL-1Ra que vai inibir a síntese da IL-1 $\beta$ (feedback negativo) e de acordo com as características das citocinas, as quais têm um efeito breve e auto-limitado seus níveis diminuirão rapidamente. Por outro lado, como a IL-1Ra é um inibidor natural da IL-1 $\beta$, os efeitos deletérios da IL-1 $\beta$ são bloqueados pela IL-1Ra. (Loisa et al, 2003).

A IL-6 tem meia vida curta e pico entre 6 a 12 horas (Abbas e Lichtman, 2005). Sua elevação reflete na ativação da resposta inflamatória sistêmica na sepse.

Níveis de IL-6 são significativamente elevados na maioria dos pacientes com sepse e estão associados à gravidade do quadro séptico (Hack et al., 1989; Calandra et al., 1991; Damas et al., 1992; Loisa et al., 2003). E os níveis desta citocina persistentemente elevados têm sido correlacionados com o desenvolvimento de falência múltipla de órgãos e pior prognóstico. (Pinsky et al., 1993; Loisa et al., 2003). 


\section{CITOCINAS ANTIINFLAMATÓRIAS (IL-10; IL-1Ra)}

A sepse ativa também a produção e elevação de citocinas antiinflamatórias específicas.

A IL-10 é produzida por macrófagos e células dendríticas e esta envolvida no controle da reação imune inata. Ela inibe a função do macrófago, caracterizando-se como exemplo clássico de feedback negativo, pois inibe a própria célula que a sintetiza. Inibe ainda outras citocinas: IL-1 $\alpha$; IL-1 $\beta$; IL-6; IL-8; ela própria IL-10; IL-12; IFN- $\gamma$; GM-CSF; G-CSF e TNF- $\alpha$ (Abbas e Lichtman, 2005).

Em adultos e crianças maiores a concentração de IL-10 em níveis elevados tem sido associada a choque séptico ( $\mathrm{Ng}$ et al., 2003).

Elevado nível sérico de IL-10 tem sido correlacionado com pior prognóstico no choque séptico, sugerindo que a superprodução pode ser o maior preditor de gravidade e óbito por sepse (Derkx et al., 1995; Gogos et al., 2000). Tanigushi et al., em 1999 demonstrou que a resposta adequada de IL-10 pode ser um efeito protetor a SIRS e que a relação IL-6/L-10 elevada foi detectada em pacientes com pior prognóstico.

O antagonista do receptor da IL-1 (IL-1Ra) também tem produção por monócitos e macrófagos, mas outras células a produzem, como neutrófilos e hepatócitos.

Após endotoxemia ou estímulo pela IL-1 $\beta$, o IL-1Ra alcança pico entre 2 e 4 horas e permanece elevada por mais de 24 horas e, portanto é considerado um bom marcador no diagnóstico de sepse (Küster et al., 1998). 
O IL-1Ra é um inibidor natural da IL-1 competindo com o receptor de IL-1, inibindo a ação da IL-1ß (Dinarello, 1997; Loisa et al., 2003). A importância clínica da produção de IL-1Ra na sepse ainda não está clara. No entanto, parece que níveis elevados de IL-1Ra foram encontrados em voluntários submetidos à injeção de endotoxina são semelhantes aos encontrados em pacientes criticamente doentes, sugerindo que esta citocina inibitória seja bom preditor de sepse (Fischer et al., 1992). Teoricamente esta substância antiinflamatória pode ter uma função reguladora no controle e atenuação da resposta inflamatória sistêmica na sepse (Loisa et al., 2003).

\section{PROTEÍNA C-REATIVA}

A proteína C-reativa (PCR) é um membro da família protéica das pentraxinas, assim denominadas, pois são formadas por cinco subunidades idênticas. Não atravessa a placenta (Janeway et al., 2002).

Faz parte das proteínas da fase aguda que são induzidas por TNF- $\alpha$, IL-1 $\beta$ e IL-6. É sintetizada pelo fígado após 6 a 8 horas de exposição a processos infecciosos. Tem meia vida de 19 horas ( $\mathrm{Ng}, 2004)$. Liga-se a porção fosforilcolina de certos polissacarídeos da parede celular de certas bactérias e fungos promovendo a opsonização e ativação da cascata do sistema complemento pela ligação C1q (Janeway et al., 2002)

A PCR é um marcador diagnóstico em recém-nascidos porque tem maior sensibilidade e especificidade que a contagem neutrofílica total ou índice neutrofílico. Estudos sugerem que a PCR é particularmente útil na sepse neonatal tardia, infecção sistêmica bacteriana ou fúngica ou 
enterocolite necrosante (NEC). Contudo, como a concentração da PCR eleva-se preferencialmente lentamente numa fase inicial, a sensibilidade neste período da sepse é de apenas $60 \%$. A mensuração seriada em 24 e 48 horas após o início da doença melhora a sensibilidade (82 e 84\%, respectivamente). A especificidade e o valor preditivo positivo (VPP) variam de 93 a 100\% no período de estudo. Por isso, a PCR pode ser considerada como marcador específico tardio na infecção neonatal. Além disso, a oscilação e normalização da elevação da sua concentração são consideradas úteis para o monitoramento do progresso do tratamento e guia para tratamento com antibióticos $(\mathrm{Ng}, 2004)$.

\section{HOMEOSTASE DA CASCATA INFLAMATÓRIA}

O termo homeostase é uma expressão relacionada à estabilidade do meio interno do organismo que permite manter o estado de equilíbrio de suas variáveis essenciais. O desequilíbrio dessas variáveis, de forma excessiva ou escassa, age como um sistema de controle deflagrando feedback negativo ou positivo, que consiste numa seqüência de eventos com o objetivo de fazer as variáveis retornarem até um valor médio mantendo assim a homeostase.

As citocinas, como mediadores químicos endógenos, têm papel importante na coordenação da cascata inflamatória ( $\mathrm{Ng}$ et al., 2003).

O conceito de que algumas citocinas funcionam primariamente como indutoras de inflamação (citocinas pró-inflamatórias) enquanto outras suprimem a inflamação (citocinas antiinflamatórias) é fundamental para o 
entendimento da homeostase da resposta imune. (Dinarello, 2000). A produção de citocinas pró e antiinflamatórias é rigorosamente controlada por complexo mecanismo de "feedback" ( $\mathrm{Ng}$ et al., 2003).

Frente a agravos iniciais, como a infecção há uma reação inflamatória generalizada e anormal caracterizando a Síndrome da Resposta Inflamatória Sistêmica (SIRS) (Bone, 1991; Bone et al., 1997; Ulloa e Tracey, 2005; Henneke e Bener, 2006). Quando o processo é gerado por infecção, Bone (1991) define o termo sepse e SIRS como sinônimos.

Estes insultos vão ativar o sistema imune inato a produzir mediadores próinflamatórios (Figura 5).

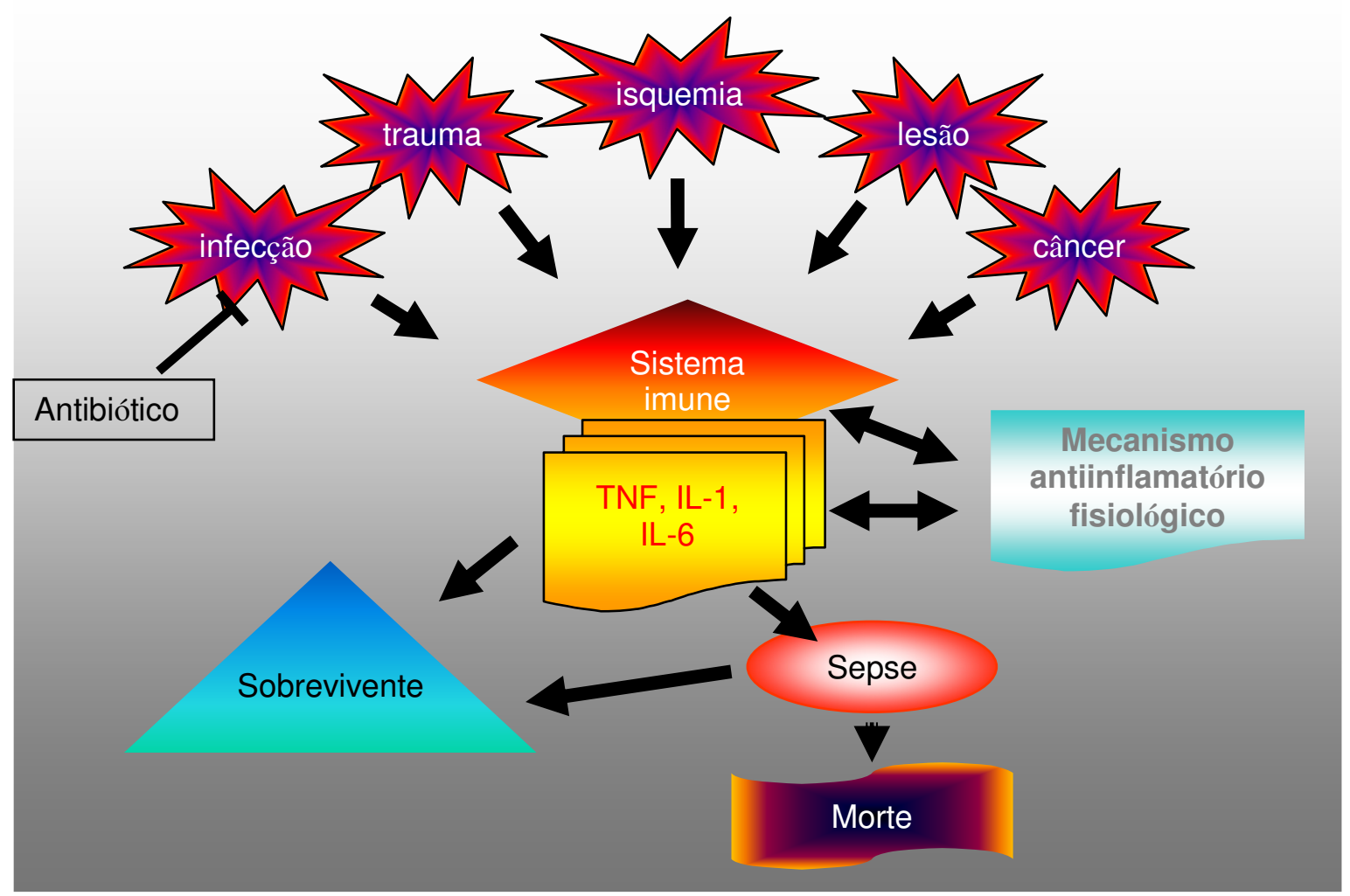

Ulloa e Tracey, 2005.

Figura 5: Interação dos mecanismos da homeostase dos mediadores inflamatórios 
Paralelamente há um estímulo antiinflamatório fisiológico que irá propiciar um equilíbrio destes mediadores promovendo a sobrevida ao nosso paciente. No entanto, se houver um desequilíbrio destes mediadores, a evolução da sepse será para choque, falência múltipla de órgãos e morte (Figura 5)

A patogênese da sepse tem sido atribuída a processo inflamatório com resposta inflamatória inicial (Pinsky, 2000). Fazem parte das citocinas pró-inflamatórias o fator de necrose tumoral (TNF), a interleucina 1 (IL-1), a interleucina 6 (IL-6), a interleucina 8 (IL-8), interleucina 12 (IL-12), interleucina 18 (IL-18), interferon- $\gamma($ IFN- $\gamma)$ e a proteína 1 monocitária (MCP1), que funcionam como mediadores do sistema imune (Lowry, 1993; Hageman e Caplan, 1995; Meadow e Rudinsky, 1995; Gogos et al., 2000; Sikora et al., 2001; Abbas e Lichtman, 2005;,). Eles iniciam efetivamente o processo inflamatório contra a infecção. TNF-a, IL-1, IL-6 são responsáveis por elevação de proteínas na fase aguda inflamatória, e que inclui a proteína C-reativa (PCR) durante a infecção. O aumento do nível sérico destas citocinas e IFN- $\gamma$ tem sido correlacionado com a gravidade e mortalidade no curso da sepse (Sikora et al., 2001).

A excessiva produção destes mediadores promovendo estado hiperinflamatório pode conduzir o paciente a vasodilatação, aumento da permeabilidade vascular, hipotensão, choque, falência múltipla de órgãos e êxito letal (Koch, 1998; Oberholzer et al., 2000; Netea et al., 2003).

Mecanismos antiinflamatórios associados ao controle da resposta imune promovem a manutenção da homeostase do sistema através do 
bloqueio do processo inflamatório ou supressão da intensidade da cascata inflamatória. Estes mecanismos envolvem 0 aumento das citocinas antiinflamatórias. Fazem parte das citocinas antiinflamatórias: a interleucina 4 (IL-4), a interleucina 10 (IL-10), a interleucina 13 (IL-13), e o fator transformador de crescimento (TGF $\beta$ ) e as citocinas inibitórias como receptor antagonista da interleucina 1 (IL-1Ra), receptor solúvel TNF I e II (sTNFR I e II)(Lowry, 1993; Hageman e Caplan, 1995, Meadow e Rudinsky, 1995, Gogos et al. 2000; Sikora et al., 2001; Abbas, Lichtman, 2005;). Estas suprimem a produção de IL-1, TNF- $\alpha$, IL-8 e moléculas de adesão vascular. Portanto, o equilíbrio entre os efeitos das citocinas pró e antiinflamatórias determina a manutenção da homeostase preservando a função vital do organismo ( $\mathrm{Ng}$ et al., 2003). No entanto, a resposta antiinflamatória excessiva resulta na supressão da resposta imune.

\section{CINÉTICA DA HOMEOSTASE DOS MEDIADORES INFLAMATÓRIOS}

Após um agravo inflamatório há ativação do sistema imune com elevação inicial de mediadores pró-inflamatórios. Neste exato momento (tempo 1), estes mediadores estão elevados e os mediadores antiinflamatórios estão baixos. Logo a seguir, há estímulo para a produção dos mediadores antiinflamatórios, num mecanismo de compensação. Há, portanto aumento dos mediadores antiinflamatórios e a manutenção dos mediadores pró-inflamatórios em elevado nível, porém já na descendente (tempo 2). E por fim, no tempo 3, vamos ter os mediadores pró-inflamatórios 
em concentração sérica baixa, enquanto os mediadores antiinflamatórios em concentração elevada (Carrigan et al, 2004). (Figura 6)

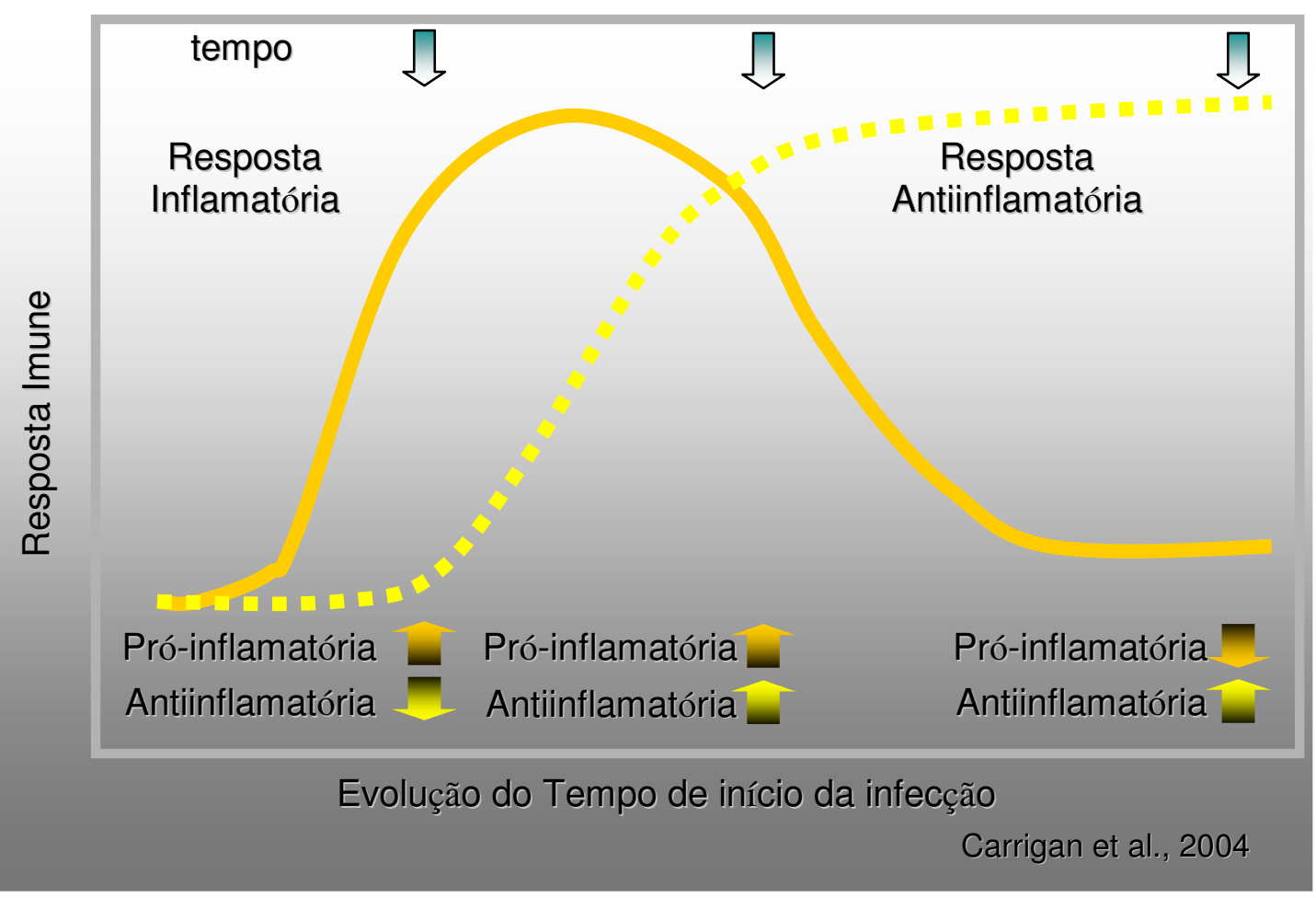

Figura 6: Cinética da homeostase dos mediadores inflamatórios

\section{PAPEL DAS CITOCINAS NA SEPSE}

A sepse envolve complexa interação de mediadores pró e antiinflamatórios (Nasraway, 2003).

Alguns estudos têm sugerido que a susceptibilidade a doença é geneticamente determinado pelo desequilíbrio da homeostase com expressão exacerbada da resposta pró-inflamatória ou da resposta antiinflamatória. No entanto, estudos relacionados com a genética são difíceis de serem interpretados. Tem sido observado em animais de 
experimentação que a deleção do gene IL-10 resulta em desenvolvimento espontâneo de doença inflamatória intestinal fatal. A deleção do gene TGF$\beta 1$ também resulta em doença inflamatória espontânea. Em ratos deficientes do antagonista do receptor da IL-1 (IL-1Ra) é observada doença espontânea praticamente idêntica à artrite reumatóide (Dinarello, 2000).

A produção de citocinas pró-inflamatórias ativa a resposta inflamatória sistêmica (SIRS), mas paralelamente a este processo, há produção de mediadores antiinflamatórios que na homeostase fazem a auto-regulação da cascata inflamatória (Koch, 1998). Esta resposta antagonista foi definida por Bone, em 1996, como Síndrome da Resposta Antiinflamatória Compensatória (CARS). Porém, a linha que demarca as respostas pró e antiinflamatórias não está bem delimitada, e a homeostase por ser um evento dinâmico, os pacientes graves podem mudar temporária e repetitivamente seus estados pró e antiinflamatórios (Oberholzer et al., 2000).

Se o equilíbrio das citocinas não pode ser estabelecido, pode haver resposta pró-inflamatória intensa, mediado por grande extravasamento de citocinas pró-inflamatórias levando o paciente a um estado de hiperinflamação caracterizando a Síndrome da Resposta Inflamatória Sistêmica (SRIS), com evolução clínica para sepse, síndrome séptica, refratária e síndrome da disfunção de múltiplos órgãos (figura 7). Por outro lado, pode haver reação antiinflamatória intensa e mais sustentada, também mediada por grande extravasamento de citocinas antiinflamatórias, podemos observar a evolução do paciente para um estado de hipoinflamação 
caracterizado pela Síndrome da Resposta Compensatória Antiinflamatória (CARS) com evolução clínica para supressão do sistema imune (figura 7). Embora o tempo exato para o desenvolvimento tanto da SIRS como CARS seja variável, existe consenso geral de que a interação entre mediadores pró-inflamatórios e antiinflamatórios determine o quadro final da sepse.

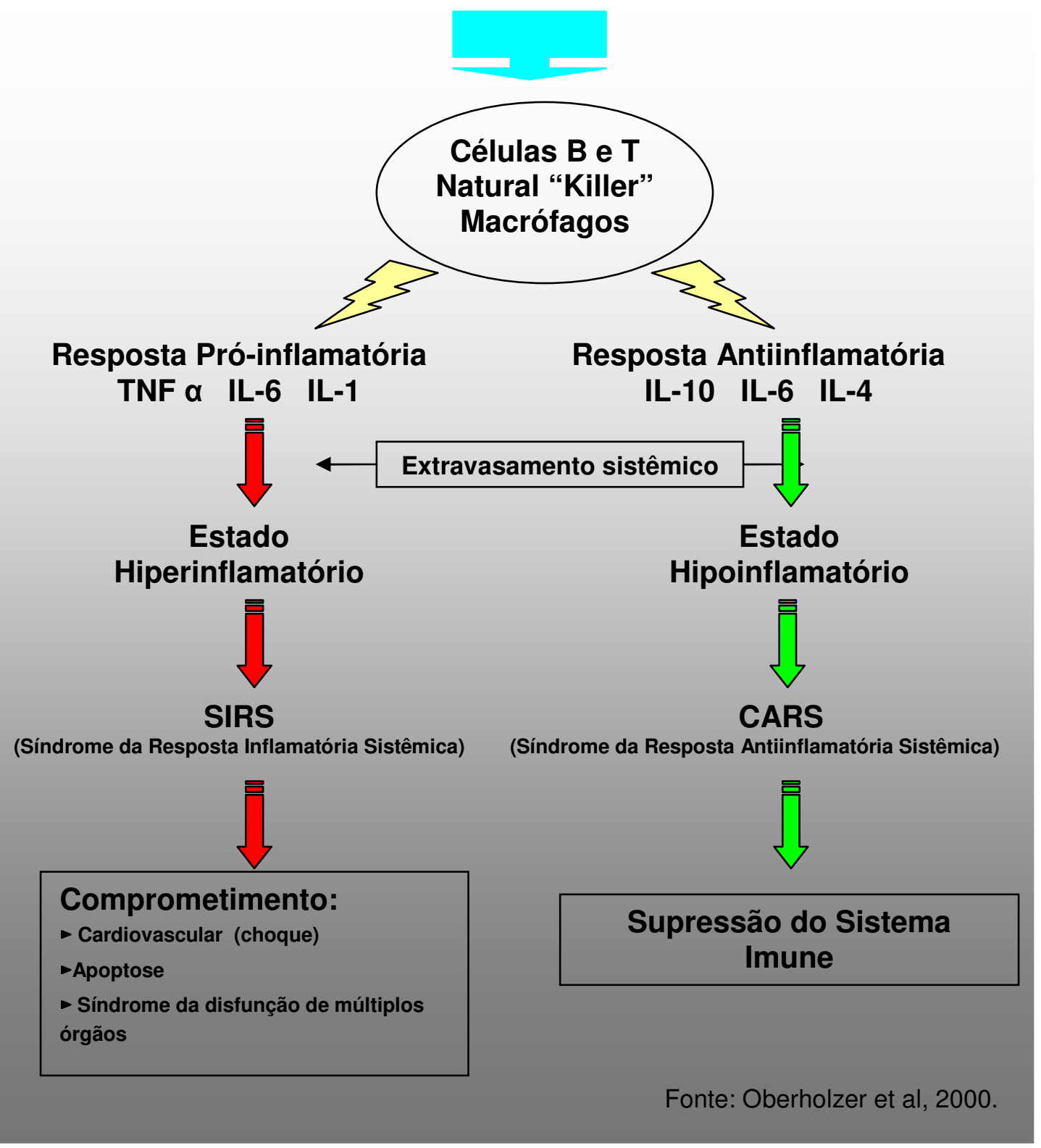

Figura 7: Seqüência clínica do extravasamento sistêmico das citocinas 


\section{MODELO DE ESTUDO PROPOSTO}

\section{a) Interação de citocinas na sepse neonatal}

Citocinas são sintetizadas e liberadas em resposta a estímulo inflamatório por monócitos, macrófagos, células endoteliais, fibroblastos (Silveira e Procianoy, 1999).

Três citocinas - FNT- $\alpha$, IL-1 e IL-6 - têm papel crítico na regulação da resposta imune: iniciam a resposta imune inata e depois, desenvolve e propaga a resposta imune adquirida. Ambas são inter-relacionadas e reguladas. No entanto, na produção exagerada de mediadores próinflamatórios (TNF- $\alpha$, IL-1 e IL-6) pode advir uma seqüência patológica devastadora levando a colapso vascular, choque e morte (Oberholzer et al., 2000).

Paralelamente a resposta inflamatória há reação antiinflamatória compensatória, com grande importância na auto-regulação da cascata inflamatória (Loisa et al., 2003). O sistema imune adquirido além de promover o aumento na síntese de citocinas antiinflamatórias, tais como IL4, IL-10 e IL-13, propicia outros mecanismos antiinflamatórios para manter a homeostase do sistema, que inclui diminuição dos receptores das citocinas, através da liberação de receptores solúveis ou receptores antagonistas (Sikora et al.,2001).

Das citocinas antiinflamatórias, a IL-10 apresenta característica particular porque tem como função a de "feedback" regulador na rede de citocinas por supressão de FNT- $\alpha$, IL-1 e IL-6 (Sikora et al.,2001). No entanto, alta concentração plasmática de IL-10 tem sido associada com pior 
prognóstico em choque séptico, sugerindo que a IL-10 pode ser o maior preditor de gravidade e êxito letal em sepse (Derkx et al.,1995; Gogos et al., 2000).

Das citocinas antagonistas de receptores, a IL-1Ra é antagonista natural do receptor da IL-1ß e concentrações plasmáticas elevadas desta citocina está associado a choque séptico em adultos (Fischer et al., 1992) e sepse e doença neonatal grave (De Bont, 1995).

No modelo de interação entre citocinas em processo de homeostase com "feedback" positivo e "feedback" negativo proposto neste estudo, de maneira didática e simplista, observamos a resposta imune de recémnascidos frente a um agravo infeccioso. Nesta situação ocorre a síntese de mediadores pró-inflamatórios sendo liberado TNF- $\alpha$ e a seguir IL-1 $\beta$. Estas duas induzem a liberação de IL-6. No entanto, concomitante ao estímulo da síntese de IL-1 $\beta$ há estímulo para a síntese de IL-1Ra. A própria IL-6 quando se eleva acaba tendo também capacidade antiinflamatória na forma de feedback negativo, inibindo a produção de TNF- $\alpha$ e IL-1 pelos monócitos.

A resposta antiinflamatória segue-se com a liberação de IL-10 que inibirá a síntese e liberação de TNF- $\alpha$ e de IL-6 e estimulará a formação de IL-1Ra, restabelecendo a homeostase (Figura 8). 


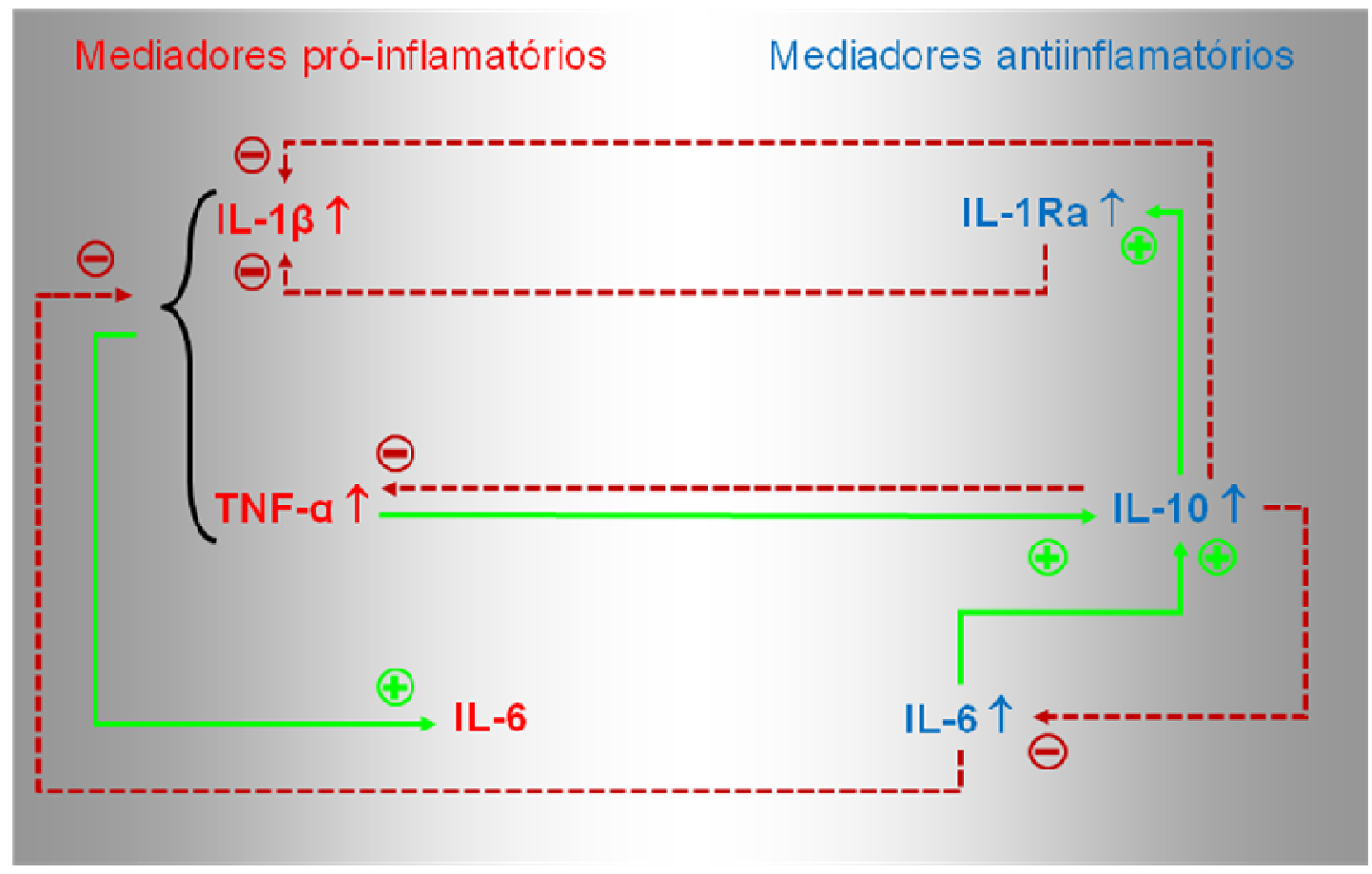

Figura 8: Interação entre citocinas em processo de homeostase com feedback positivo $(\oplus)$ e feedback negativo $(\Theta)$

b) Proposta do Estudo: Hipótese

Acreditamos que a análise da homeostase dos mediadores próinflamatórios e antiinflamatórios na sepse neonatal fornecerá conhecimento no sentido de confirmar o diagnóstico e verificar se o comportamento destes mediadores e da proteína C-reativa estão relacionados ao prognóstico da doença. 
02

OBJETIVOS 


\section{OBJETIVOS}

2.1 Avaliar a utilidade dos mediadores pró-inflamatórios (TNF- $\alpha$; IL-1 $\beta$ e IL-6), dos mediadores antiinflamatórios (IL-10 e IL-1Ra) e da proteína C-reativa para o diagnóstico na sepse neonatal.

2.2 Verificar se os valores isolados e/ou a relação entre IL-6, como mediador pró-inflamatório e IL-1Ra, como mediador antiinflamatório têm valor preditivo de gravidade, na evolução clínica da doença.

2.3 Determinar se a homeostase ou o desequilíbrio entre os mediadores pró-inflamatórios e antiinflamatórios e a proteína $\mathrm{C}$ reativa definem o prognóstico da doença. 
03

CASUÍSTICA 


\section{CASUÍSTICA}

\section{MODELO DO ESTUDO}

Trata-se de estudo do tipo coorte prospectiva e consiste na descrição da análise dos perfis dos mediadores pró-inflamatórios representados por:

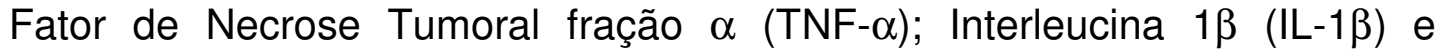
Interleucina 6 (IL-6) e dos mediadores antiinflamatórios representados pela Interleucina 10 (IL-10) e pelo antagonista do Receptor da Interleucina 1 (IL1Ra), e da proteína C-reativa em recém-nascidos com evolução clínicolaboratorial de sepse neonatal (precoce ou tardia).

\section{LOCAIS DE ESTUDO}

a) Unidade de Cuidados Intensivos Neonatal do Instituto da Criança do Hospital das Clinicas da FMUSP (UCINE).

Conta de 20 leitos e os recém-nascidos internados procedem além do Berçário Anexo à Maternidade do Hospital das Clínicas, de outros Hospitais ou Maternidades da capital, do interior ou de outros estados.

Os doentes apresentam diversas patologias, com gravidade relevante sendo grande parte dos casos de etiologia infecciosa com evolução para sepse neonatal. 
b) Unidade Neonatal do Hospital Universitário da Universidade de São Paulo (HU)

Conta com seis leitos de terapia intensiva neonatal e 24 leitos de berçário, distribuídos em semi-intensiva (9 leitos) e cuidados intermediários (15 leitos). Os recém-nascidos internados procedem do Centro Obstétrico anexo à Maternidade do Hospital Universitário ou do Pronto Atendimento (PA), mas também de outros Hospitais ou Maternidades da capital, do interior ou de outros estados.

\section{POPULAÇÃO E PERÍODO DE ESTUDO}

A população de estudo foi constituída por 35 recém-nascidos com evolução clínico-laboratorial de sepse neonatal (precoce ou tardia) internados na UCINE ou na Unidade Neonatal do HU no período de 2 anos (janeiro de 2004 a janeiro de 2005) e que preencham os critérios de inclusão e exclusão.

\section{CRITÉRIOS DE INCLUSÃO}

a) Recém-nascidos que apresentaram manifestações clínicas e/ou laboratoriais de infecção nas primeiras 72 horas de vida, caracterizando sepse neonatal precoce (Ng, 2004; Palazzi et al., 2006).

b) Recém-nascidos que apresentaram manifestações clínicas e/ou laboratoriais de infecção a partir do quarto dia de vida até três meses de idade, caracterizando a sepse neonatal tardia ( $\mathrm{Ng}, 2004$; Palazzi et al., 2006). 
Os 35 RN incluídos no período de 15 de janeiro de 2004 a 15 de janeiro de 2005, apresentaram manifestações clínicas da síndrome da resposta inflamatória sistêmica com indicação de tratamento com antibióticos e monitoramento clínico-laboratorial.

\section{CRITÉRIOS DE EXCLUSÃO}

Situações que alterem o valor das citocinas:

a) Uso de antiinflamatórios, tais como indometacina, ibuprofeno e corticóides.

b) Procedimento cirúrgico.

c) Diagnóstico de Hemorragia intracraniana comprovada por ultrasonografia de crânio e/ou tomografia computadorizada de crânio.

d) Recém-nascidos com asfixia perinatal grave, definido com Apgar no 5ํㅡㄴ minuto inferior a 4 (Academia Americana de Pediatria, 1997)

Foram excluídos do estudo quatro RN:

Casos no 6 e no 22: RN com evolução clínico-laboratorial que não confirmaram o quadro de sepse neonatal.

Caso no 15: RN que evoluiu com enterocolite necrosante e foi submetido a procedimento cirúrgico, fato que pode alterar o valor das interleucinas (Sakamoto et al., 1994).

Caso no 17: RN pré-termo que evoluiu com persistência do canal arterial e foi submetido a tratamento com indometacina e posteriormente a fechamento cirúrgico. O uso de antiinflamatórios pode alterar o valor das interleucinas. 
Dos $35 \mathrm{RN}$ avaliados foram incluídos no estudo os dados relativos a 31 RN. As características demográficas dos RN do estudo estão demonstradas na tabela 6 .

A idade gestacional foi determinada considerando-se a informação materna da data da última menstruação (OMS - 1976) e, na ausência, a USG fetal realizada no primeiro trimestre ou o método de New Ballard.

Em relação à classificação dos $\mathrm{RN}$, pré-termos foram definidos por idade gestacional $<37$ semanas e de termos, idade gestacional $\geq 37$ semanas. Quanto ao tamanho para idade gestacional adotamos a curva de Ramos (1983), ou seja, pequenos para idade gestacional (PIG - definido pelo percentil abaixo de 10 na curva de Ramos), adequado para idade gestacional (AIG - definido pelo percentil entre 10 e 90 na mesma curva) e grande para idade gestacional (GIG - definido pelo percentil acima de 90, na mesma curva). Quanto ao peso de nascimento consideramos o peso normal aquele $\geq$ a $2.500 \mathrm{~g}$, baixo peso, com peso $<2.500 \mathrm{~g}$ e muito baixo peso, com peso $<1.500 \mathrm{~g}$ 
Tabela 6: Características Demográficas dos recém-nascidos do estudo

\begin{tabular}{|c|c|c|c|}
\hline \multirow{2}{*}{\multicolumn{2}{|c|}{ Variáveis }} & $\mathrm{N}^{\dagger}$ & $\%$ \\
\hline & & \multicolumn{2}{|c|}{ Ou conforme especificado } \\
\hline \multicolumn{4}{|c|}{ Idade na Internação } \\
\hline & Mediana & \multicolumn{2}{|c|}{2 horas } \\
\hline & Mínimo - Máximo & \multicolumn{2}{|c|}{1 hora -28 dias } \\
\hline \multicolumn{4}{|c|}{ Idade de Início dos sintomas } \\
\hline & Mediana & \multicolumn{2}{|c|}{11 horas } \\
\hline & Mínimo - Máximo & \multicolumn{2}{|c|}{1 hora -39 dias } \\
\hline \multicolumn{4}{|c|}{ Idade Gestacional (semanas) } \\
\hline & Mediana & \multicolumn{2}{|c|}{$386 / 7$} \\
\hline & Mínimo - Máximo & \multicolumn{2}{|c|}{$265 / 7-413 / 7$} \\
\hline \multicolumn{4}{|c|}{ Método da Idade gestacional } \\
\hline & DUM & 22 & 73,3 \\
\hline & Capurro & 5 & 16,7 \\
\hline & New Ballard & 1 & 3,3 \\
\hline & USG ( $1^{\circ}$ trimestre $)$ & 2 & 6,7 \\
\hline \multicolumn{4}{|c|}{ Peso de Nascimento (gramas) } \\
\hline & Mediana & \multicolumn{2}{|c|}{2880} \\
\hline & Mínimo - Máximo & \multicolumn{2}{|c|}{$1000-4000$} \\
\hline \multicolumn{4}{|c|}{ Classificação dos Recém-nascidos (Idade Gestacional) } \\
\hline & Pré-termo & 15 & 48,4 \\
\hline & Termo & 16 & 51,6 \\
\hline \multicolumn{4}{|c|}{ Classificação dos Recém-nascidos (Tamanho x Idade Gestacional) } \\
\hline & PIG & 4 & 12,9 \\
\hline & AIG & 26 & 83,9 \\
\hline & GIG & 1 & 3,2 \\
\hline \multicolumn{4}{|c|}{ Classificação dos Recém-nascidos (Peso de nascimento) } \\
\hline & Normal & 20 & 64,5 \\
\hline & Baixo Peso & 4 & 12,9 \\
\hline & Muito Baixo Peso & 7 & 22,6 \\
\hline \multicolumn{4}{|l|}{ Gênero } \\
\hline & Masculino & 16 & 51,6 \\
\hline & Feminino & 15 & 48,4 \\
\hline
\end{tabular}

${ }^{\dagger} \mathrm{N}$ : número de recém-nascidos do estudo 
As manifestações clínicas dos RN do estudo estão demonstradas na tabela 7 .

Tabela 7 Distribuição dos RN de acordo com as manifestações clínicas

\begin{tabular}{lcc}
\hline Manifestações Clínicas & $\mathbf{N}^{\dagger}$ & $\%$ \\
\hline Respiratórias & 31 & 100,0 \\
Cardiovasculares & 23 & 74,2 \\
SNC & 16 & 51,6 \\
Gastrintestinais & 16 & 51,6 \\
Pele e subcutâneo & 8 & 25,8 \\
Hematológicas & 11 & 35,5 \\
Instabilidade Térmica & 20 & 64,5
\end{tabular}

${ }^{\dagger} \mathrm{N}$ : número de recém-nascidos do estudo

Em relação à positividade das culturas, a tabela 8 mostra a distribuição dos $\mathrm{RN}$ de acordo com os resultados da cultura.

Tabela 8: Distribuição dos RN de acordo com a positividade das culturas

\begin{tabular}{l|r|r}
\hline Culturas & $\mathrm{N}^{\dagger}$ & $\%$ \\
\hline Hemocultura & 7 & 22,6 \\
Hemocultura e urocultura & 3 & 9,7 \\
Hemocultura e Cultura de LCR & 1 & 3,2 \\
Hemocultura negativa & 20 & 64,5 \\
\hline Total & 31 & 100,0 \\
\hline
\end{tabular}

${ }^{\dagger} \mathrm{N}$ : número de recém-nascidos do estudo

Entre os agentes etiológicos isolados nas hemoculturas observamos germes Gram positivos, germes Gram negativos e fungos conforme descrito na tabela 9 . 
Tabela 9: Distribuição dos RN de acordo com a etiologia das hemoculturas

\begin{tabular}{lrr}
\hline Agente Etiológico - Hemocultura & $\mathrm{N}^{\dagger}$ & $\%$ \\
Gram positivos & & \\
$\quad$ Streptococcus agalactiae & 2 & 18,2 \\
Staphylococcus aureus & 1 & 9,1 \\
$\quad$ Staphylococcus epidermidis & 2 & 18,2 \\
Gram negativos & & \\
$\quad$ Pseudomonas aeruginosa & 1 & 9,1 \\
Serratia marcencens & 1 & 9,1 \\
$\quad$ Acinetobacter baumanni & 1 & 9,1 \\
Fungos & & 18,2 \\
$\quad$ Candida albicans & 2 & 9,1 \\
$\quad$ Candida tropicalis & 1 & 100,0 \\
\hline Total $\quad 11$ & \\
\hline${ }^{\dagger} \mathrm{N}:$ número de recém-nascidos do estudo & &
\end{tabular}

A cultura do LCR foi positiva em apenas um recém-nascido (4,2\%),o qual apresentou de forma concomitante hemocultura positiva para Staphylococcus aureus. 
04

METODOLOGIA 


\section{METODOLOGIA}

\section{CRITÉRIOS PARA O DIAGNÓSTICO DE SEPSE NEONATAL}

O diagnóstico de sepse neonatal foi assim estabelecido:

a) Sepse Neonatal comprovada: presença de dois sinais e/ou sintomas clínicos (Gerdes, 2004) associados à hemocultura positiva;

b) Sepse Neonatal clínica: presença de pelo menos dois sinais ou sintomas clínicos (Gerdes, 2004) associados a PCR $\geq 10 \mathrm{mg} / \mathrm{L}$ na vigência de hemocultura negativa.

\section{CRITÉRIOS CLÍNICOS PARA O DIAGNÓSTICO DE SEPSE}

\section{NEONATAL}

Para o diagnóstico de sepse neonatal foram adotados os conceitos clínicos de Bone (1991) aprovados na conferência ACCP/SCCM, em 1992, e modificados por Jafari e McCraken, no mesmo ano, para o uso em recémnascidos, além de outros sinais e/ou sintomas importantes no período neonatal:

a) Instabilidade térmica: hipotermia, com temperatura axilar $\leq$ $36^{\circ} \mathrm{C}$ ou hipertermia, com temperatura axilar $\geq 38^{\circ} \mathrm{C}$. 
b) Alterações respiratórias: cianose, gemência, respirações irregulares, crises de apnéia ou taquipnéia (freqüência respiratória $>60$ bpm), retrações de xifóide ou intercostal, necessidade de aumento progressivo dos parâmetros ventilatórios, necessidade de maiores frações inspiratórias de oxigênio.

c) Alterações cardiovasculares: palidez, cianose, pele fria e viscosa, taquipnéia, arritmia, edema, bradicardia (freqüência cardíaca $\leq 100$ bpm), taquicardia (freqüência cardíaca $\geq 160 \mathrm{bpm}$ ), perfusão periférica lentificada com tempo de enchimento capilar $>3$ segundos, hipotensão arterial com necessidade de expansão para manter euvolemia ou necessidade de aumento de dose das drogas inotrópicas para manter a pressão adequada e sustentada.

d) Alterações no sistema nervoso central: letargia ou irritabilidade, contrações ou hiporreflexia, tremores ou convulsões, coma, fontanelas abauladas, movimentos oculares anormais, hipotonia, hipertonia, sucção débil, secreção inapropriada de hormônio antidiurético.

e) Alterações gastrintestinais: recusa da dieta, vômitos, diarréia ou constipação, distensão abdominal, edema ou eritema da parede abdominal, hepatomegalia, resíduo gástrico aumentado, sangramentos nas fezes.

f) Alterações na pele e subcutâneo: palidez ou eritema, cútis marmorata, petéquias, equimoses, pústulas, onfalite, ectimas, esclerema, baixa perfusão periférica, pele seca e desidratada. 
g) Alterações no sistema hematopoiético: icterícia com aumento de bilirrubina direta (> $2 \mathrm{mg} / \mathrm{dl}$ ), hemorragia, púrpura, equimoses, esplenomegalia.

\section{CRITÉRIOS LABORATORIAIS PARA O DIAGNÓSTICO DE SEPSE NEONATAL}

Após aprovação do estudo pela Comissão de Ética do Hospital das Clínicas da Faculdade de Medicina da Universidade de São Paulo (HCFMUSP) e pela Comissão de Ética do Hospital Universitário da Faculdade de Medicina da Universidade de São Paulo e do consentimento livre e esclarecido obtido por escrito dos pais ou responsável, foram colhidas amostras de sangue do $\mathrm{RN}$ através de veia periférica para a realização de exames laboratoriais:

\section{a) Gerais}

Esses exames laboratoriais foram colhidos no dia da suspeita diagnóstica de sepse (dia 0), antes da introdução de antibióticos e durante a evolução, nos dias 3 e 7 de acordo com a rotina do serviço e realizados no Laboratório de Investigação Médica (LIM-36) do Instituto da Criança do HCFMUSP e do Instituto Central e no Laboratório de Investigação Médica do Hospital Universitário, e a metodologia segue em cada exame laboratorial colhidos: 


\section{a.1. Hemograma completo}

Consideraram-se como valores alterados (Manroe et al., 1979):

i. Leucócitos superiores a $20.000 / \mathrm{mm}^{3}$

ii. Leucócitos inferiores a $5.000 / \mathrm{mm}^{3}$

iii. № absoluto de neutrófilos inferiores a $1.750 / \mathrm{mm}^{3}$

iv. Índice neutrofílico superior a 0,2.

v. Contagem de plaquetas inferior a $150.000 / \mathrm{mm}^{3}$

\section{Métodos}

- Hemoglobina: método da cianometahemoglobina

- Hematócrito: método do microhematócrito

(centrifugação capilar)

- Leucócitos: contagens globais automatizada, diferenciais em lâmina com coloração de Leishman

- Hemácias: contagem global automatizada

- Plaquetas: método de Fonio

- Volume de sangue: $1 \mathrm{ml}$

\section{a.2. Proteína $\mathrm{C}$ reativa (PCR)}

Considerou-se como representativo de infecção:

i. $P C R \geq 10 \mathrm{mg} / \mathrm{L}$.

\section{Método}

Dosada em equipamento automatizado ("analyzer nefelometer" 100) da marca Behring, com determinação quantitativa.

- Volume de sangue: $0,7 \mathrm{ml}$ 


\section{a.3. Hemocultura (HMC)}

\section{Método}

- Repiques sucessivos em meio Agar sangue até isolamento do agente etiológico

- Volume de sangue: $1 \mathrm{ml}$

\section{a.4. Líquido cefalorraquidiano (LCR)}

Colhido por punção lombar

Consideraram-se como valores alterados os seguintes parâmetros (Overall, 1970; Klein e Marcy, 1990 e 1995):

Quimiocitológico

i. $\quad$ Celularidade maior que 20 leucócitos $/ \mathrm{mm}^{3}$

ii. Neutrófilos acima de $20 \%$

iii. Proteínas: acima de $100 \mathrm{mg} \%$ nos $\mathrm{RN}$ a termo acima de 120 mg \% nos RN PT

iv. Glicorraquia menor que $75 \%$ da glicemia

Bacterioscopia positiva

Cultura positiva

\section{Método}

- Glicose: método de glicose-oxidase

- $\quad$ Proteína: método do TCA (ácido tricloroacético)

- Cloretos: método titulométrico

- $\quad$ Cultura: semeadura em placa (Agar chocolate)

- Volume do líquor: $3 \mathrm{ml}$ para quimiocitológico 


\section{b) Específicos}

Esses exames laboratoriais foram realizados no Laboratório de Investigação Médica (LIM-36) do Instituto da Criança do HC-FMUSP.

\section{Mediadores pró-inflamatórios:}

- $\quad$ Fator de necrose tumoral fração alfa (TNF- $\alpha$ );

- $\quad$ Interleucina $1 \beta($ IL-1 $\beta)$;

- Interleucina 6 (IL-6).

\section{Mediadores antiinflamatórios:}

- Antagonista do receptor da interleucina 1 (IL1Ra);

- Interleucina 10 (IL-10).

Foram mensurados nos dias 0 (dia da suspeita diagnóstica), com 3 dias e 7 dias de evolução.

Foram considerados alterados valores acima do valor de referência para a infecção segundo o fabricante R \& D System, (Inc.614 Mckinley Place NE):
i. TNF- $\alpha$ : $>1,6 \mathrm{pg} / \mathrm{ml}$
ii. IL-13: $\quad>1,0 \mathrm{pg} / \mathrm{ml}$
iii. IL-6: $>0,7 \mathrm{pg} / \mathrm{ml}$
iv. IL-10: $>3,9 \mathrm{pg} / \mathrm{ml}$
v. IL-1Ra: $>14,0 \mathrm{pg} / \mathrm{ml}$ 


\section{Método}

- Imediatamente após a coleta, o sangue foi centrifugado sob refrigeração e as amostras separadas em microtubos, colocadas em "freezer" a -70 graus centígrados até o momento da análise laboratorial conjunta através da técnica ELISA (“Enzyme-linked Immunosorbent Assay”).

- A técnica ELISA utiliza "kits" com placas de microtitulação sensibilizadas com um tampão o qual contém o anticorpo monoclonal contra a citocina a ser detectada. $\mathrm{O}$ anticorpo monoclonal "ancorado" na placa captura a citocina presente nas amostras do material biológico do paciente. Em seguida, há a ligação da citocina capturada a um segundo anticorpo, que pode estar diretamente conjugado a peroxidase ou complexo formado por anticorpo biotinilado conjugado à peroxidaseestreptavidina. A peroxidase catalisa a mudança de cor desencadeada pela adição de seu substrato (peróxido tetrametilbenzidina) A absorbância obtida é diretamente proporcional a concentração da citocina presente na amostra.

- As vantagens desta técnica incluem a facilidade de execução (formato ELISA), rapidez (duas a três horas), necessidade de poucos reagentes, sensibilidade da ordem de picogramas $/ \mathrm{ml}$ e excelente reprodutividade intra e interensaios. 


\section{DETERMINAÇÃO DOS GRUPOS DE ESTUDO}

Os RN com diagnóstico de sepse neonatal, tanto comprovada quanto clínica, foram divididos em dois grupos, de acordo com a evolução clínica, a saber:

Grupo Sepse: RN com manifestações clínicas de sepse neonatal que tiveram boa evolução da doença.

Grupo Sepse Grave: RN com sepse neonatal com evolução complicada com choque séptico ou coagulação intravascular disseminada (CIVD) ou falência múltipla de órgãos e sistemas ou óbito.

Nestes grupos acompanhamos a curva dos valores dos mediadores pró-inflamatórios (TNF- $\alpha$; IL-1 $\beta$ e IL-6), mediadores antiinflamatórios (IL-10 e IL-1Ra) e da PCR mensurados no dia do diagnóstico (Dia 0), e nos dias 3 e 7 (dias de evolução), tendo como valores de referência aqueles mínimos detectáveis pelo método laboratorial de cada interleucina mensurados em picogramas / mililitros ( $\mathrm{pg} / \mathrm{ml}$ ), de acordo com o fabricante (R \& D System). 


\section{METODOLOGIA ESTATÍSTICA}

Para as variáveis qualitativas foi calculada a freqüência absoluta e relativa (número de casos e porcentagens).

Para as variáveis quantitativas foi calculado a média, o desvio padrão, a mediana e os valores de mínimo e máximo para cada um dos mediadores avaliados em cada um dos dias de avaliação. Como os valores do desvio padrão variam de acordo com o dia da avaliação, os dados não apresentam variância constante (são denominados heterocedásticos).

Foram construídos os gráficos de perfis individuais (dados não apresentados) que confirmaram a possível heterocedasticidade mencionada acima e, em função do "paralelismo" dos perfis individuais sugere uma correlação entre as medidas realizadas no mesmo indivíduo. Com base nos perfis individuais foi construído o perfil médio (com barras verticais representando erros padrões).

Para a modelagem dos dados foi utilizada técnicas de análise de dados longitudinais (Crowder e Hand, 1990; Singer e Andrade, 1999). Entre estes modelos foi utilizada a Análise de Variância (ANOVA) com medida repetida, o que permitiu um ajuste levando em conta tanto a correlação como a heterocedasticidade dos dados avaliados. Para a comparação tanto entre as médias das medidas nos tempos avaliados como entre grupos foram construídos contrastes que permitiram avaliar possíveis diferenças existentes.

Em toda a análise estatística foi adotado um nível de significância de $5 \%(\alpha=0,05)$, ou seja, foram considerados com estatisticamente 
significantes os resultados que apresentaram valor de $p$ inferior a $5 \%(p<$ $0,05)$.

\section{DELINEAMENTO DO ESTUDO}

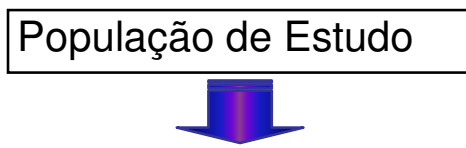

$35 \mathrm{RN}$ que preenchiam os critérios de inclusão

\section{Critérios de Inclusão}

RN com diagnóstico de sepse neonatal

Precoce ou Tardia ou Muito Tardia

Critérios de Exclusão: situações que alteram o valor das citocinas:

* Uso de antiinflamatórios

* Procedimentos cirúrgicos

* Hemorragia intracraniana comprovada com USG e/ou TC de crânio

* Asfixia perinatal grave (Apgar 5'<4)

31 RN que preencheram os critérios de inclusão e exclusão

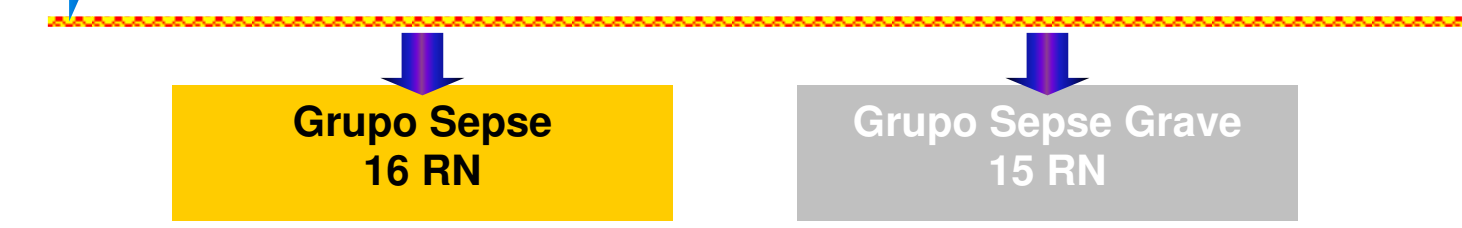

I

Evolução do quadro séptico:

Sepse: Boa evolução: Sem complicações

Sepse Grave: $\quad$ Evolução complicada:

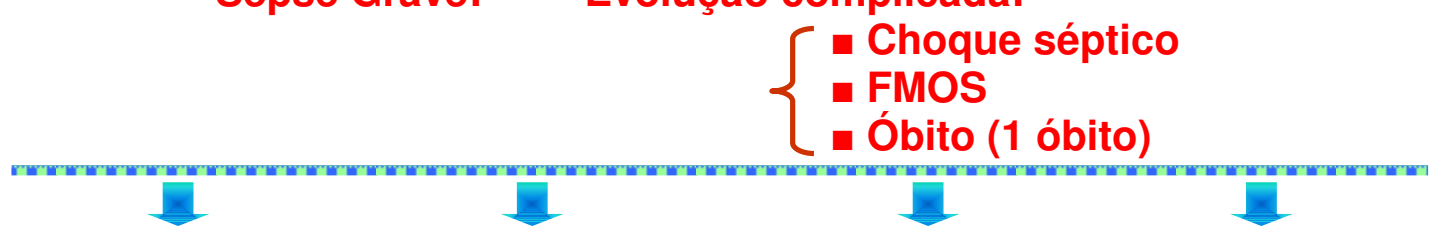

Exames específicos: TNF- $\alpha$; IL-1 $\beta$;IL-6 ; IL-10 ; IL-1Ra e PCR mensurados nos dias: 0 (diagnóstico), 3 e 7 (dias de evolução).

Avaliar os mediadores pró e antiinflamatórios e PCR quanto:

1) Ao diagnóstico da sepse neonatal

2) Ao valor preditivo de gravidade da doença

3) A homeostase ou desequilíbrio definindo o prognóstico da doença 
05

RESULTADOS 


\section{RESULTADOS}

Serão apresentados, a princípio, os resultados das medidas descritivas das citocinas com a evolução temporal dos seus valores séricos médios nos 31 recém-nascidos desta casuística sob a forma de tabelas e gráficos correspondentes.

Posteriormente, apresentaremos os resultados subdivididos nos dois grupos: grupo sepse e grupo sepse grave.

\section{Mediadores pró-inflamatórios}

a) TNF- $\alpha$

a.1) Evolução geral

Tabela 10: Medidas descritivas de TNF- $\alpha$ nos RN avaliados

\begin{tabular}{lccc}
\hline TNF- $\alpha(\mathrm{pg} / \mathrm{ml})$ & \multicolumn{3}{c}{ Dias de evolução } \\
\cline { 2 - 4 } Média & Dia 0 & Dia 3 & Dia 7 \\
Desvio Padrão & 105,34 & 62,31 & 14,88 \\
Mediana & 326,72 & 194,34 & 52,08 \\
Mínimo & 1,60 & 1,60 & 1,60 \\
Máximo & 1,60 & 1,60 & 1,60 \\
№ de Observações & 1316,00 & 766,50 & 248,80 \\
\hline
\end{tabular}


Figura 9: Média \pm erro padrão de TNF-a de acordo com o tempo nos RN avaliados

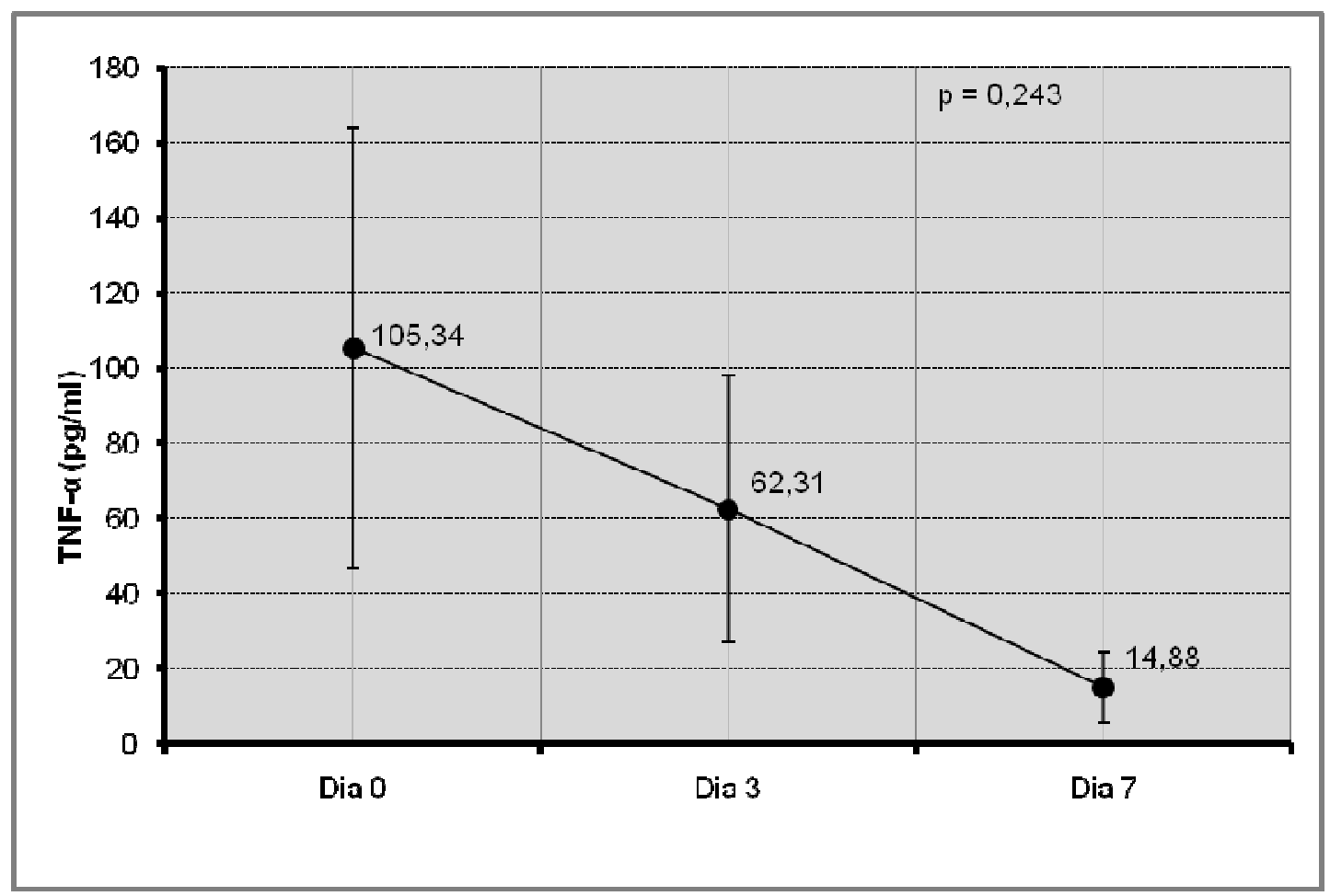

\section{a.1). Análise descritiva evolutiva geral}

Em relação aos valores séricos médios do TNF- $\alpha$ dos recém-nascidos desta casuística, observamos que estão elevados no dia do diagnóstico (dia 0) e que há alta variabilidade de dados, uma vez que o desvio padrão é maior que a média. No entanto, estes valores, média e variabilidade, vão diminuindo progressivamente com o decorrer do tempo (tabela 10; figura 9). Em termo de mediana não se observa tal comportamento, ou seja, não houve variação de TNF- $\alpha$.

Através de uma Análise de Variância (ANOVA) com medida repetida levando-se em conta a alta variabilidade dos dados através da modelagem da estrutura de correlação, observamos que não houve efeito 
estatisticamente significante de tempo $(p=0,243)$. Ou seja, apesar da variação do TNF-a observada através da figura 9, o teste estatístico não foi capaz de evidenciar esse decréscimo.

\section{a.2) Evolução subdividida em grupos: sepse e sepse grave}

Tabela 11: Medidas descritivas dos valores séricos de TNF- $\alpha$ segundo os grupos

\begin{tabular}{|c|c|c|c|c|c|c|}
\hline \multirow[t]{2}{*}{ TNF- $\alpha(p g / m l)$} & \multicolumn{2}{|c|}{ Dia 0} & \multicolumn{2}{|c|}{ Dia 3} & \multicolumn{2}{|c|}{ Dia 7} \\
\hline & Sepse & $\begin{array}{l}\text { Sepse } \\
\text { Grave }\end{array}$ & Sepse & $\begin{array}{l}\text { Sepse } \\
\text { Grave }\end{array}$ & Sepse & $\begin{array}{l}\text { Sepse } \\
\text { Grave }\end{array}$ \\
\hline Média & 1,60 & 216,01 & 1,60 & 131,70 & 1,60 & 30,06 \\
\hline Desvio Padrão & 0,0 & 450,91 & 0,0 & 273,00 & 0,0 & 74,75 \\
\hline Mediana & 1,60 & 1,60 & 1,60 & 1,60 & 1,60 & 1,60 \\
\hline Mínimo & 1,60 & 1,60 & 1,60 & 1,60 & 1,60 & 1,60 \\
\hline Máximo & 1,60 & 1316,00 & 1,60 & 766,50 & 1,60 & 248,80 \\
\hline № observações & 16 & 15 & 16 & 14 & 16 & 14 \\
\hline
\end{tabular}


Figura 10: Perfil médio da TNF- $\alpha$ de acordo com sepse e tempo

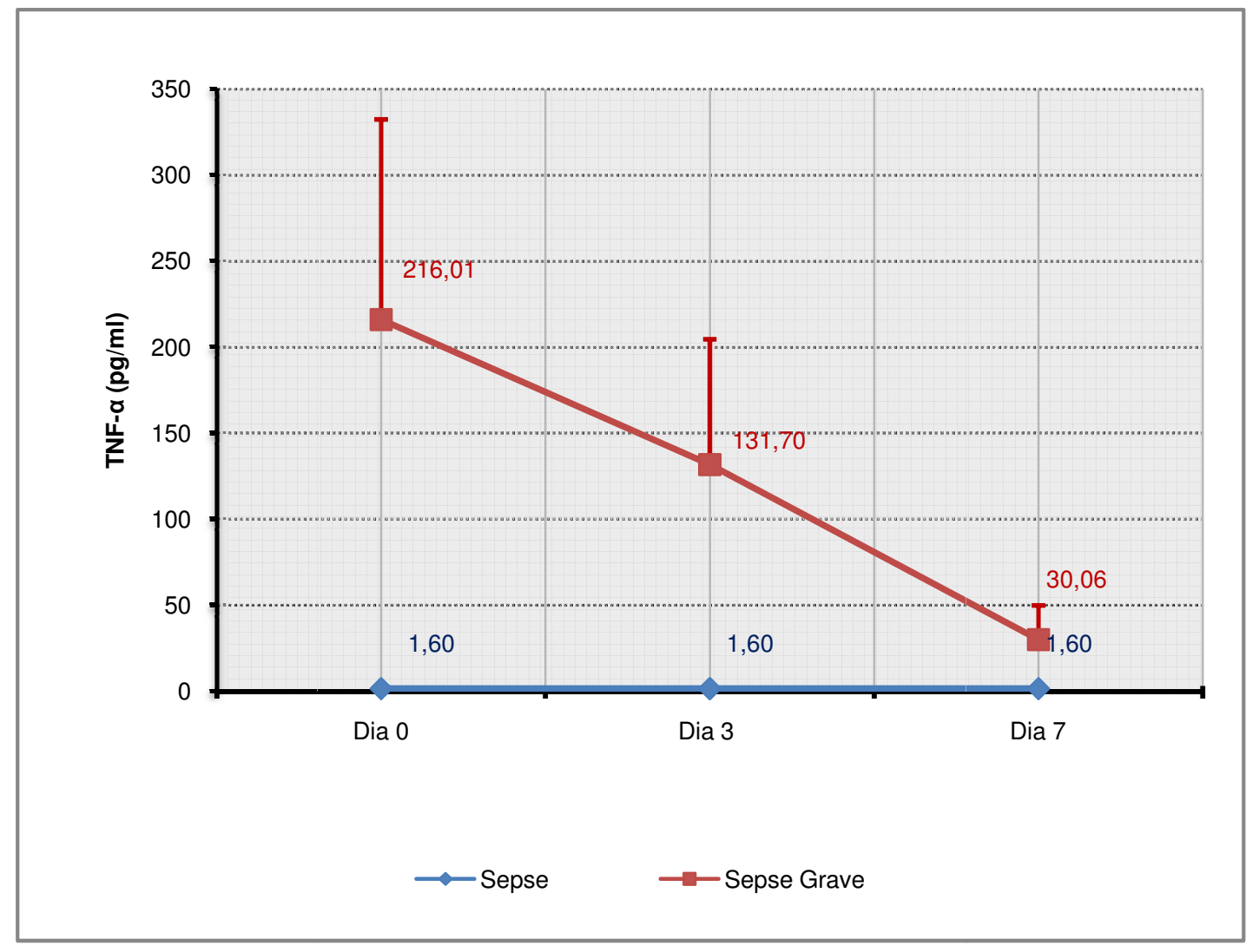

\section{a.2) Análise evolutiva subdividida em grupos sepse e sepse grave}

Em relação aos valores séricos médios do TNF-a podemos observar que no grupo sepse, os recém-nascidos apresentaram valores mínimos detectados desta citocina, ou seja, nos três dias avaliados, o TNF-a dos 16 recém-nascidos deste grupo apresentou valores séricos médios iguais a 1,6 $\mathrm{pg} / \mathrm{ml}$. Enquanto nos 15 recém-nascidos do grupo sepse grave, observamos que no dia 0 obtivemos a maior média e esta ao longo do tempo apresentou decréscimos, melhor visualizado na tabela 11 e figura 10.

Como o grupo sepse não apresentou variação ao longo do tempo não foi possível realizar a comparação entre os dois grupos. 


\section{b) IL-1 $\beta$}

\section{b.1) Evolução geral}

Tabela 12: Medidas descritivas dos valores séricos de IL-1 $\beta$ nos RN avaliados

\begin{tabular}{lrcc}
\hline IL-1 $\beta$ (pg/ml) & \multicolumn{3}{c}{ Dias de evolução } \\
\cline { 2 - 4 } Média & Dia 0 & Dia 3 & Dia 7 \\
Desvio Padrão & 8,10 & 1,54 & 1,51 \\
Mediana & 36,49 & 2,94 & 1,93 \\
Mínimo & 1,00 & 1,00 & 1,00 \\
Máximo & 1,00 & 1,00 & 1,00 \\
№ de Observações & 204,50 & 17,10 & 9,20 \\
\hline
\end{tabular}

Figura 11: Média \pm erro padrão de IL-1 $\beta$ de acordo com o tempo nos RN avaliados

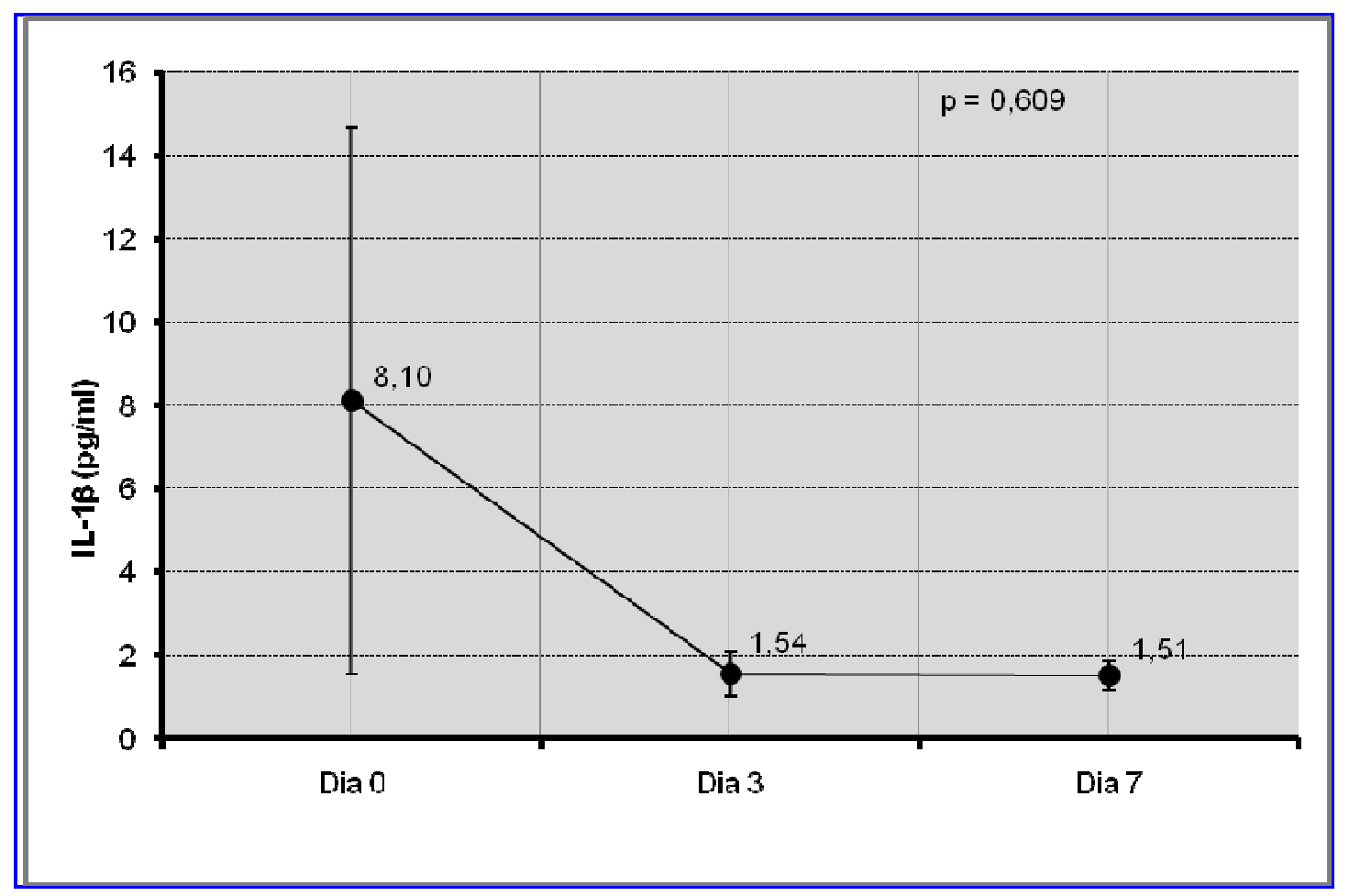




\section{b.1). Análise descritiva evolutiva geral}

Em relação aos valores séricos médios da IL-1 $1 \beta$ dos recém-nascidos desta casuística observamos que o dia 0 apresentou maior média sérica e variabilidade, mas que durante a evolução temporal, tanto as médias séricas quanto a variabilidade vão diminuindo progressivamente (tabela 12; figura 11). Em termos de mediana não se observa tal comportamento, ou seja, não houve variação de IL-1 $\beta$.

Através da ANOVA com medida repetida não houve efeito estatisticamente significante de tempo $(p=0,609)$, ou seja, apesar de se observar um decréscimo no valor médio da IL-1ß no dia 0 para 0 dia 3 (figura 11), o teste estatístico não foi capaz de evidenciar tal diminuição.

\section{b.2) Evolução subdividida em grupos: sepse e sepse grave}

Tabela 13: Medidas descritivas dos valores séricos de IL-1 $1 \beta$ segundo os grupos

\begin{tabular}{|c|c|c|c|c|c|c|}
\hline \multirow[t]{2}{*}{ IL-1 $\beta$ (pg/ml) } & \multicolumn{2}{|c|}{ Dia 0} & \multicolumn{2}{|c|}{ Dia 3} & \multicolumn{2}{|c|}{ Dia 7} \\
\hline & Sepse & $\begin{array}{l}\text { Sepse } \\
\text { Grave }\end{array}$ & Sepse & $\begin{array}{l}\text { Sepse } \\
\text { Grave }\end{array}$ & Sepse & $\begin{array}{l}\text { Sepse } \\
\text { Grave }\end{array}$ \\
\hline Média & 1,59 & 15,05 & 1,00 & 2,15 & 1,44 & 1,58 \\
\hline Desvio Padrão & 1,65 & 52,44 & 0,0 & 4,30 & 1,75 & 2,19 \\
\hline Mediana & 1,00 & 1,00 & 1,00 & 1,00 & 1,00 & 1,00 \\
\hline Mínimo & 1,00 & 1,00 & 1,00 & 1,00 & 1,00 & 1,00 \\
\hline Máximo & 6,60 & 204,50 & 1,00 & 17,10 & 8,00 & 9,20 \\
\hline № observações & 16 & 15 & 16 & 14 & 16 & 14 \\
\hline
\end{tabular}


Figura 12: Perfil médio da IL-1 $\beta$ de acordo com sepse e tempo

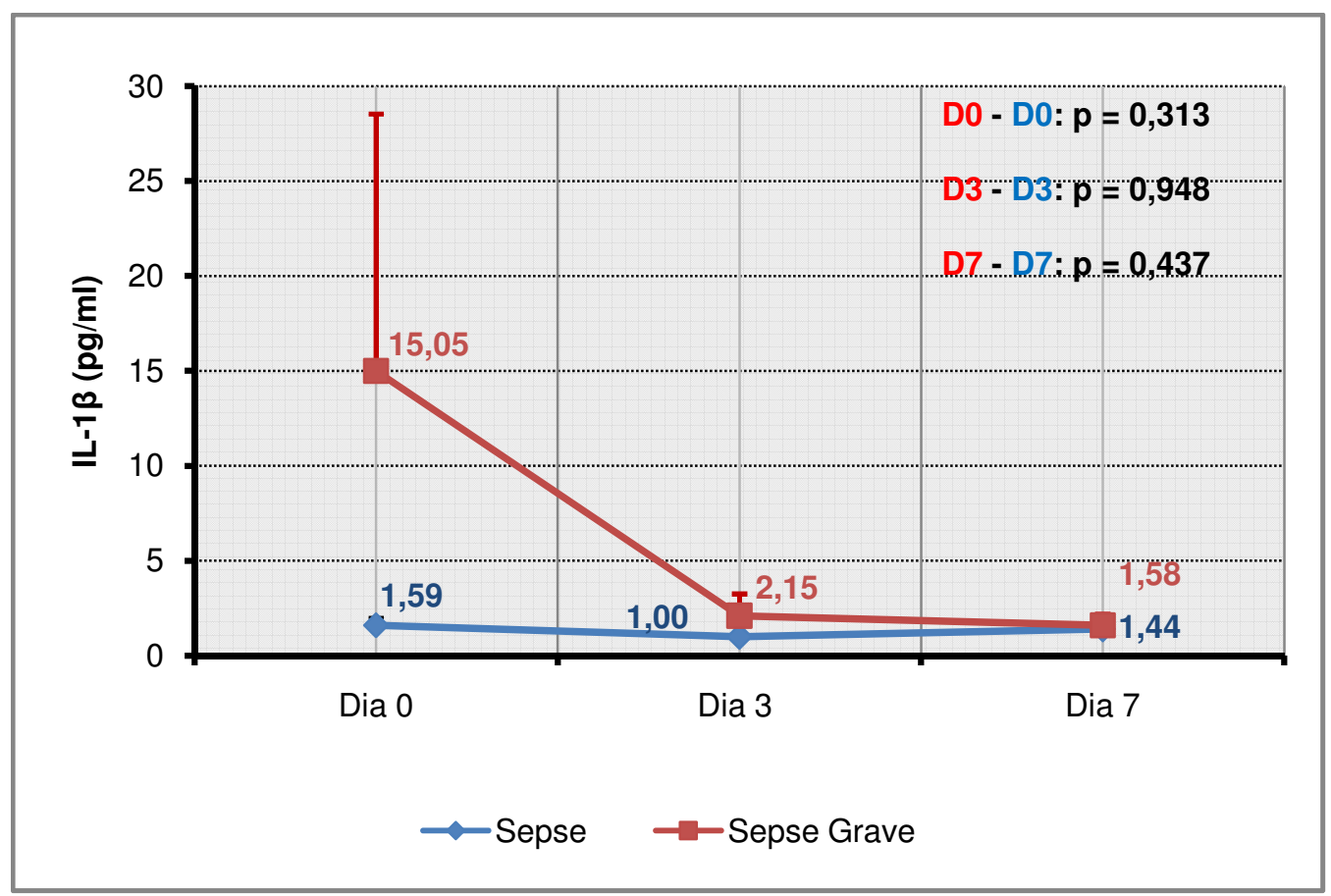

\section{b.2) Análise descritiva evolutiva subdividida em grupos sepse e sepse}

\section{grave}

Em relação aos valores médios da IL-1 $\beta$ podemos observar que no grupo sepse, os 16 recém-nascidos apresentaram valores próximos aos mínimos detectados, enquanto que nos 15 recém-nascidos do grupo sepse grave apresentaram no dia 0 a maior média e que esta diminui de forma progressiva, melhor visualizada na tabela 13 e figura 12.

Através de uma ANOVA com medida repetida pode-se observar que apesar da variação observada na tabela 13 e na figura 12, não houve diferença estatisticamente significante entre os dois grupos ao longo da avaliação. No dia 0 , a diferença foi estimada em 13,46 $\pm 13,1 \mathrm{pg} / \mathrm{ml}$ com valor estatisticamente não significante $(p=0,313)$. No dia 3 , a diferença 
estimada foi de $1,15 \pm 1,62 \mathrm{pg} / \mathrm{ml}$ com valor estatisticamente não significante ( $p=0,948)$. No dia 7 , a diferença entre os dois grupos foi estimada em 1,12 $\pm 1,43 \mathrm{pg} / \mathrm{ml}$ também se mostrou com valor estatisticamente não significante $(p=0,437)$.

c) IL-6

\section{c.1) Evolução geral}

Tabela 14: Medidas descritivas dos valores séricos de IL-6 nos RN avaliados

\begin{tabular}{lccc}
\hline IL-6 (pg/ml) & \multicolumn{3}{c}{ Dias de evolução } \\
\cline { 2 - 4 } Média & Dia 0 & Dia 3 & Dia 7 \\
Desvio Padrão & 1717,04 & 551,33 & 209,39 \\
Mediana & 2453,29 & 1551,33 & 444,80 \\
Mínimo & 763,90 & 82,45 & 43,60 \\
Máximo & 0,70 & 0,70 & 0,70 \\
№ de Observações & 9887,80 & 7493,60 & 1797,10 \\
\hline
\end{tabular}

Figura 13: Média \pm erro padrão de IL-6 de acordo com o tempo nos RN avaliados

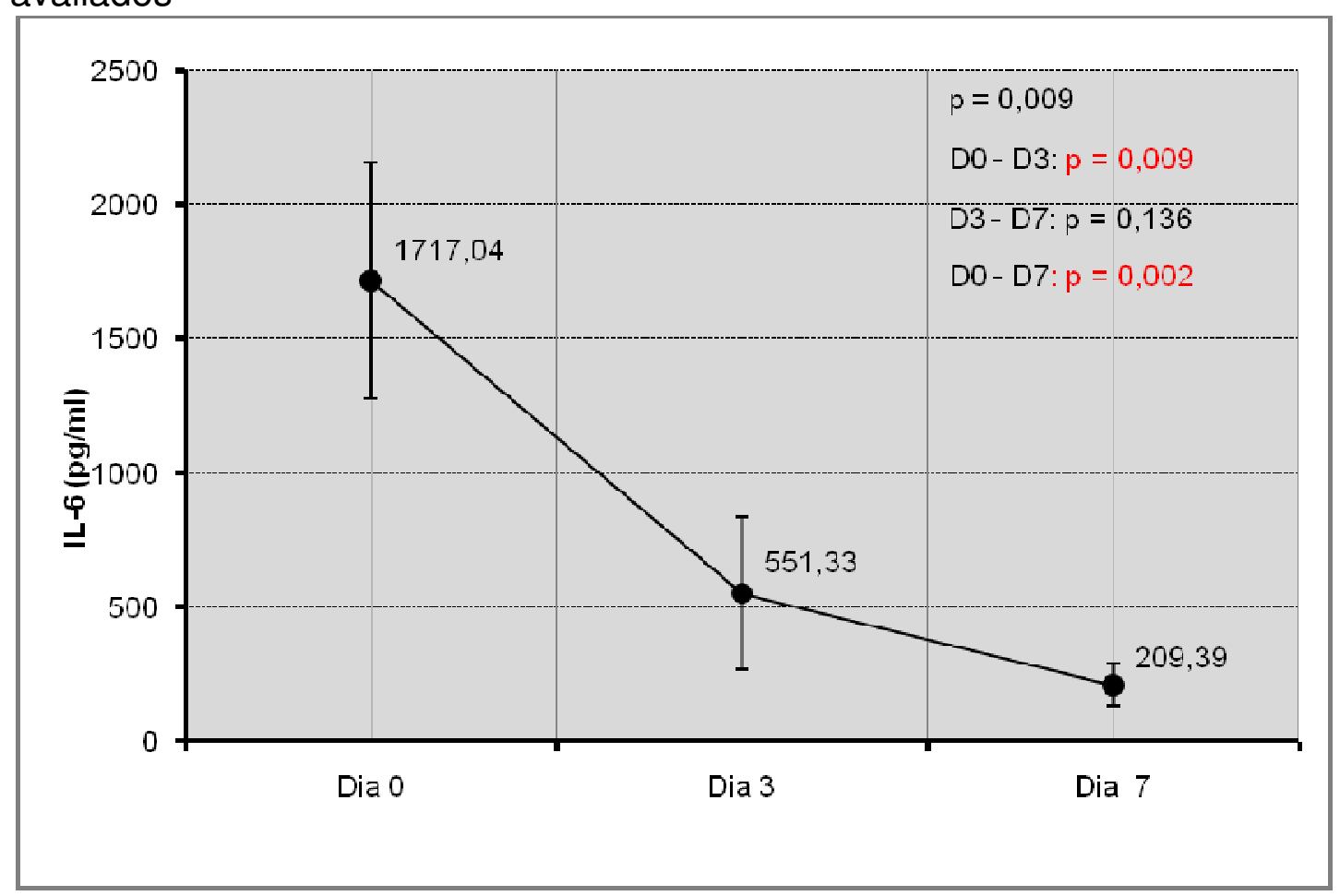




\section{c.1). Análise descritiva evolutiva geral}

Em relação aos valores séricos médios da IL-6 nos recém-nascidos desta casuística, observamos que o dia 0 apresentou a maior média e variabilidade e que a medida da evolução temporal estes valores médios vão diminuindo progressivamente, bem como os valores da variabilidade (tabela 14; figura 13).

Através de uma ANOVA com medida repetida verificou-se que houve efeito estatisticamente significante de tempo $(p=0,009)$. Quando estratificamos o tempo para detectar onde se encontram as diferenças prosseguiu-se a análise através da construção de contrastes e foi observado que do dia 0 para o dia 3 houve importante decréscimo de 1071,5 $\pm 384,5$ $\mathrm{pg} / \mathrm{ml}$ com valor estatisticamente significante $(\mathrm{p}=0,009)$. Do dia 0 para o dia 7 houve decréscimo médio de 1510,9 $\pm 453,1 \mathrm{pg} / \mathrm{ml}$ com valor estatisticamente significante $(p=0,002)$. No dia 3 para 0 dia 7 houve decréscimo de 439,4 $\pm 286,9 \mathrm{pg} / \mathrm{ml}$, porém com valor estatisticamente não significante $(p=0,136)$. 


\section{c.2) Evolução subdividida em grupos: sepse e sepse grave}

Tabela 15: Medidas descritivas dos valores séricos de IL-6 segundo os grupos

\begin{tabular}{|c|c|c|c|c|c|c|}
\hline \multirow[t]{2}{*}{ IL-6 (pg/ml) } & \multicolumn{2}{|c|}{ Dia 0} & \multicolumn{2}{|c|}{ Dia 3} & \multicolumn{2}{|c|}{ Dia 7} \\
\hline & Sepse & $\begin{array}{l}\text { Sepse } \\
\text { Grave }\end{array}$ & Sepse & $\begin{array}{l}\text { Sepse } \\
\text { Grave }\end{array}$ & Sepse & $\begin{array}{l}\text { Sepse } \\
\text { Grave }\end{array}$ \\
\hline Média & 1150,51 & 2321,35 & 71,23 & 1100,02 & 40,21 & 402,73 \\
\hline Desvio Padrão & 1216,20 & 3248,72 & 79,58 & 2180,22 & 46,99 & 602,75 \\
\hline Mediana & 632,40 & 784,60 & 61,30 & 171,95 & 21,30 & 89,25 \\
\hline Mínimo & 0,70 & 0,70 & 0,70 & 0,70 & 0,70 & 0,70 \\
\hline Máximo & 4166,20 & 9887,80 & 279,80 & 7493,60 & 131,90 & 1797,10 \\
\hline № observações & 16 & 15 & 16 & 14 & 16 & 14 \\
\hline
\end{tabular}

Figura 14: Perfil médio da IL-6 de acordo com sepse e tempo

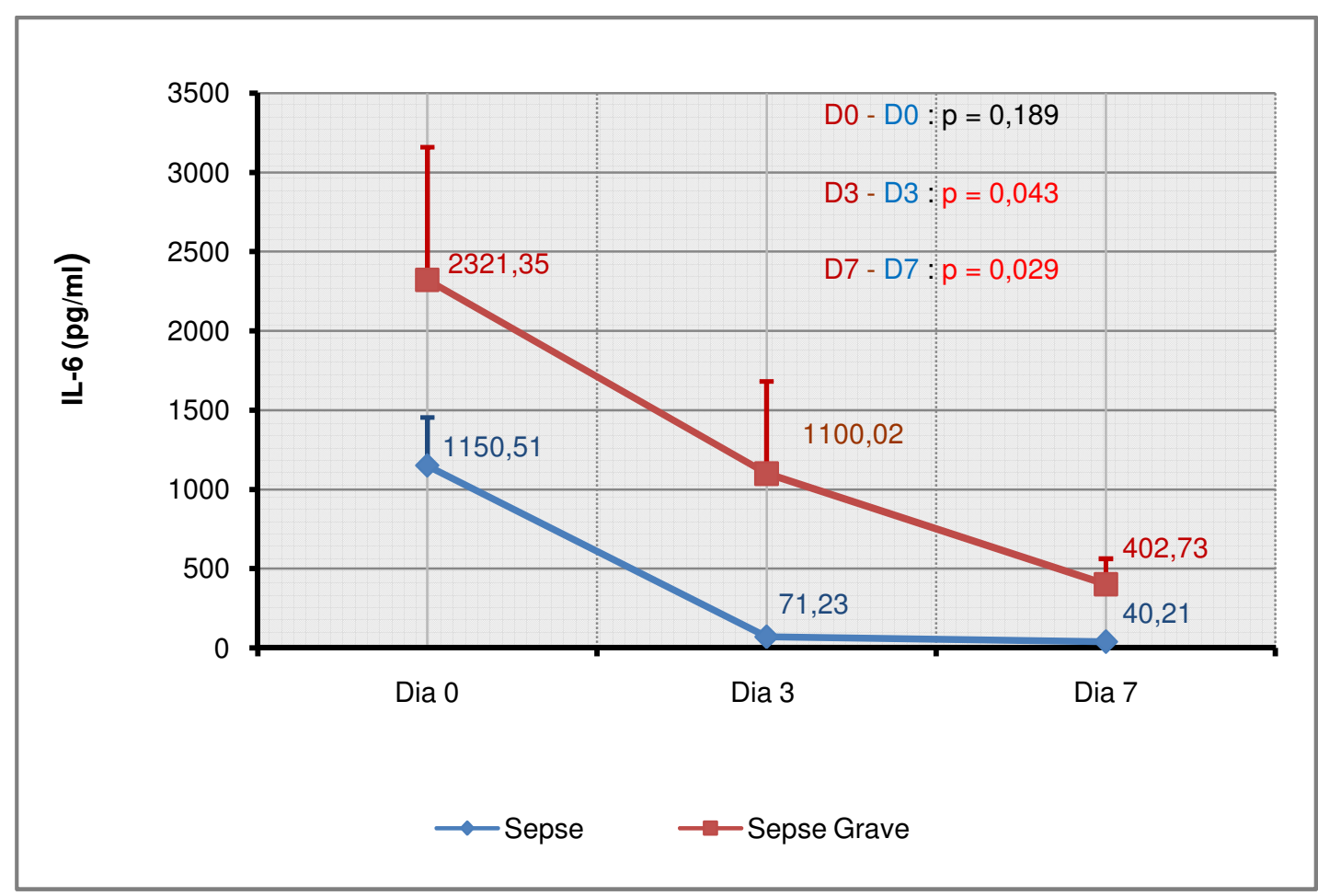




\section{c.2) Análise descritiva evolutiva subdividida em grupos sepse e}

\section{sepse grave}

Em relação aos valores médios da IL-6 podemos observar que no grupo sepse grave, os 15 recém-nascidos apresentaram valores evolutivos maiores do que apresentados pelos 16 recém-nascidos do grupo sepse, em todas as avaliações. O perfil médio dos dois grupos apresentou o mesmo comportamento ao longo do tempo, ou seja, em ambos os grupos, a partir do terceiro dia ocorre um decréscimo na média dos valores da IL-6. (tabela 15; figura 14)

Através de uma ANOVA com medida repetida podemos observar que no dia 0 , os dois grupos - sepse e sepse grave não se diferenciam em termos de IL-6 ( $p=0,189)$. No dia 3, o grupo sepse grave apresentou média $1196,9 \pm 564,8 \mathrm{pg} / \mathrm{ml}$ a mais do que o grupo sepse, e esta diferença apresentou-se estatisticamente significante $(p=0,043)$. No dia 7 , foi observado diferença estatisticamente significante entre os dois grupos ( $p=$ 0,029), ou seja, o grupo sepse grave apresentou média de IL-6 maior que o

do grupo sepse sendo a diferença entre eles estimada em 347,4 \pm 151,4 $\mathrm{pg} / \mathrm{ml}$. 


\section{Mediadores Antiinflamatórios}

a) IL-10

\section{a.1) Evolução geral}

Tabela 16: Medidas descritivas dos valores séricos de IL-10 nos RN avaliados

\begin{tabular}{lrcc}
\hline IL-10 $(\mathrm{pg} / \mathrm{ml})$ & \multicolumn{3}{c}{ Dias de evolução } \\
\cline { 2 - 4 } Média & Dia 0 & Dia 3 & Dia 7 \\
Desvio Padrão & 76,77 & 42,04 & 6,68 \\
Mediana & 317,65 & 139,64 & 9,93 \\
Mínimo & 3,90 & 3,90 & 3,90 \\
Máximo & 3,90 & 3,90 & 3,90 \\
№ de Observações & 1732,60 & 569,00 & 55,80 \\
\hline
\end{tabular}

Figura 15: Média \pm erro padrão de IL-10 de acordo com o tempo nos RN avaliados

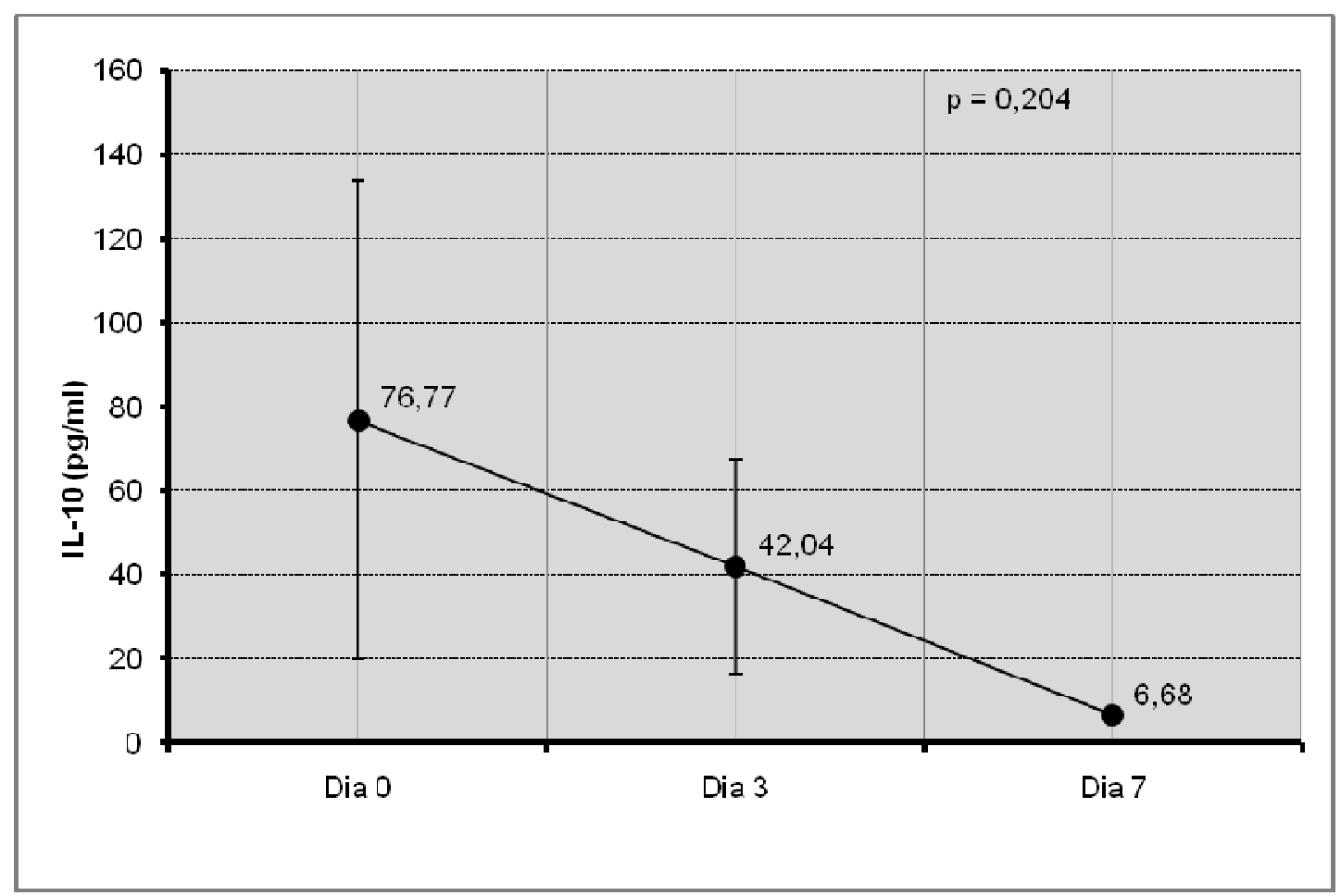




\section{a.1). Análise descritiva evolutiva geral}

Em relação aos valores séricos médios da IL-10 nos recém-nascidos desta casuística, observamos que o dia 0 apresentou a maior média e variabilidade e que a medida da evolução temporal estes valores vão diminuindo progressivamente. Este comportamento pode ser melhor visualizado através da tabela 16 e da figura 15.

No dia 0, o valor máximo da IL-10 ocorreu no caso que foi a óbito, o que acabou por ofuscar o padrão de curva esperado para esta citocina antiinflamatória. Esperava-se que atingisse o pico no $3^{0}$ dia e após resolução do quadro séptico este valor diminuísse até o $7^{0}$ dia.

Através de uma ANOVA com medida repetida verificou-se que não houve efeito estatisticamente significante de tempo $(p=0,204)$, ou seja, apesar de se observar um decréscimo no valor médio de IL-10 do dia 0 para o dia 3 (gráfico 7) este não se mostrou significativo. 


\section{a.2) Evolução subdividida em grupos: sepse e sepse grave}

Tabela 17: Medidas descritivas dos valores séricos de IL-10 segundo os grupos

\begin{tabular}{|c|c|c|c|c|c|c|}
\hline \multirow[t]{2}{*}{ IL-10 (pg/ml) } & \multicolumn{2}{|c|}{ Dia 0} & \multicolumn{2}{|c|}{ Dia 3} & \multicolumn{2}{|c|}{ Dia 7} \\
\hline & Sepse & $\begin{array}{l}\text { Sepse } \\
\text { Grave }\end{array}$ & Sepse & $\begin{array}{l}\text { Sepse } \\
\text { Grave }\end{array}$ & Sepse & $\begin{array}{l}\text { Sepse } \\
\text { Grave }\end{array}$ \\
\hline Média & 3,90 & 154,51 & 3,90 & 85,62 & 3,90 & 9,86 \\
\hline Desvio Padrão & 0,0 & 451,31 & 0,0 & 199,15 & 0,0 & 14,13 \\
\hline Mediana & 3,90 & 3,90 & 3,90 & 3,90 & 3,90 & 4,00 \\
\hline Mínimo & 3,90 & 3,90 & 3,90 & 3,90 & 3,90 & 3,90 \\
\hline Máximo & 3,90 & 1732,60 & 3,90 & 569,00 & 3,90 & 55,80 \\
\hline № observações & 16 & 15 & 16 & 14 & 16 & 14 \\
\hline
\end{tabular}

Figura 16: Perfil médio da IL-10 de acordo com sepse e tempo

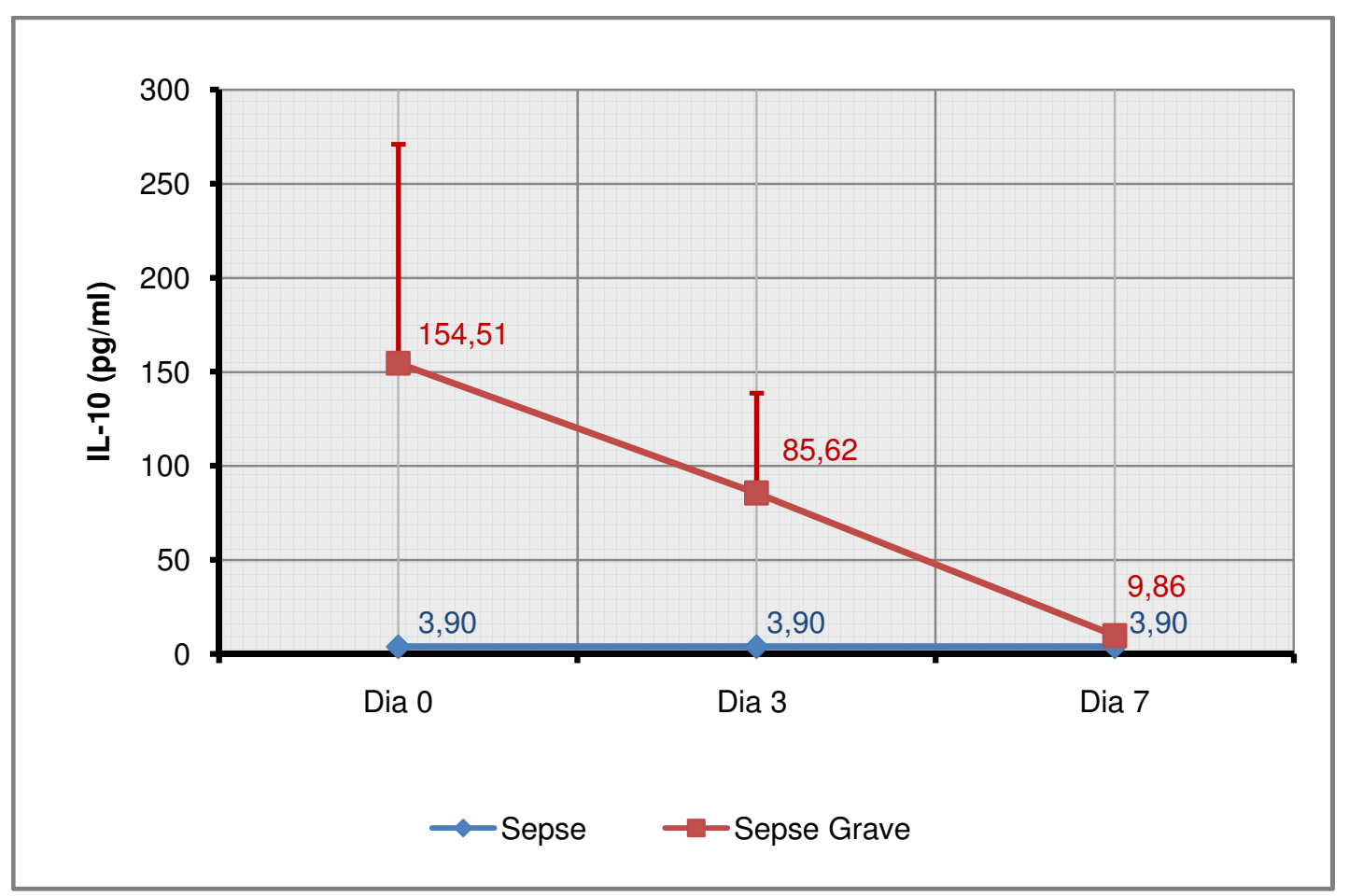




\section{a.2) Análise evolutiva subdividida em grupos sepse e sepse}

grave

Em relação aos valores séricos médios da IL-10 podemos observar que o grupo sepse não apresentou variação da IL-10 ao longo do tempo, acompanhando os valores das citocinas pró-inflamatórias, mantendo-se nos valores mínimos detectados. O grupo sepse grave apresentou a maior média sérica do que o grupo sepse em todos os instantes da avaliação. No perfil médio do grupo sepse grave ocorreu um decréscimo na média ao longo das avaliações e que de maneira geral acompanha os decréscimos das citocinas pró-inflamatórias, neste grupo (sepse grave) (tabela 17; figura 16). Como o grupo sepse não apresentou variação de valores ao longo do tempo não foi possível realizar a comparação entre os dois grupos.

b) IL-1Ra

\section{b.1) Evolução geral}

Tabela 18: Medidas descritivas dos valores séricos de IL-1Ra nos RN avaliados

\begin{tabular}{lccc}
\hline IL-1Ra(pg/ml) & \multicolumn{3}{c}{ Dias de evolução } \\
\cline { 2 - 4 } & Dia 0 & Dia 3 & Dia 7 \\
Média & 1322,38 & 777,76 & 771,85 \\
Desvio Padrão & 1232,71 & 1347,08 & 1195,16 \\
Mediana & 842,20 & 321,30 & 271,65 \\
Mínimo & 93,20 & 71,70 & 27,90 \\
Máximo & 4548,80 & 6491,60 & 4742,70 \\
№ de Observações & 31 & 30 & 30 \\
\hline
\end{tabular}


Figura 17: Média \pm erro padrão de IL-1Ra de acordo com o tempo nos RN avaliados

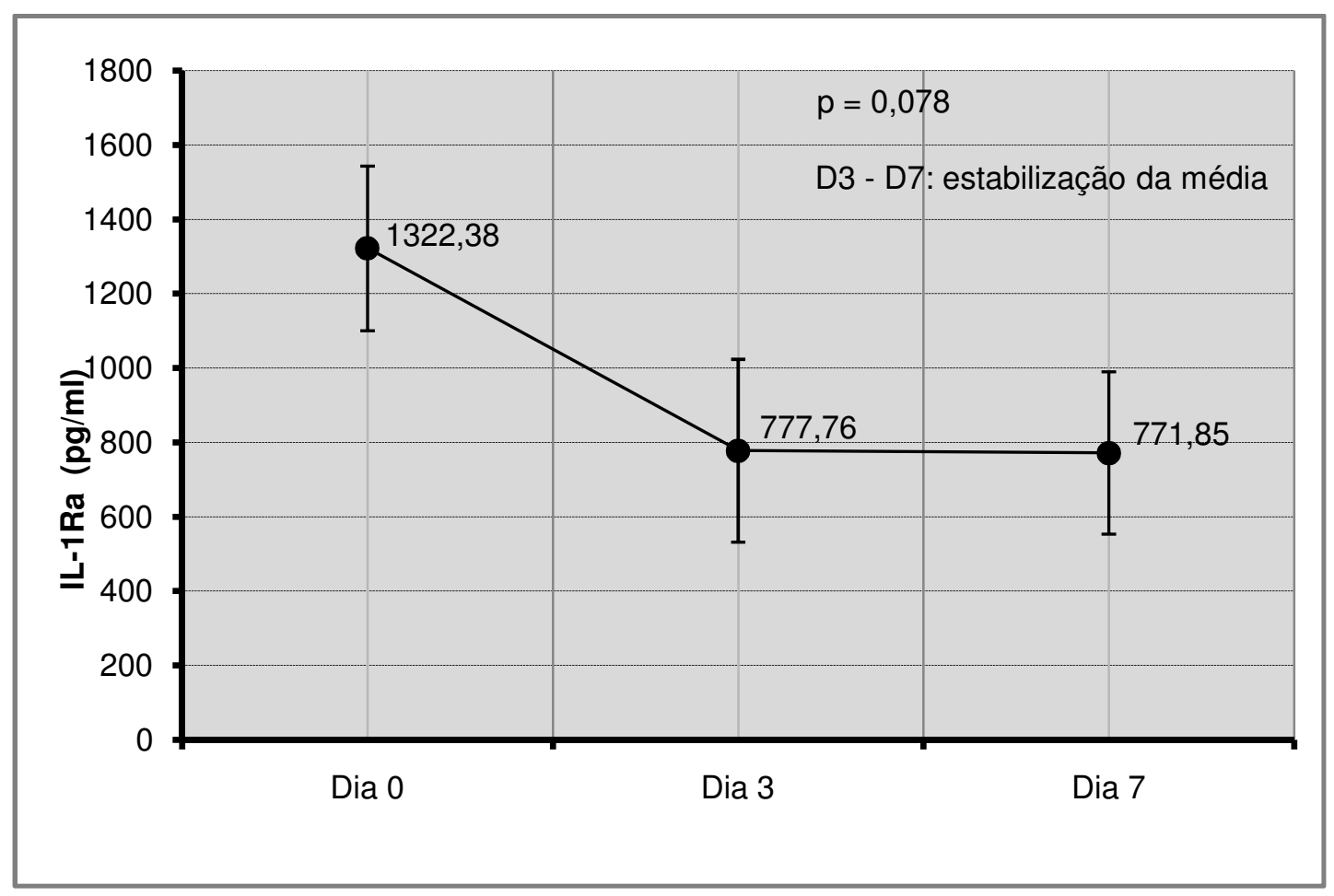

\section{b.1). Análise descritiva evolutiva geral}

Em relação aos valores séricos médios da IL-1Ra nos recém-nascidos desta casuística, observamos que o dia 0 apresentou a maior média e que nos dia 3 e 7 de evolução houve estabilização da média. Este comportamento pode ser melhor visualizado através da figura 17; tabela 18.

Através da Análise de Variância (ANOVA) com medida repetida verificou-se que não houve efeito estatisticamente significante de tempo, ou seja, apesar de se observar um decréscimo no valor médio da IL-1Ra do dia 0 para o dia 3 (figura 17) este não se mostrou significativo $(p=0,078)$. 


\section{b.2) Evolução subdividida em grupos: sepse e sepse grave}

Tabela 19: Medidas descritivas dos valores séricos de IL-1Ra segundo os grupos

\begin{tabular}{|c|c|c|c|c|c|c|}
\hline \multirow[t]{2}{*}{ IL-1Ra (pg/ml) } & \multicolumn{2}{|c|}{ Dia 0} & \multicolumn{2}{|c|}{ Dia 3} & \multicolumn{2}{|c|}{ Dia 7} \\
\hline & Sepse & $\begin{array}{l}\text { Sepse } \\
\text { Grave }\end{array}$ & Sepse & $\begin{array}{l}\text { Sepse } \\
\text { Grave }\end{array}$ & Sepse & $\begin{array}{l}\text { Sepse } \\
\text { Grave }\end{array}$ \\
\hline Média & 1092,76 & 1567,31 & 312,93 & 1309,00 & 186,68 & 1440,61 \\
\hline Desvio Padrão & 775,93 & 1576,91 & 201,65 & 1852,36 & 106,41 & 1506,75 \\
\hline Mediana & 863,30 & 667,50 & 240,45 & 462,30 & 164,41 & 604,70 \\
\hline Mínimo & 227,10 & 93,20 & 71,70 & 105,00 & 27,90 & 87,10 \\
\hline Máximo & 3014,30 & 4548,80 & 674,30 & 6491,60 & 414,80 & 4742,70 \\
\hline № observações & 16 & 15 & 16 & 14 & 16 & 14 \\
\hline
\end{tabular}

Figura18: Perfil médio da IL-1Ra de acordo com sepse e tempo

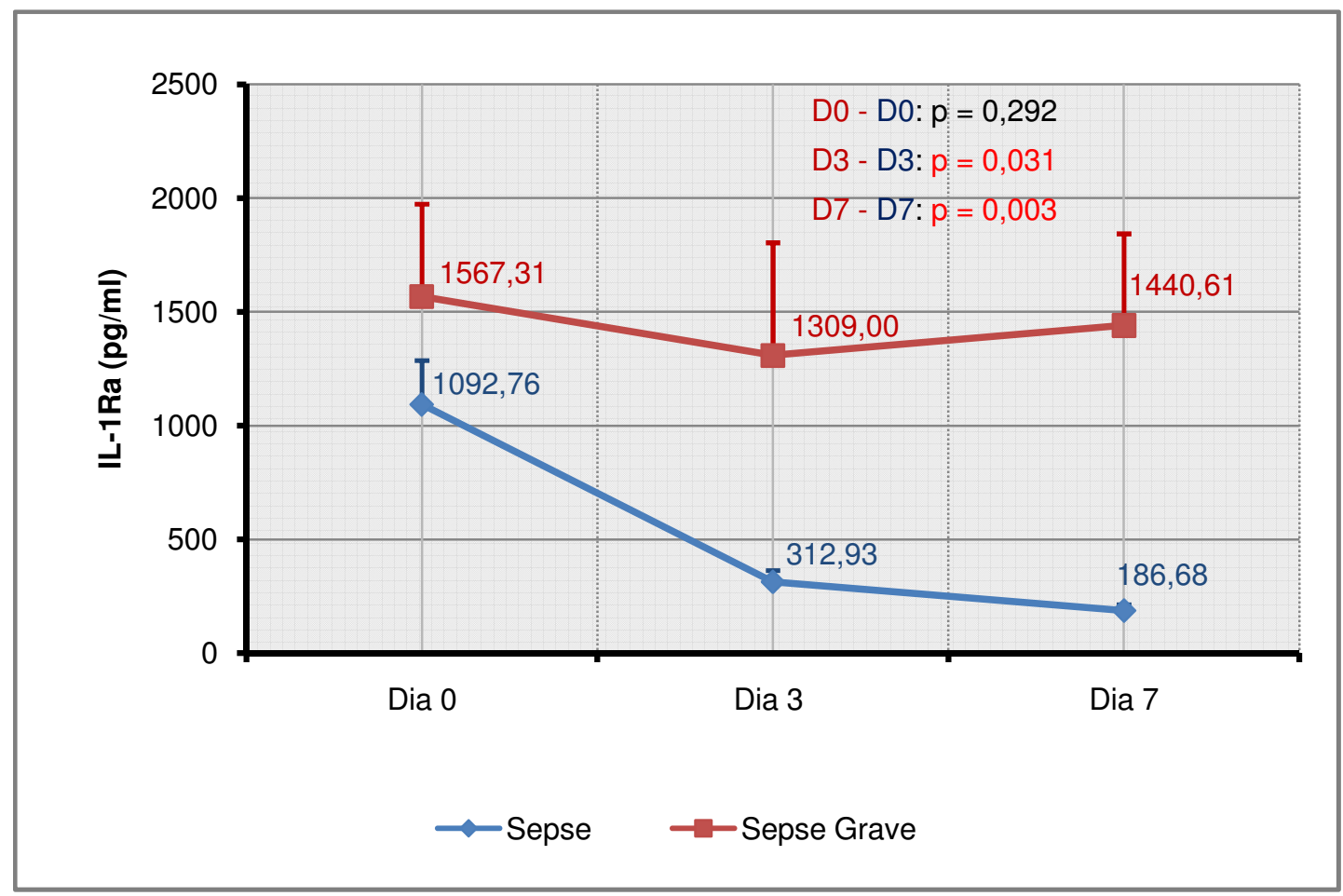




\section{b.2) Análise descritiva evolutiva subdividida em grupos sepse e sepse grave}

Em relação aos valores séricos médios da IL-1Ra podemos observar que os 15 recém-nascidos classificados como sepse grave apresentaram valores maiores nos dias 0,3 e 7 de evolução do que os apresentados pelo grupo sepse em todas as avaliações, conforme podemos observar na tabela 19. Na figura 18, o perfil médio do grupo sepse grave mostra que houve um decréscimo na média da IL-1Ra do dia 0 para o dia 3, porém do dia 3 para o dia 7 ocorre um ligeiro acréscimo na sua média, indicando um aumento da produção de mediadores antiinflamatórios, ou seja, há um possível desequilíbrio homeostático (tabela 19 e figura 18).

No grupo sepse ocorreu um decréscimo na média da IL-1Ra ao longo das avaliações, conforme a tabela 19 e a figura 18, acompanhando a curva dos mediadores pró-inflamatórios, ou seja, em possível equilíbrio homeostático entre mediadores pró-inflamatórios e antiinflamatórios, caracterizando a resolução do processo séptico sem complicações.

Através de uma ANOVA com medida repetida podemos observar que no dia 0 os dois grupos não se diferenciam em termos de IL-1Ra $(p=0,292)$. No dia 3, o grupo sepse grave apresentou média da IL-1Ra maior do que no grupo sepse e o teste estatístico foi capaz de evidenciar tal diferença $(p=$ 0,031). A diferença entre os dois grupos no dia 3 foi estimada em 1053,5 \pm $463,6 \mathrm{pg} / \mathrm{ml}$. No dia 7 , foi observada diferença estatisticamente significante entre os dois grupos $(p=0,003)$, ou seja, o grupo sepse grave apresentou 
maior média que a do grupo sepse sendo esta diferença entre eles estimada em $1226,4 \pm 376,4 \mathrm{pg} / \mathrm{ml}$.

\section{Relação: mediadores pró-inflamatórios / antiinflamatórios}

a) Relação IL-6 / IL-1Ra

\section{a.1) Evolução geral}

Tabela 20: Medidas descritivas dos valores séricos da relação IL-6/L-1Ra nos $\mathrm{RN}$ avaliados

\begin{tabular}{lccc}
\hline IL-6/IL-1Ra & \multicolumn{3}{c}{ Dias de evolução } \\
\cline { 2 - 4 } Média & Dia 0 & Dia 3 & Dia 7 \\
Desvio Padrão & 1,93 & 1,07 & 0,32 \\
Mediana & 3,19 & 2,97 & 0,16 \\
Mínimo & 1,04 & 0,43 & 0,27 \\
Máximo & 0,10 & 0,04 & 0,08 \\
№ de Observações & 14,44 & 14,64 & 0,63 \\
\hline
\end{tabular}

Figura 19: Média \pm erro padrão de IL-6/IL-1Ra de acordo com o tempo

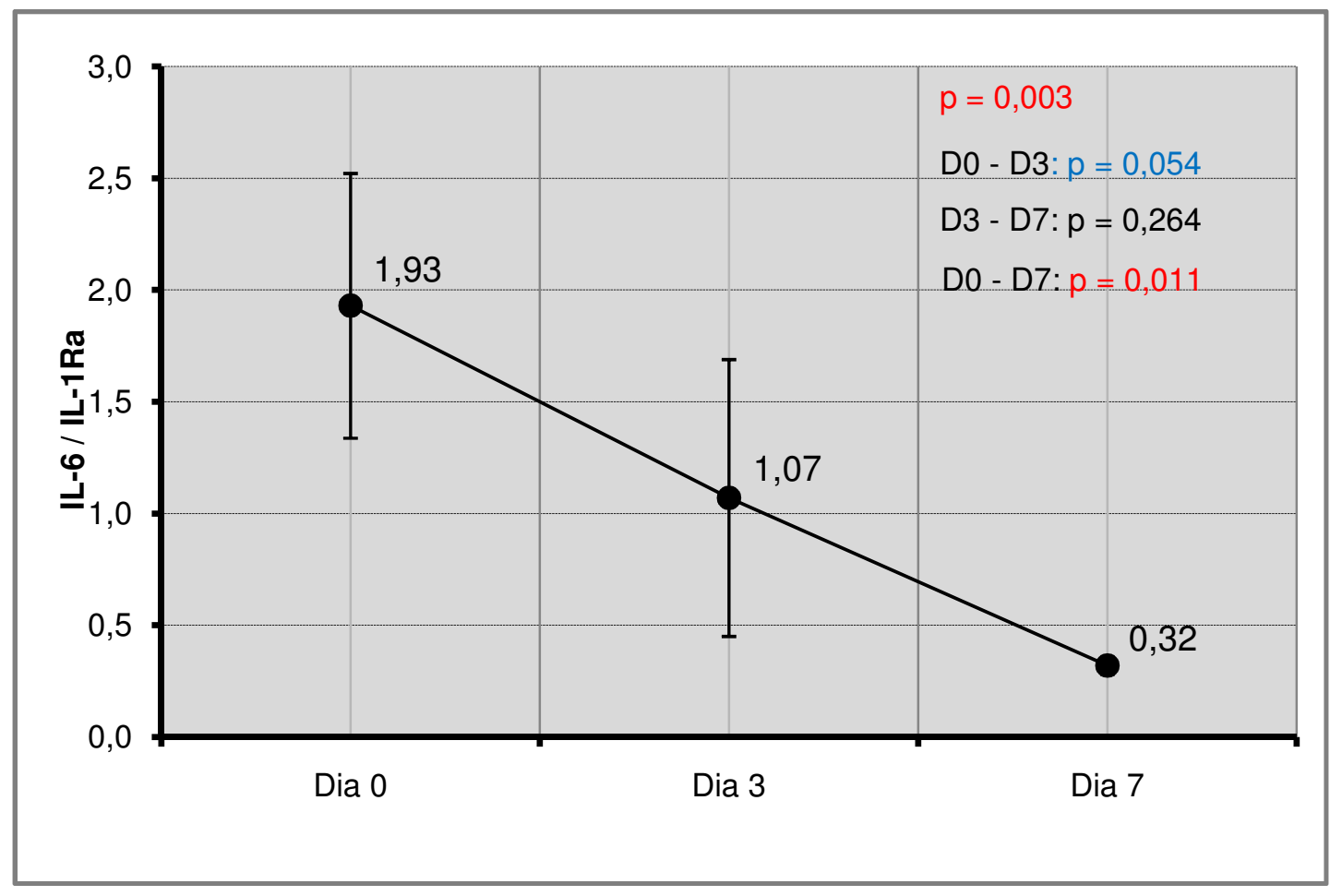




\section{a.1). Análise descritiva evolutiva geral}

Na relação entre um mediador pró-inflamatório, representado pela IL6, e um mediador antiinflamatório, representado pelo IL-1Ra, observamos que no dia 0 obtivemos a maior média e que a partir daí houve decréscimo nos dias seguintes. Este comportamento pode ser melhor visualizado na tabela 20 e na figura 19.

Através de uma ANOVA com medida repetida verificou-se que houve efeito estatisticamente significante de tempo $(p=0,027)$. Quando estratificamos o tempo para detectar onde está a diferença, do dia 0 para o dia 3 houve decréscimo médio de $0,96 \pm 0,48$, porém este decréscimo mostrou-se apenas marginalmente significante $(p=0,054)$. Do dia 0 para 0 dia 7 houve um decréscimo médio de 1,59 \pm 0,58, com efeito, estatisticamente significante $(p=0,011)$. Do dia 3 para 0 dia 7 houve um decréscimo médio de $0,63 \pm 0,55$, porém não significante $(p=0,264)$.

Interpretando melhor a figura 19, observamos que no dia 0 , a relação IL-6 sobre IL-1Ra, o valor é superior a 1, ou seja, há um efeito predominante da IL-6 em relação a IL-1Ra e que a medida da evolução do tempo esta relação se inverte no dia 7 quando a relação torna-se inferior a 1 , caracterizando a maior ação da IL-1Ra, ação antiinflamatória. 


\section{a.2) Evolução subdividida em grupos: sepse e sepse grave}

Tabela 21: Medidas descritivas dos valores séricos da relação IL-6/IL-1Ra segundo os grupos

\begin{tabular}{|c|c|c|c|c|c|c|}
\hline \multirow[t]{2}{*}{ IL-6/IL-1Ra } & \multicolumn{2}{|c|}{ Dia 0} & \multicolumn{2}{|c|}{ Dia 3} & \multicolumn{2}{|c|}{ Dia 7} \\
\hline & Sepse & $\begin{array}{l}\text { Sepse } \\
\text { Grave }\end{array}$ & Sepse & $\begin{array}{l}\text { Sepse } \\
\text { Grave }\end{array}$ & Sepse & $\begin{array}{l}\text { Sepse } \\
\text { Grave }\end{array}$ \\
\hline Média & 1,72 & 2,15 & 0,36 & 1,61 & 0,33 & 0,31 \\
\hline Desvio Padrão & 2,79 & 3,66 & 0,20 & 3,93 & 0,17 & 0,15 \\
\hline Mediana & 0,77 & 1,40 & 0,34 & 0,53 & 0,29 & 0,27 \\
\hline Mínimo & 0,10 & 0,11 & 0,17 & 0,04 & 0,08 & 0,13 \\
\hline Máximo & 11,17 & 14,44 & 0,82 & 14,64 & 0,62 & 0,63 \\
\hline № observações & 15 & 14 & 10 & 13 & 9 & 9 \\
\hline
\end{tabular}

Figura 20: Perfil médio da relação IL-6/LL-1Ra de acordo com sepse e tempo

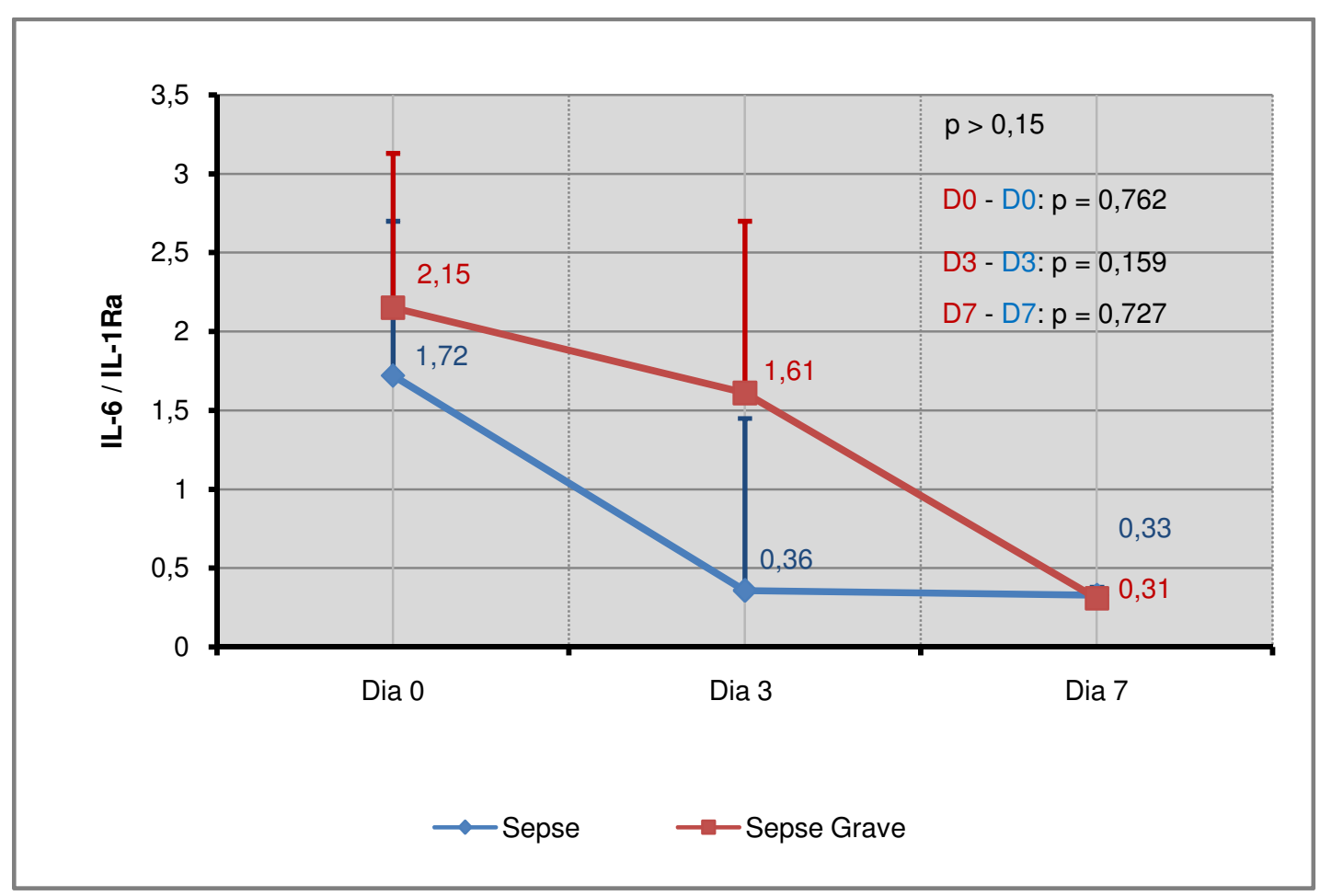




\section{a.2) Análise evolutiva subdividida em grupos sepse e sepse}

grave

$\mathrm{Na}$ relação IL-6 / IL-1Ra observamos que o grupo sepse grave apresentou valores maiores do que o apresentado pelo grupo sepse nos dias 0 e 3, com relação superior a 1, ou seja com predomínio de ação próinflamatória e que no dia 7 , esta relação se inverte com valor inferior a 1 , com predomínio antiinflamatório, conforme tabela 21 e figura 20. Enquanto o grupo sepse apresentou somente no dia 0 uma relação superior a 1, mas já nos dias 3 e 7 estão inferiores a 1, revelando aumento da atividade antiinflamatória e melhora clínica e cura do processo séptico (tabela 21 e figura 20).

Apesar das diferenças observadas descritivamente o modelo de ANOVA com medida repetida não foi capaz de detectar diferenças significativas entre as médias de IL-6/IL-1Ra entre os dois grupos em nenhum dos tempos avaliados $(p>0,15)$. As diferenças médias estimadas da relação IL-6 / IL-1Ra foram iguais a 0,43 $\pm 1,18(p=0,762) ; 1,25 \pm 1,09$ ( $p$ $=0,159)$ e 0,02 $\pm 0,08(p=0,727)$ para os dias 0,3 e 7 , respectivamente. 
b) Relação IL-6 / (IL-6 + IL-1Ra)

\section{b.1) Evolução geral}

Tabela 22: Medidas descritivas dos valores séricos da relação IL-6/(IL-6 + IL1Ra) nos $\mathrm{RN}$ avaliados

\begin{tabular}{lccc}
\hline IL-6/(IL-6 + IL-1Ra) & \multicolumn{3}{c}{ Dias de evolução } \\
\cline { 2 - 4 } Média & Dia 0 & Dia 3 & Dia 7 \\
Desvio Padrão & 0,47 & 0,32 & 0,23 \\
Mediana & 0,25 & 0,18 & 0,09 \\
Mínimo & 0,51 & 0,30 & 0,21 \\
Máximo & 0,09 & 0,04 & 0,07 \\
№ de Observações & 0,93 & 0,94 & 0,39 \\
\hline
\end{tabular}

Figura 21: Média \pm erro padrão de IL-6/(IL-6+IL-1Ra) de acordo com o tempo

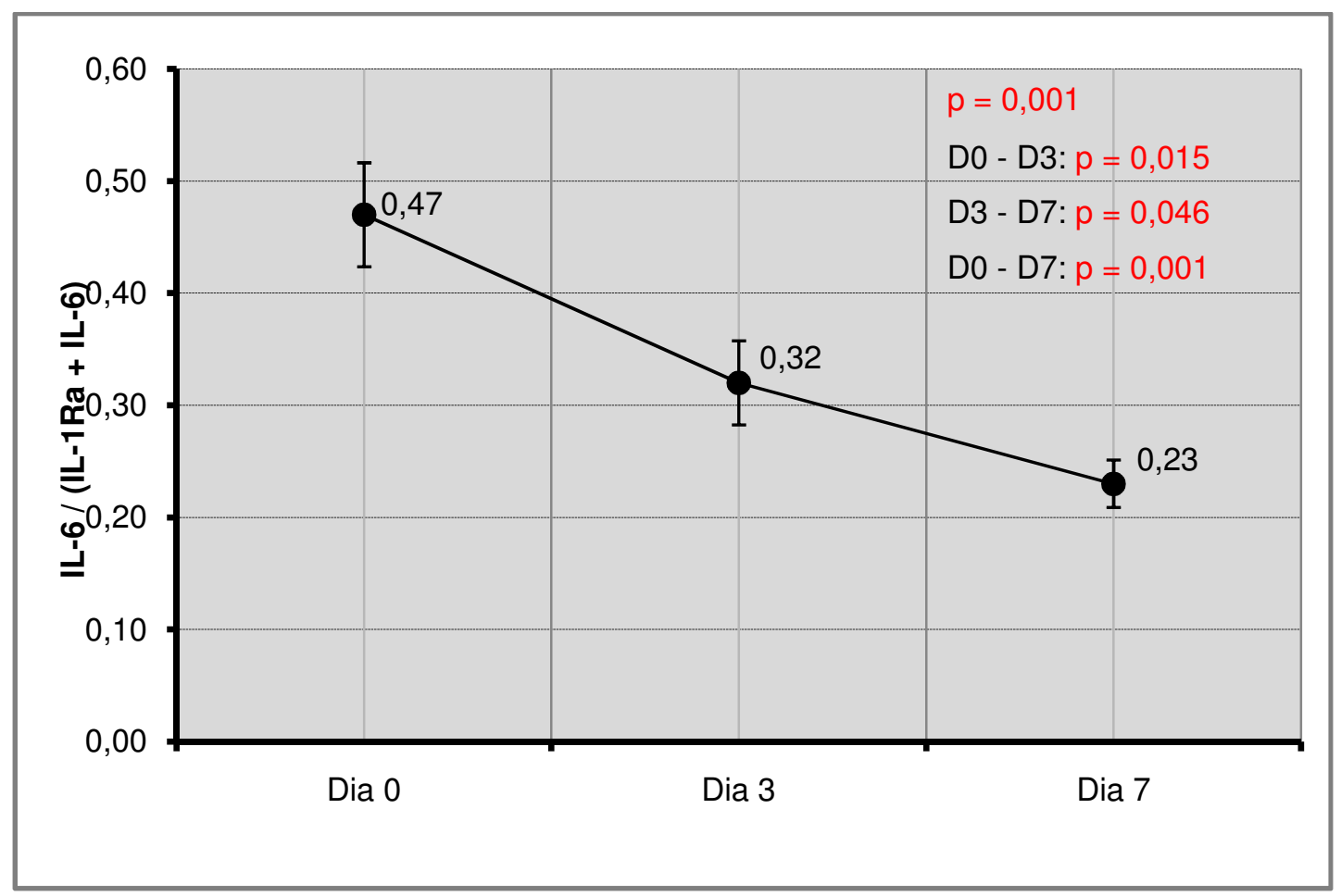




\section{b.1)Analise descritiva da evolução geral}

Por conta dos relatos na literatura (Oberholzer et al., 2000; Borish e Steinke, 2003; Loisa et al., 2003; Abbas e Lichtman, 2005), que referem que a IL-6 teria inicialmente um efeito pró-inflamatório e que na evolução temporal, pela sua elevação teria uma ação antiinflamatória, a partir deste dado foi construída a relação IL-6 / (IL-6 + IL-1Ra). Nesta relação observamos que no dia 0 obtivemos a maior média e que houve um decréscimo nos dia 3 e 7 de evolução, respectivamente. Este comportamento pode ser melhor visualizado na tabela 22 e figura 21).

Através de uma ANOVA com medida repetida verificou-se que houve efeito estatisticamente significante de tempo $(p=0,001)$. Quando estratificado o tempo para detectar onde estava a diferença, do dia 0 para o dia 3 houve um decréscimo médio de $0,15 \pm 0,06$, sendo este estatisticamente significante $(p=0,015)$. Do dia 0 para 0 dia 7 houve um decréscimo médio de 0,24 $\pm 0,05$, com efeito, estatisticamente significante ( $p$ $=0,001)$. Do dia 3 para o dia 7 houve um decréscimo médio de $0,09 \pm 0,04$, sendo este também estatisticamente significante $(p=0,046)$.

Na figura 21 observamos que a relação no dia 0 é inferior a 1 e que permanece inferior ao longo do tempo, sugerindo um predomínio da resposta antiinflamatória com resolução do quadro séptico 


\section{b.2) Evolução subdividida em grupos: sepse e sepse grave}

Tabela 23: Medidas descritivas dos valores séricos da relação IL-6/ (IL-6 + IL-1Ra) segundo os grupos

\begin{tabular}{|c|c|c|c|c|c|c|}
\hline IL-6/ & \multicolumn{2}{|c|}{ Dia 0} & \multicolumn{2}{|c|}{ Dia 3} & \multicolumn{2}{|c|}{ Dia 7} \\
\hline (IL-6+IL-1Ra) & Sepse & $\begin{array}{l}\text { Sepse } \\
\text { Grave }\end{array}$ & Sepse & $\begin{array}{l}\text { Sepse } \\
\text { Grave }\end{array}$ & Sepse & $\begin{array}{l}\text { Sepse } \\
\text { Grave }\end{array}$ \\
\hline Média & 0,45 & 0,49 & 0,25 & 0,36 & 0,24 & 0,22 \\
\hline Desvio Padrão & 0,25 & 0,27 & 0,10 & 0,22 & 0,10 & 0,08 \\
\hline Mediana & 0,43 & 0,58 & 0,25 & 0,34 & 0,23 & 0,21 \\
\hline Mínimo & 0,09 & 0,10 & 0,14 & 0,04 & 0,07 & 0,11 \\
\hline Máximo & 0,92 & 0,93 & 0,45 & 0,94 & 0,38 & 0,39 \\
\hline № observações & 15 & 14 & 10 & 13 & 9 & 9 \\
\hline
\end{tabular}

Figura 22: Perfil médio da relação IL-6/(IL-6+lL-1Ra) de acordo com sepse e tempo

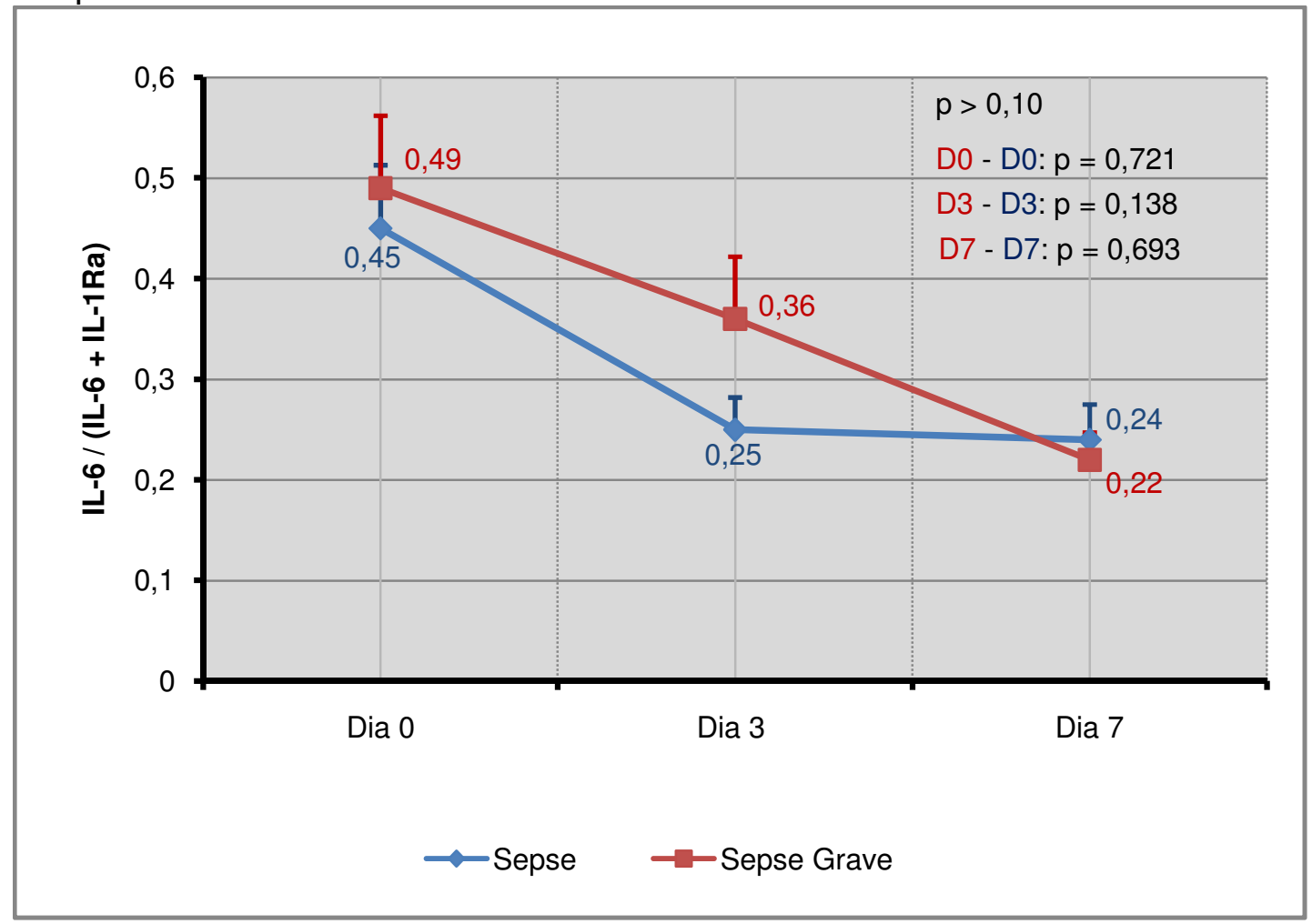




\section{b.2) Análise evolutiva subdividida em grupos sepse e sepse}

grave

Nos RN com sepse grave esta relação apresentou valores maiores do que os apresentados pelo grupo sepse até o terceiro dia. No dia 7, o grupo sepse apresentou valor médio maior do que o grupo sepse grave. Este comportamento pode ser melhor visualizado na figura 22 e tabela 23.

Os valores desta relação tanto na sepse grave como na sepse permanecem sempre inferiores a 1, ou seja, com predomínio da ação antiinflamatória da IL-6 + IL-1Ra sobre a ação pró-inflamatória da IL-6.

Apesar das diferenças observadas descritivamente, o modelo da ANOVA com medida repetida não foi capaz de detectar diferenças significativas entre as médias dos dois grupos em nenhum dos tempos avaliados $(p>0,10)$

As diferenças médias estimadas de IL-6 / (IL-6 + IL-1Ra) foram iguais a $0,04 \pm 0,10(p=0,721) ; 0,11 \pm 0,08(p=0,138)$ e $0,02 \pm 0,04(p=0,693)$, para os dias 0,3 e 7 , respectivamente. 


\section{Proteína $\mathbf{C}$ reativa}

\section{a.1) Evolução geral}

Tabela 24: Medidas descritivas dos valores séricos de PCR nos RN avaliados

\begin{tabular}{lccc}
\hline PCR (mg/L) & \multicolumn{3}{c}{ Dias de evolução } \\
\cline { 2 - 4 } Média & Dia 0 & Dia 3 & Dia 7 \\
Desvio Padrão & 52,58 & 45,55 & 23,41 \\
Mediana & 57,17 & 52,95 & 39,10 \\
Mínimo & 30,80 & 18,00 & 6,00 \\
Máximo & 3,20 & 3,20 & 3,20 \\
№ de Observações & 189,60 & 194,00 & 147,60 \\
\hline
\end{tabular}

Figura 23: Média \pm erro padrão de PCR de acordo com o tempo nos RN avaliados

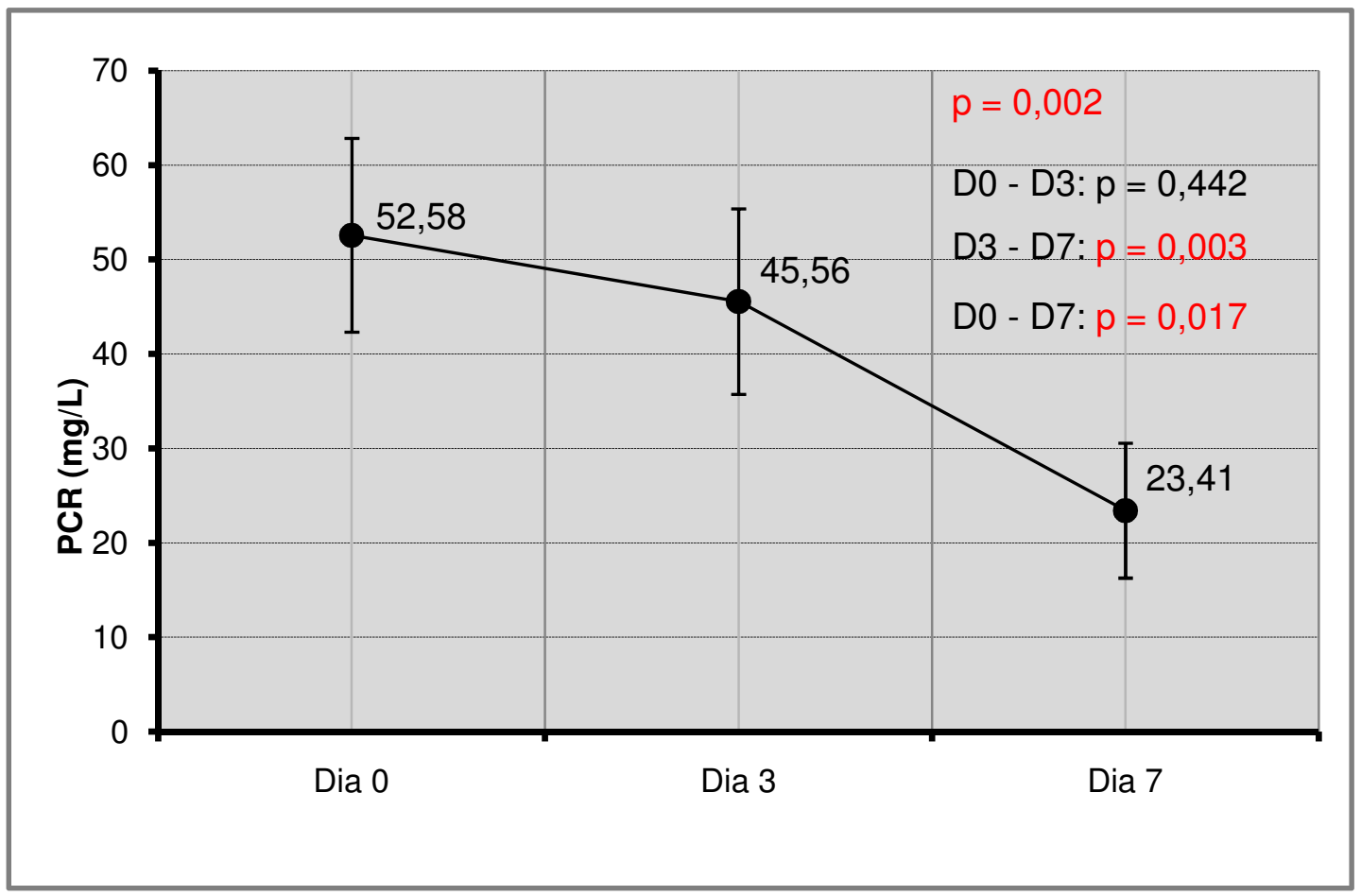




\section{a.1) Análise descritiva evolutiva geral da PCR}

Em relação aos valores séricos médios da PCR nos recém-nascidos do estudo, observamos que o dia 0 apresentou a maior média e alta variabilidade dos dados, uma vez que o desvio padrão é maior que o valor da média. Na tabela 24 e figura 23 , observamos que no dia 0 ocorreu a maior média e variabilidade e que houve um decréscimo tanto na média como na variabilidade nos dias 3 e 7 de evolução. Podemos observar também que no dia 0 para o dia 3 ocorreu um leve decréscimo da PCR, sendo que houve um maior decréscimo no dia 7 quando comparado com os outros dias.

Através de uma Análise de Variância (ANOVA) com medida repetida levando-se em consideração a alta variabilidade dos dados através da modelagem da estrutura de correlação, observamos que houve um efeito estatisticamente significante de tempo $(p=0,002)$, ou seja, a variação da PCR observada através do gráfico 15 mostrou-se estatisticamente significante. Com o objetivo de detectar onde se encontravam as diferenças prossegui-se a análise através da construção de contrastes e foi observado que do dia 0 para o dia 3 de evolução houve um decréscimo médio de 9,96 \pm $12,79 \mathrm{mg} / \mathrm{L}$, porém este não se mostrou estatisticamente significante $(p=$ 0,442). Do dia 0 para o dia 7 de evolução houve decréscimo médio de 29,92 $\pm 11,83 \mathrm{mg} / \mathrm{L}$, que se mostrou estatisticamente significante $(p=0,017)$. Já no dia 3 para o dia 7 de evolução houve um decréscimo médio de 19,96 \pm 6,22 $\mathrm{mg} / \mathrm{L})$ que também se mostrou estatisticamente significante $(p=0,003)$. 


\section{a.2) Evolução subdividida em grupos: sepse e sepse grave}

Tabela 25: Medidas descritivas dos valores séricos da PCR segundo os grupos

\begin{tabular}{|c|c|c|c|c|c|c|}
\hline \multirow{2}{*}{ PCR (mg/L) } & \multicolumn{2}{|c|}{ Dia 0} & \multicolumn{2}{|c|}{ Dia 3} & \multicolumn{2}{|c|}{ Dia 7} \\
\hline & Sepse & $\begin{array}{l}\text { Sepse } \\
\text { Grave }\end{array}$ & Sepse & $\begin{array}{l}\text { Sepse } \\
\text { Grave }\end{array}$ & Sepse & $\begin{array}{l}\text { Sepse } \\
\text { Grave }\end{array}$ \\
\hline Média & 57,67 & 47,14 & 33,19 & 58,81 & 8,19 & 40,81 \\
\hline Desvio Padrão & 57,48 & 58,33 & 35,57 & 65,66 & 5,17 & 52,62 \\
\hline Mediana & 35,00 & 24,30 & 17,00 & 31,15 & 6,00 & 6,40 \\
\hline Mínimo & 5,00 & 3,20 & 5,00 & 3,20 & 5,00 & 3,20 \\
\hline Máximo & 180,00 & 189,60 & 110,00 & 194,00 & 24,60 & 147,60 \\
\hline № observações & 16 & 15 & 15 & 14 & 16 & 14 \\
\hline
\end{tabular}

Figura 24: Perfil médio da PCR de acordo com sepse e tempo

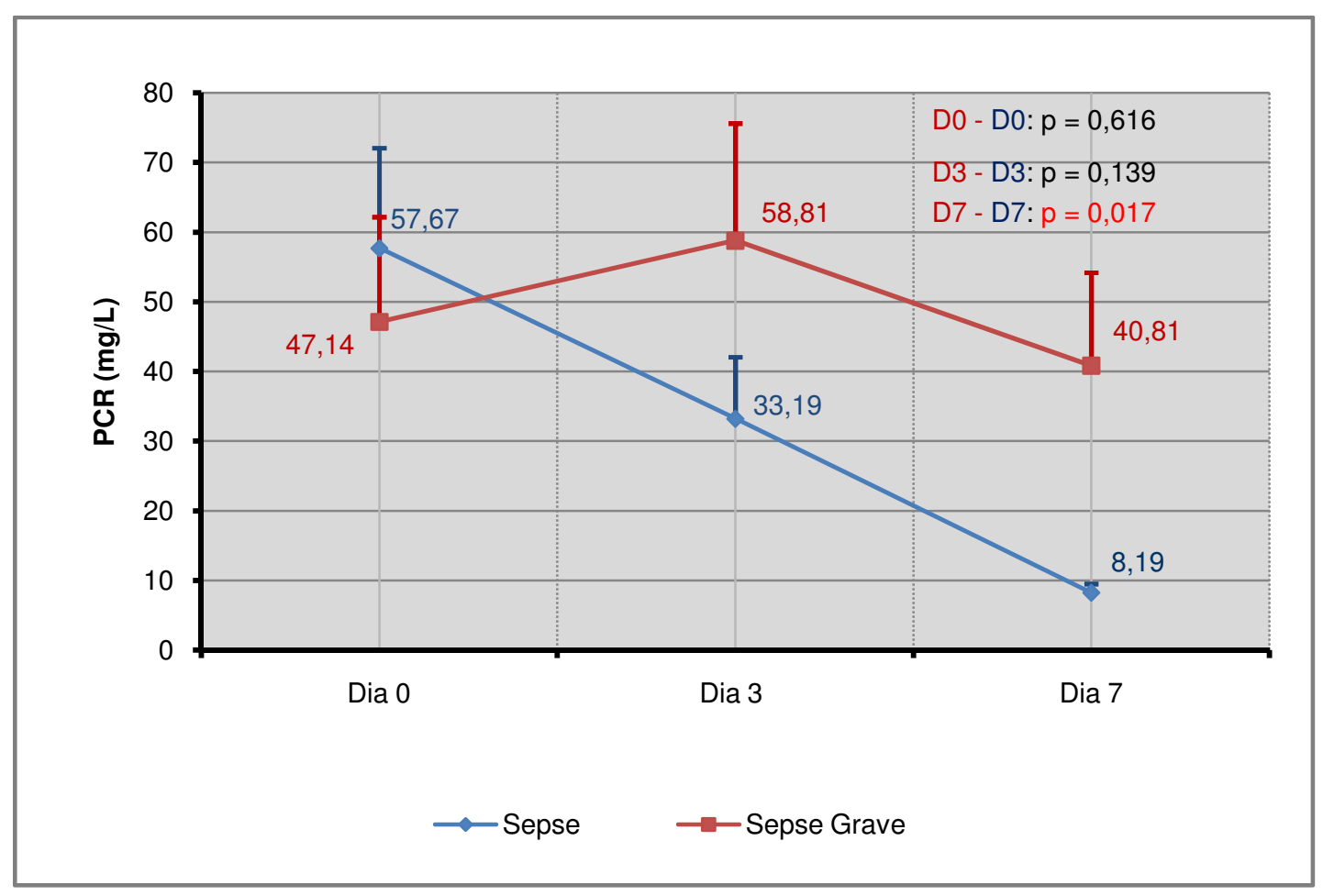




\section{a.2) Análise evolutiva subdividida em grupos sepse e sepse}

grave

Em relação aos valores médios da PCR podemos observar que no dia 0, o grupo sepse apresentou maior média do que a apresentada pelo grupo sepse grave (Tabela 25). Entretanto, a partir do dia 3 este comportamento se altera, ou seja, enquanto no grupo sepse ocorre um decréscimo da PCR nos dias 3 e 7 de evolução enquanto no grupo sepse grave ocorre inicialmente um acréscimo na média da PCR no terceiro dia, indicando a possibilidade da gravidade do processo séptico para depois, apresentar um decréscimo na média do dia 7 (tabela 25; figura 24).

Através de uma ANOVA com medida repetida pode-se observar que nos dias 0 e 3 , os dois grupos não se diferenciam, com $p=0,616$ e $p=$ 0,139 , respectivamente. No dia 7 foi observada a diferença estatisticamente significante entre os dois grupos ( $p=0,017$ ), ou seja, o grupo sepse grave apresentou média de PCR maior do que o grupo sepse sendo esta diferença estimada em 33,3 $\pm 13,2 \mathrm{mg} / \mathrm{L}$ 
06

DISCUSSÃO 


\section{6- DISCUSSÃO}

Realizaremos a discussão na ordem da apresentação dos resultados. Analisaremos primeiro o comportamento geral de cada citocina e a seguir a evolução dentro do grupo sepse com boa evolução e sepse grave com evolução complicada.

\section{Mediadores pró-inflamatórios}

a) TNF- $\alpha$

O TNF- $\alpha$ é o primeiro mediador inflamatório a ser produzido em resposta a um estímulo infeccioso, é considerado um mediador primário do sistema imune inato, e crucial para induzir proteção local (Van Deventer et al., 1990, Ulloa e Tracey, 2005). Quantidades mínimas de TNF- $\alpha$ contribuem para a defesa do hospedeiro por limitar a propagação de organismos patogênicos para a circulação sangüínea fato observado durante uma resposta inflamatória bem sucedida típica, na qual a duração e a magnitude da liberação de TNF-a são limitadas (Tracey, 2002; Ulloa e Tracey, 2005)

No entanto, quando a produção é excessiva e prolongada, esta se torna deletéria para o organismo (Netea et al., 2003), uma vez que supera a regulação normal da resposta imune induzindo a ativação de outras citocinas, de óxido nítrico e espécies de oxigênio reativo, os quais promovem 
inflamação e lesão tecidual potencialmente letal (Tracey, 2002; Ulloa e Tracey, 2005).

Esta situação é especialmente notada na sepse grave, onde ocorre excessiva produção desta citocina pró-inflamatória a qual causa aumento da permeabilidade capilar, provoca lesão tecidual e morte por falência orgânica (Netea et al., 2003; Ulloa e Tracey, 2005).

O TNF- $\alpha$ é considerado um mediador necessário para a ocorrência de choque séptico (Tracey, 2002; Ulloa e Tracey, 2005) e isto é comprovado na literatura por algumas evidências como:

1ํ) É encontrado em pacientes e modelos experimentais de choque séptico.

2º) É capaz de desencadear alterações hemodinâmicas e metabólicas que provocam hipotensão, coagulação intravascular, necrose hemorrágica e lesão tecidual (Tracey e Cerami, 1993 e 1994; Hotchkiss e Karl, 2003).

$3^{\circ}$ ) A neutralização do TNF- $\alpha$ previne endotoxemia e bacteremia, em animais, mesmo quando endotoxinas e bactérias persistem na circulação sangüínea (Tracey e Cerami, 1993 e 1994; Gea-Banacloche et al., 2004), porém esta terapêutica de neutralização do TNF-a não teve bons resultados na sepse de recém-nascidos e ou adultos (Ulloa e Tracey, 2005).

Durante o processo infeccioso o nível sérico de TNF- $\alpha$ eleva-se durante os primeiros 30 a 90 minutos após a exposição ao LPS com pico entre 3 e 4 horas e tem boa correlação com o aparecimento da febre e/ou instabilidade térmica no recém-nascido (Cohen, 2002; Cunneen e Cartwright, 2004). 
Alguns estudos mostram que os níveis séricos e plasmáticos de TNFa podem permanecer elevados em pacientes com sepse, embora a magnitude da elevação dependa, em parte, da gravidade da evolução. $\mathrm{Na}$ meningite bacteriana fulminante os níveis de TNF- $\alpha$ são elevados e mostram alta correlação com a mortalidade (Waage et al., 1987).

No entanto no paciente com sepse ou com meningite não fulminante, esses níveis não se mostram tão elevados (Casey et al., 1993). Este último achado foi evidenciado por trabalhos que mostraram que:

$1^{\circ}$ ) Níveis séricos de TNF- $\alpha$ são quase indetectáveis em pacientes com sepse grave;

$\left.2^{\circ}\right)$ Ratos com deficiência de TNF- $\alpha$ podem desenvolver sepse grave quando recebem altas doses de endotoxinas;

$3^{\circ}$ ) Pico de produção de TNF- $\alpha$ durante a sepse correlaciona-se com o desenvolvimento agudo e choque séptico mas não com a característica progressivamente lenta da sepse grave.

$\left.4^{\circ}\right)$ Morte por sepse grave ocorre freqüentemente vários dias após a produção de TNF- $\alpha$ estar resolvida;

5) Anticorpos contra TNF- $\alpha$ são ineficientes ou dão poucos resultados em modelo padronizado de peritonite induzindo a sepse grave.

Küster et. al., em 1998, em estudo multicêntrico com 101 recémnascidos: 21 recém-nascidos com sepse neonatal tardia, definida por sepse diagnosticada após 72 horas de vida; 20 recém-nascidos sem infecção e 60 recém-nascidos não classificados compararam os valores dos mediadores IL-1Ra; IL-6 e ICAM nos dias 4 a 1 que antecederam o dia do diagnóstico 
clínico da sepse definido como dia zero e os dias 1 a 5, após o diagnóstico. Estes autores chegaram à conclusão que os níveis das citocinas apresentam-se elevados dois dias antes de ser feito o diagnóstico de sepse.

Na pesquisa por nós apresentada, observamos que o valor máximo do TNF-a foi observado no paciente que evoluiu para óbito (caso 1) nas primeiras 48 horas de evolução da doença (TNF- $\alpha$ de 1316,0 pg/ml).

Nos outras pacientes da nossa casuística que tiveram sepse e que evoluíram sem complicações, os níveis séricos de TNF-a, mesmo no dia 0 , estavam no limite inferior detectável pelo método utilizado, isto provavelmente devido à meia vida fugaz dessa citocina nos pacientes que evoluem bem, o que está de acordo com o descrito por Küster.

No entanto, nos pacientes que evoluíram com sepse complicada houve elevação deste mediador, mesmo nos dias 3 e 7 de evolução (tabela 11; figura 10).

\section{b) IL-1 $\beta$}

A IL-1ß é outra das citocinas pró-inflamatórias cuja função aparentemente é similar à do TNF-a (Cunneen e Cartwright, 2004), pois induz a resposta inflamatória sistêmica contra um agravo inicial (Loisa et al., 2003), agindo sinergicamente com o TNF-a neste processo (Dinarello, 2000; Del Vecchio et al., 2004).

A IL-1ß é responsável pela elevação da temperatura corpórea e por este motivo é denominada também de pirógeno endógeno. Esta elevação da temperatura geralmente é benéfica ao hospedeiro uma vez que a maioria 
dos microorganismos se multiplica em temperaturas mais baixas, e a resposta imune adaptativa é mais intensa em temperaturas elevadas.

Além da febre, esta citocina também induz ao sono, anorexia e hipotensão (Dinarello e Wolff, 1993); ativa as células endoteliais a induzirem a expressão de moléculas de adesão, as quais são essenciais para a adesão de leucócitos e posterior diapedese (Dinarello, 2000).

Como mediador de doença, a IL-1 $\beta$ às vezes, pode apresentar uma rápida elevação, enquanto em outras, a sua produção é lenta e intermediária (Dinarello e Wolff, 1993). Por exemplo, no choque séptico, a IL-1 $\beta$ age diretamente nos vasos sangüíneos, induzindo vasodilatação através da produção rápida do fator ativador de plaquetas, prostaglandinas e óxido nítrico (Dinarello e Wolff, 1993). Estas substâncias são potentes vasodilatadores e induzem o choque em animais de laboratório. Nestes animais os achados sugerem que o papel da IL-1ß é semelhante ao do TNF$\alpha$ na sepse. A simples injeção endovenosa da IL-1 $1 \beta$, em animais, diminui a pressão arterial média e a resistência vascular sistêmica induzindo a hipotensão (Okusama et al., 1988).

A utilidade da IL-1 $\beta$ como citocina para o diagnóstico de sepse é pequena devido aos relatos conflitantes da concentração sérica desta citocina ora elevada ora diminuída em associação a sepse (Reyes et al., 2003; Mishra et al., 2005). Apesar dos níveis séricos de IL-1 $\beta$ serem freqüentemente indetectáveis quando medidos na sepse (e por essa razão literatura relata pouca correlação com a gravidade da doença) (Loisa et al., 2003), em alguns pacientes são observados níveis elevados e quando isto 
acontece, há uma significante correlação com a gravidade do quadro séptico (Casey, 2000).

A seguir citamos algumas das razões que propiciam valores freqüentemente não detectáveis desta citocina:

1ํ) Concomitante ao estímulo da produção da IL-1ß há estímulo a síntese de IL-1Ra, que por sua vez, bloqueia sua produção por mecanismo de feedback negativo. E como a IL- IL-1 $\beta$ é uma citocina, cuja vida é breve e transitória, seus níveis séricos diminuem rapidamente.

$\left.2^{\circ}\right)$ A citocina IL-1Ra a qual é um inibidor natural da IL-1, apresenta estrutura homóloga e é biologicamente inativo, liga-se ao receptor da IL-1 inibindo a ligação desta interleucina por mecanismo competitivo (Abbas e Lichtman, 2005)

$3^{\circ}$ ) Outras citocinas, como IL-4, IL-10 e FGT- $\beta$,em algum momento, diminuem a produção de IL-1 $\beta$ e estimulam a produção de IL-1Ra.

$\mathrm{Na}$ pesquisa por nós realizada, quando observamos a evolução temporal da IL-1 $\beta$ (tabela 12; figura 11), verificamos que o valor sérico médio no dia 0 encontrava-se discretamente elevado $(8,1 \mathrm{pg} / \mathrm{ml})$ enquanto nos dias 3 e 7 de evolução, os níveis séricos médios já se encontravam muito próximos aos mínimos detectáveis (1,54 e 1,51, respectivamente), o que condiz com os dados da literatura.

Quando os grupos foram estratificados em sepse e sepse grave (tabela 13; figura 12), observamos que no grupo sepse grave, os valores médios sempre foram superiores aos valores médios do grupo sepse. 
$\mathrm{Na}$ interpretação da figura 12 vale a premissa do estudo de Küster (1998), com um adendo: a IL-1Ra, que é um antagonista natural da IL-1ß, está aumentada e inibe esta última, ou seja, no grupo sepse provavelmente já está ocorrendo à resolução do processo infeccioso enquanto que o grupo sepse grave ainda caminha para esta resolução.

Na maioria dos trabalhos publicados, a IL-1 $\beta$ raramente é detectada porque a IL-1Ra é realmente um potente inibidor (Cunneen e Cartwright, 2004).

\section{c) IL-6}

A IL-6 é considerada como importante marcador da resposta inflamatória sistêmica, pois frente a um agravo infeccioso alcança rapidamente picos de concentração sérica caracterizando-se como citocina de alarme da infecção (Casey, 2000; Ceccon, 2002). Aparentemente, a IL-6 não é um mediador direto da sepse, pois reflete os efeitos em rede da produção prévia da IL-1 $\beta$ e TNF- $\alpha$ (Dinarello, 1997; Casey, 2000).

Embora existam pesquisas correlacionando a IL-6 com a mortalidade de pacientes com sepse, a infusão isolada de IL-6 pode causar febre, mas não produz alterações hemodinâmicas ou outras mudanças sugestivas de sepse ou falência múltiplas de órgãos (Dinarello, 1997; Casey, 2000).

Ao contrário da TNF- $\alpha$, os níveis séricos de IL-6 estão significativamente elevados na maioria dos pacientes sépticos (Loisa et al, 2003) e são sustentados por tempo maior, refletindo a intensidade da resposta inflamatória, agindo como "hormônios" que sintonizam todo o 
processo (Loisa et al., 2003). Portanto, esta interleucina é freqüentemente utilizada como marcador no diagnóstico de sepse neonatal ( $\mathrm{Ng}, 2004$; Cunneen e Cartwright, 2004) pela acurácia no diagnóstico precoce (Gonzalez et al., 2003), e também pode ser utilizada para verificar a resposta evolutiva ao tratamento (Casey et al., 1993; Ceccon, 2002).

Valores superiores a $1.000 \mathrm{pg} / \mathrm{ml}$ de IL-6 têm sido relatados como preditivos de sepse e valores superiores a $7.000 \mathrm{pg} / \mathrm{ml}$ associados com aumento da mortalidade (Hack et al., 1989; Casey et al.1993).

A IL-6 é o principal indutor do hepatócito na síntese da proteína Creativa, esta proteína ativa as células $T$ e atrai os neutrófilos aos sítios de infecção (Cunneen e Cartwright, 2004).

Em contraste aos efeitos pró-inflamatórios, a IL-6 promove também efeitos antiinflamatórios na medida da sua elevação sérica, inibindo a IL-1 e o TNF- $\alpha$, além de estimular a síntese de IL-1Ra (Borish e Steinke, 2003), o que faz com que esta citocina (IL-6) tenha propriedades pró e antiinflamatórias (Oberholzer et al., 2000; Loisa et al., 2003; Abbas e Lichtman ,2005).

Em nosso estudo, o paciente que foi a óbito (caso 1), apresentou o maior nível sérico de IL-6, de $9887,80 \mathrm{pg} / \mathrm{ml}$, bem acima do valor máximo dos pacientes com sepse grave $(7325,80 \mathrm{pg} / \mathrm{ml})$ e bem acima também dos valores séricos dos pacientes com sepse $(4166,20 \mathrm{pg} / \mathrm{ml})$, mas que sobreviveram (tabela 15; figura 14). Neste mesmo caso todas as citocinas pró-inflamatórias (TNF- $\alpha$; IL-1 $\beta$ e IL-6) tiveram valores muito elevados, o que caracteriza segundo a literatura, a magnitude e o prolongamento do 
processo inflamatório potencializando os efeitos deletérios das citocinas TNF- $\alpha$; IL-1 $\beta$.

Nos outros pacientes no dia 0 , dia do diagnóstico, obtivemos a maior média $(1444,69 \mathrm{pg} / \mathrm{ml})$, e no decorrer da evolução observou-se diminuição desses valores como podemos observar nos dias 3 e 7 de evolução.

Quando os pacientes foram estratificados em grupos sepse e sepse grave, observamos que as médias dos níveis séricos do grupo sepse grave são sempre superiores ao grupo sepse, refletindo a intensidade do processo séptico naquele grupo. Podemos verificar que a curva evolutiva nos dois grupos é muito semelhante (tabela 15; figura 14).

O grupo sepse grave apresentou valores séricos médios bem superiores aos valores relatados por Hack et al, 1989 e Casey et al., 1993 como preditivos de sepse, principalmente no dia do diagnóstico - D0 $(2321,35 \mathrm{pg} / \mathrm{ml})$ e no dia 3 de evolução $(1100,02 \mathrm{pg} / \mathrm{ml})$ declinando deste valor no dia 7 (402,73 pg/ml). No grupo sepse os valores séricos médios apresentados seguiram no dia $0(1150,51 \mathrm{pg} / \mathrm{ml})$ muito próximo aos preconizados por aqueles autores, mas nos dias 3 de evolução $(71,30 \mathrm{pg} / \mathrm{ml})$ e 7 de evolução $(40,21 \mathrm{pg} / \mathrm{ml})$ houve diminuição acentuada com a resolução do processo inflamatório. 


\section{Mediadores antiinflamatórios}

a) IL-10

A IL-10 é a principal citocina contra-reguladora da resposta imune inata (Oberholzer et al., 2002). Atua como citocina antiinflamatória agindo por feedback negativo, ou seja, inibindo a síntese de citocinas próinflamatórias (Doughty et al., 1998; Casey, 2000). Elevadas concentrações de IL-10 reduzem a produção de TNF- $\alpha$; IL-1; IL-6 e IL-8 pelos monócitos, enquanto ativam (por feedback positivo) a produção de IL-1Ra (Howard et al, 1992).

A supressão de IL-10 resulta em aumento dos níveis séricos circulantes de TNF- $\alpha$ e IL-6, o que sugere que esta citocina tem um grande poder antiinflamatório (Cunneen e Cartwright, 2004) e quando a IL-10 endógena é neutralizada por anticorpos monoclonais, observa-se que a mortalidade aumenta (Doughty et al., 1998).

Oberholzer et al., em 2002 sugeriram que a magnitude da resposta da IL-10 parece correlacionar-se com a gravidade do processo inflamatório e a concentração plasmática de citocinas pró-inflamatórias, com a ativação da TNF-a. Existe de fato um mecanismo homeostático que envolve a IL-10 e as citocinas pró-inflamatórias. Enquanto o TNF- $\alpha$ e outras citocinas estimulam a síntese de IL-10, na vigência de estímulo inflamatório, esta bloqueia a síntese de TNF- $\alpha$ na medida da resolução do processo inflamatório levando a normalização dos níveis séricos das citocinas (Borish e Steinke, 2003), e restaurando a homeostase (Bone et al., 1997). 
A normalização da IL-10 também é importante, pois a sua manutenção em níveis séricos elevados propicia o desenvolvimento da falência múltipla de órgãos (Doughty et al., 1998). Desta maneira, no processo de homeostase, a IL-10 acompanha a evolução dos mediadores pró-inflamatórios e paralelamente estimula a IL-1Ra, citocina biologicamente inativa, para a manutenção da ação antiinflamatória e, posterior diminuição dos seus níveis séricos com a resolução do processo inflamatório.

Em nosso estudo, acreditamos que no paciente que foi a óbito e que apresentou o maior nível sérico desta citocina $(1732,60 \mathrm{pg} / \mathrm{ml})$ bem superiores aos valores séricos médios $(76,77 \mathrm{pg} / \mathrm{ml})$ dos casos que não foram a óbito, estes níveis persistentemente elevados tenham propiciado a evolução para falência múltipla de órgãos.

Na nossa pesquisa observamos que a IL-10 atinge o pico sérico mais elevado no $3^{\circ}$ dia de evolução refletindo provavelmente o estímulo do TNFa. A IL-10 teve auxílio da IL-1Ra para a manutenção da ação antiinflamatória.

Quando os pacientes foram estratificados em grupos sepse e sepse grave, o estudo de Küster (1998) aplica-se novamente nos casos de sepse sem complicações, onde podemos observar que o nível sérico desta citocina esta reduzido provavelmente devido à resolução do quadro séptico. Enquanto no grupo sepse grave, os valores de IL-10 seguem rigorosamente a curva da TNF-a e IL-6, caracterizando a evolução do processo séptico para cura. 


\section{b) IL-1Ra}

O antagonista do receptor da IL-1 $\beta$ tem estrutura homóloga à da IL-1 e função biológica inativa. Esta interleucina, como citado anteriormente se liga ao receptor da IL-1 como seu inibidor competitivo. (Goldie et al., 1995; Kilpatrick e Harris, 1998; Abbas e Lichtman, 2005). Com aproximadamente $5 \%$ dos receptores da IL-1 ocupados há indução da resposta biológica, sugerindo que a elevação de IL-1Ra possa ter um efeito modulador (Goldie et al., 1995).

Sua produção é subseqüente a síntese de IL-1 e outras citocinas, tais como IL-10, IL-4 e TGF- $\beta$ as quais estimulam a sua síntese, ao passo que inibem em algum momento a produção de IL-1ß (Dinarello e Wolff, 1993).

Enquanto os níveis séricos de $\mathrm{IL}-1 \beta$ estão freqüentemente indetectáveis (Loisa et al., 2003), os níveis séricos de IL-1Ra mostram-se consistentemente elevados em pacientes sépticos, tanto em adultos como em recém-nascidos, podendo ser superiores em até 100 vezes os valores de IL-1 $\beta$ (Goldie et al., 1995; Küster et al., 1998; Doller et al., 2001; Carrigan et al., 2004).

Fisher et al., em 1992 relataram que a concentração de IL-1Ra correlaciona-se com a magnitude da resposta inflamatória. A sua produção modula os efeitos potencialmente deletérios da IL-1 $\beta$ e o curso natural da inflamação (Borish e Steinke, 2003).

Em nosso estudo, na evolução geral desta citocina obtivemos a maior média, no dia 0 , e nos dias 3 e 7 de evolução houve uma estabilização dos valores séricos (tabela 18; figura 17). 
Quando estratificado em grupos sepse e sepse grave (tabela 19; figura 18), os valores médios do último grupo foram sempre superiores aos do grupo sepse. E os dois grupos refletem a premissa que a concentração da IL-1Ra modula a resposta inflamatória seguindo as curvas dos mediadores pró-inflamatórios, mostrando o processo séptico controlado, levando a cura, enquanto no grupo sepse grave, o desequilíbrio séptico corrobora para que ocorra uma exacerbação da síntese de IL-1Ra (tabela 19; figura 18).

De Bont et al., em 1995, analisaram a concentração sérica de IL-1Ra em 47 recém-nascidos subdivididos em 3 grupos: Grupo 1: 11 recémnascidos com quadro clínico de sepse associado à positividade de culturas (9 com hemocultura positiva e 2 com urocultura positiva) e que se apresentaram com infecção bacteriana grave; Grupo 2: 28 recém-nascidos com suspeita de infecção, mas com hemocultura negativa e Grupo 3: grupo controle com 8 recém-nascidos saudáveis admitidos na unidade por outras razões que não doenças infecciosas e imunológicas. A IL-1Ra foi mensurada e observou-se que os recém-nascidos do grupo 1 tiveram concentrações de IL-1Ra elevadas (5635 $\pm 411 \mathrm{ng} / \mathrm{L})$ à semelhança daqueles da nossa casuística, do grupo sepse grave, e o grupo 2 destes pesquisadores apresentou valores inferiores ( $2597 \pm 433 \mathrm{ng} / \mathrm{L})$, fato que também ocorreu na pesquisa apresentada. No grupo controle eles observaram valores bem inferiores aos outros grupos (273 $\pm 88 \mathrm{ng} / \mathrm{L})$. Estes autores concluíram que a concentração de IL-1Ra não contribuiu para o aumento da morbidade e 
mortalidade dos recém-nascidos com sepse, o que também está de acordo com nosso pensamento.

\section{Homeostase dos mediadores e relações entre os pró-inflamatórios e os antiinflamatórios}

Traduzir a homeostase ou seu desequilíbrio em números constitui trabalho árduo. Loise et al. (2003) relataram que a relação entre a resposta das citocinas pró e antiinflamatórias na sepse é inconsistente e variável. Muitas das relações entre citocinas pró e antiinflamatórias são fundamentadas com base nas suas propriedades, porém seus valores séricos, por vezes são discrepantes.

Na literatura foram estudadas algumas relações entre mediadores pró e antiinflamatórios como a IL-1 $\beta / \mathrm{LL}-1 \mathrm{Ra}$, que, a princípio, pareceu promissora, no entanto não apresentou valores preditivos em relação à mortalidade (Goldie et al., 1995).

Outra relação estudada foi a TNF-a/lL-10 e durante algum tempo esta relação foi utilizada como preditor de gravidade, uma vez, que na sepse grave a produção de TNF- $\alpha$ ocorre em larga escala e é deletéria para o hospedeiro, enquanto a IL-10, por ser um potente inibidor, promove resposta antiinflamatória compensatória. Com base nisso, uma concentração sérica de TNF- $\alpha$ baixa, promoveria risco fatal para pacientes com sepse e meningococcemia (lembrando que elevados níveis de IL-10 induzem a falência múltipla de órgãos e sistemas). Desta forma um estado antiinflamatório elevado na relação IL-10/TNF-a, também estaria associado 
com uma evolução fatal (Netea et al., 2003). Van Dissel et al., 1998, reportaram que os pacientes que apresentaram relação IL-10/TNFa elevada não sobreviveram. No entanto esta relação é difícil de interpretar, pois o TNFa, nos casos graves tem meia vida sérica curta e nos casos com evolução benigna pode ser indetectável e por isso, não reflete necessariamente a homeostase ou o desequilíbrio.

Taniguchi et al, 1999, analisando 25 pacientes graves com SIRS, observaram que tanto os sobreviventes quanto os que foram a óbito apresentaram níveis séricos elevados de IL-10, os quais declinaram durante a internação na UTI. Entretanto, a relação IL-6/IL-10 foi mais elevada nos não sobreviventes, o que os levou a concluir que a falência do mecanismo antiinflamatório pode ter um papel importante na fisiopatologia da sepse.

Nós optamos por estudara as relações IL-6/IL-1Ra e IL-6/(IL-6+IL1Ra) porque consideramos a IL-6 como marcador de sepse e sua elevação caracterizaria a magnitude do processo inflamatório. Esta citocina se mantém elevada por período prolongado, facilitando sua mensuração seriada, o mesmo acontecendo com a IL-1Ra.

Em nossa pesquisa, um valor das relações (IL-6/IL1-Ra e IL-6 (IL-6/ IL-1Ra) igual a 1 seria representativo de um equilíbrio das ações próinflamatórias e antiinflamatórias. Desta forma quando a relação mostra-se superior a 1 caracteriza predomínio da ação pró-inflamatória, enquanto a inferior a 1 o predomínio da ação antiinflamatória. 
No grupo sepse, a relação IL-6/L-1Ra começa com predomínio da ação pró-inflamatória, porém já no dia 3 de evolução há predomínio da ação antiinflamatória que se mantém no 7 dia de evolução (tabela 21; figura 20).

No grupo sepse grave, a relação IL-6/IL-1Ra mostra a persistência da inflamação com predomínio da ação pró-inflamatória por mais tempo (tabela e figura 20).

\section{PCR}

A PCR é um parâmetro utilizado como marcador de infecção no período neonatal quando mensurado de forma seriada por pelo menos duas medidas em intervalos de 12 a 24 horas (Ceccon, 2002; Gerdes, 2004). Por não atravessar a placenta, o encontro desta proteína no sangue colhido do recém-nascido representa a sua própria produção e podem ser sintetizadas, tanto por recém-nascidos pré-termos quanto de termo (Ceccon, 1995; Jurges e Henderson, 1996; Vaz, 1998).

Analisando o comportamento geral da PCR nos recém-nascidos desta casuística podemos observar que os valores séricos médios (52,58 mg/L) se encontravam elevados no dia 0 , dia do diagnóstico da sepse, apresentaram diminuição no dia 3 de evolução ( $45,55 \mathrm{mg} / \mathrm{L})$ e mais acentuada no dia 7 de evolução (23,41 mg/L) (tabela 24; figura 23).

Quando os recém-nascidos foram estratificados em grupos - sepse e sepse grave - (tabela 25; figura 24) observamos que no grupo sepse os níveis séricos médios no dia 0 (57,7 mg/L) encontravam-se superiores ao do grupo sepse grave $(47,1 \mathrm{mg} / \mathrm{L})$, no entanto, no decorrer do tempo esta 
relação ficou invertida, com elevação dos níveis séricos no grupo sepse grave no dia 3 de evolução, e diminuição no grupo sepse no mesmo dia. No dia 7, o grupo sepse apresentou níveis considerados abaixo do valor de infecção, considerado $\geq 10 \mathrm{mg} / \mathrm{L}$, nesta casuística $(8,2 \mathrm{mg} / \mathrm{L})$ enquanto no grupo sepse grave este valor era de 40,8 mg/L.

Acreditamos que Küster está correto quando observou que nos casos de sepse, o processo inflamatório com estimulação de interleucinas ocorria desde dois antes da manifestação clinica que origina a suspeita diagnóstica, e no dia 0 a PCR pode já se encontrar elevada, pois foi estimulada anteriormente pelas citocinas. Na sepse grave a persistência da inflamação manteria a produção de citocinas elevada o que ocasionaria aumento posterior da PCR, no entanto, com intensidade maior e a diminuição desta proteína, ocorre de forma mais lenta (tabela 25; figura 24).

Desta maneira, os resultados desta pesquisa sugerem que no grupo de recém-nascidos que tiveram sepse sem complicações ocorreu homeostase entre os mediadores pró e antiinflamatórios e no grupo sepse grave a princípio ocorreu um desequilíbrio da homeostase com posterior equilíbrio que levou a cura. Apenas no caso 1, onde o paciente que foi a óbito, este desequilíbrio persistiu até o final, sem recomposição da homeostase. 
07

CONCLUSÕES 


\section{CONCLUSÕES}

Os resultados desta tese nos permitiram concluir:

\section{9) Quanto à efetividade para o diagnóstico e evolução da sepse}

- Os valores séricos médios dos mediadores pró-inflamatórios representados por TNF- $\alpha$, IL-1 $\beta$ e IL-6 e dos mediadores antiinflamatórios representados por IL-10 e IL-1Ra se mostraram elevados no dia 0 e, portanto foram efetivos para a confirmação do diagnóstico de sepse.

- Os valores séricos médios de TNF- $\alpha$, IL-1 $\beta$ e IL-6 nos dias 3 e 7 de evolução apresentaram diminuição progressiva de acordo com a melhora clínica dos pacientes associado aos aumentos do valor sérico médio da IL10 e da IL-1Ra (D3), sendo que a primeira apresentou diminuição progressiva até o dia 7 e a segundo se manteve estável.

- A IL-6, por ser um marcador de resposta inflamatória sistêmica e isoladamente não produzir alterações hemodinâmicas e a IL-1Ra, por sua ação antagonista, inibidor natural e função biológica inativa mostraram-se efetivos tanto no diagnóstico quanto na evolução da sepse. 
- $\quad$ Os valores séricos médios da PCR se mostraram elevados no dia 0 e acompanharam a evolução dos mediadores pró-inflamatórios.

\section{$\left.2^{2}\right)$ Quanto ao valor preditivo de gravidade na evolução clínica}

- $\quad$ O efeito de rede da atividade biologicamente ativa do TNF-a e da IL$1 \beta$, na dependência da magnitude da resposta inflamatória, exacerba a ação da IL-6, traduzindo-se na gravidade do processo séptico e promovendo valores séricos médios elevados e prolongados. Enquanto na evolução benigna do processo séptico, a não ocorrência dos efeitos de rede se traduz na resolução do processo séptico promovendo valores séricos médios fugazes próximos aos mínimos detectáveis. E de fato, os valores séricos médios dos mediadores pró e antiinflamatórios se mostraram superiores em todos os tempos nos recém-nascidos com sepse grave em relação aos com sepse.

- $\quad$ Os valores séricos médios da PCR se mostraram maiores no dia 0 (diagnóstico) nos pacientes com sepse (pico da resolução) em relação aos valores séricos médios dos pacientes com sepse grave. Na evolução (D3) houve um aumento da PCR nos pacientes com sepse grave (pico da resolução) e as médias séricas diminuem de forma paulatina, enquanto que os pacientes do grupo sepse apresentaram valores séricos médios inferiores e diminuição mais acentuada, caracterizando-se como indicador da evolução clínica do paciente. 
- A relação IL-6/IL-1Ra mostrou uma diminuição marginalmente significante entre os dias 3 e 7 de evolução, indicando provavelmente o equilíbrio homeostático (tendência $a=1$ ) entre os mediadores próinflamatórios e antiinflamatórios e a seguir predomínio da ação antiinflamatória (tendência $<1$ ).

- A relação IL-6 / (IL-6 + IL-1Ra) mostrou uma diminuição significativa entre os dias 0 e $3 ; 3$ e 7 e 0 e 7 , porém de forma menos abrupta indicando provavelmente o equilíbrio homeostático com tendência a ser inferior a 1 , pela ação predominante da IL-1Ra em associação aos efeitos antiinflamatórios da IL-6, lembrando que a IL-1ra não apresenta efeito biologicamente ativo.

3o) Quanto a homeostase ou desequilíbrio definindo o prognóstico da doença.

- Os níveis séricos médios de IL-6 e IL-1Ra no grupo sepse seguiram o mesmo padrão evolutivo com declínio gradual, demonstrando um equilíbrio homeostático entre os processos pró e antiinflamatórios.

- Os níveis séricos médios de IL-6 e IL-1Ra no grupo sepse grave não seguiram o mesmo padrão evolutivo. Observamos um declínio mais lento da IL-6 seguido até o $3^{\circ}$ dia pela IL-1Ra, mas a partir de então esta última apresentou aumento dos seus níveis séricos médios o que caracteriza desequilíbrio homeostático do processo séptico. 
08

ANEXOS 


\section{Anexo A: DECLARAÇÃO DE CONSENTIMENTO LIVRE E ESCLARECIDO}

Nome do Paciente:

Data de nascimento:........................

Responsável legal:

Registro e/ou documento de identidade:

do paciente:

Do responsável:

Título do Projeto: Estudo da homeostase dos mediadores pró-inflamatórios e antiinflamatórios na sepse neonatal

Responsáveis pelo Projeto:

Prof. Dra. Maria Esther Jurfest Rivero Ceccon

Telefone:

Dr. Marco Antonio Cianciarullo

Telefone:

Avaliação prévia do risco para o paciente (x) mínimo.

\section{CONSENTIMENTO LIVRE E ESCLARECIDO}

Declaro que em ___ _ _ c concordei que meu (minha) filho(a) participasse como paciente do projeto de pesquisa acima referido. $\mathrm{O}$ médico me explicou que:

- O estudo implica em que meu (minha) filho (a) se submeta a exames complementares, cujos eventuais riscos me foram explicados

- Terei acesso a qualquer tempo, às informações sobre procedimentos (coleta), riscos e benefícios relacionados à pesquisa, inclusive para dirimir eventuais dúvidas.

- Meu (minha) filho (a) não é obrigado (a) a continuar participando do projeto e pode, a qualquer momento, sair do mesmo, sem que deixe de ser tratado como os demais pacientes assistidos no Hospital.

- O estudo implica em salvaguardar da confidencialidade, sigilo e privacidade do paciente.

São Paulo, de de 200

Assinatura do responsável

Assinatura do Médico que obteve o consentimento

Nome CRM, carimbo 
Anexo B: Identificação (iniciais), gênero, idade do início dos sintomas (em dias - $d$ ou em horas - h), Peso de nascimento (em gramas), Idade gestacional (em semanas), data da internação, alta hospitalar e óbito dos RN incluídos no estudo.

\begin{tabular}{|c|c|c|c|c|c|c|c|c|}
\hline \multirow{2}{*}{ CASO } & \multirow{2}{*}{ Iniciais } & \multirow{2}{*}{ Gênero } & \multirow{2}{*}{ Idade } & \multirow{2}{*}{$\begin{array}{c}\text { Peso } \\
(\mathrm{g})\end{array}$} & \multirow{2}{*}{$\begin{array}{c}I G \\
\text { (sem) }\end{array}$} & \multicolumn{3}{|c|}{ Data de } \\
\hline & & & & & & Internação & Alta & Óbito \\
\hline 01 & J.P.A. & $\mathrm{F}$ & $32 \mathrm{~d}$ & 1.000 & $265 / 7$ & $14 / 12 / 03$ & - & $17 / 01 / 04$ \\
\hline 02 & B.X.N. & $F$ & $11 \mathrm{~d}$ & 3.150 & $365 / 7$ & $14 / 01 / 04$ & - & $30 / 01 / 04$ \\
\hline 03 & S.O.A. & $\mathrm{M}$ & $39 \mathrm{~d}$ & 3.340 & 40 0/7 & $11 / 01 / 04$ & $05 / 03 / 04$ & \\
\hline 04 & A.B.S. & $M$ & $2 \mathrm{~h}$ & 1.270 & $291 / 7$ & $16 / 02 / 04$ & & $07 / 04 / 04$ \\
\hline 05 & W.G.BS & $M$ & $6 \mathrm{~h}$ & 2.715 & $360 / 7$ & $08 / 04 / 04$ & $21 / 04 / 04$ & \\
\hline \multicolumn{9}{|l|}{06} \\
\hline 07 & C.R.S.O & $M$ & $14 \mathrm{~d}$ & 1.505 & $311 / 7$ & $30 / 09 / 04$ & & $22 / 12 / 04$ \\
\hline 08 & M.P.S. & $\mathrm{F}$ & $23 d$ & 2.885 & 40 0/7 & $12 / 09 / 04$ & $11 / 11 / 04$ & \\
\hline 09 & D.S.A. & $M$ & $7 d$ & 1.570 & $346 / 7$ & $15 / 09 / 04$ & $25 / 10 / 04$ & \\
\hline 10 & T.L.S. & $\mathrm{F}$ & $7 d$ & 3.010 & $413 / 7$ & $23 / 09 / 04$ & $26 / 10 / 04$ & \\
\hline 11 & F.A.S.S & $M$ & $5 d$ & 1.310 & 32 0/7 & $04 / 10 / 04$ & $12 / 11 / 04$ & \\
\hline 12 & C.R.L. & $\mathrm{M}$ & $7 d$ & 2.940 & 39 2/7 & $22 / 10 / 04$ & $08 / 11 / 04$ & \\
\hline 13 & R.C.V. & $M$ & $1 \mathrm{~h}$ & 1.210 & $296 / 7$ & $28 / 10 / 04$ & $23 / 12 / 04$ & \\
\hline 14 & L.C.V. & $\mathrm{F}$ & $1 \mathrm{~h}$ & 1.130 & $296 / 7$ & $28 / 10 / 04$ & $28 / 12 / 04$ & \\
\hline \multicolumn{9}{|l|}{15} \\
\hline 16 & C.C.R. & $\mathrm{F}$ & $1 \mathrm{~h}$ & 3.690 & $404 / 7$ & $31 / 10 / 04$ & $10 / 11 / 04$ & \\
\hline \multicolumn{9}{|l|}{17} \\
\hline 18 & L.C.V. & $\mathrm{F}$ & $14 \mathrm{~d}$ & 1.130 & $296 / 7$ & $28 / 10 / 04$ & $28 / 12 / 04$ & \\
\hline 19 & G.A.S.S & $M$ & $13 d$ & 3.700 & $396 / 7$ & $11 / 11 / 04$ & $19 / 11 / 04$ & \\
\hline 20 & R.B.S. & $M$ & $1 \mathrm{~h}$ & 2.400 & $331 / 7$ & $17 / 11 / 04$ & $29 / 11 / 04$ & \\
\hline 21 & N.L.F. & $M$ & $19 d$ & 1.120 & $290 / 7$ & $12 / 11 / 04$ & $07 / 01 / 05$ & \\
\hline \multicolumn{9}{|l|}{22} \\
\hline 23 & A.F.A.S. & $\mathrm{F}$ & $8 \mathrm{~h}$ & 4.000 & $403 / 7$ & $01 / 12 / 04$ & $12 / 12 / 04$ & \\
\hline 24 & S.G.S. & $\mathrm{F}$ & $2 \mathrm{~h}$ & 3.145 & $394 / 7$ & $03 / 12 / 04$ & $13 / 12 / 04$ & \\
\hline 25 & G.C.S. & $F$ & $1 \mathrm{~h}$ & 3.670 & $411 / 7$ & $25 / 11 / 04$ & $09 / 12 / 04$ & \\
\hline 26 & M.M.B. & $M$ & $11 \mathrm{~h}$ & 3.855 & $405 / 7$ & $10 / 12 / 04$ & $20 / 12 / 04$ & \\
\hline 27 & J.C.S. & $\mathrm{F}$ & $2 \mathrm{~h}$ & 2.880 & 40 2/7 & $28 / 12 / 04$ & $13 / 01 / 05$ & \\
\hline 28 & M.S.R.R & $\mathrm{F}$ & $18 \mathrm{~h}$ & 2.820 & 40 2/7 & $07 / 01 / 05$ & $17 / 01 / 05$ & \\
\hline 29 & A.L.S. & $\mathrm{F}$ & $2 \mathrm{~h}$ & 3.360 & $393 / 7$ & $18 / 01 / 05$ & $29 / 01 / 05$ & \\
\hline 30 & A.G. & $M$ & $10 \mathrm{~h}$ & 2.715 & $364 / 7$ & $04 / 02 / 05$ & $14 / 02 / 05$ & \\
\hline 31 & K.C.S. & $F$ & $1 \mathrm{~h}$ & 3.385 & $396 / 7$ & $15 / 01 / 05$ & $26 / 01 / 05$ & \\
\hline 32 & E.N.M.S & $M$ & $1 \mathrm{~h}$ & 3.130 & $404 / 7$ & $25 / 12 / 04$ & $04 / 01 / 05$ & \\
\hline 33 & I.M.D.V. & $\mathrm{F}$ & $12 \mathrm{~h}$ & 3.255 & $386 / 7$ & $26 / 12 / 05$ & $08 / 03 / 05$ & \\
\hline 34 & G.J.S. & $\mathrm{M}$ & $2 \mathrm{~h}$ & 2.165 & $314 / 7$ & $01 / 03 / 05$ & $04 / 05 / 05$ & \\
\hline 35 & A.L.D.M & $M$ & $1 \mathrm{~h}$ & 2.880 & $363 / 7$ & $25 / 02 / 05$ & $25 / 02 / 05$ & \\
\hline
\end{tabular}

Obs: 1) Em verde: Grupo Sepse

2) Em vermelho: Grupo Sepse Grave

3) Casos no 6 ; 15; 17 e 22 excluídos do estudo. 
Anexo C: Diagnóstico infeccioso dos RN incluídos no estudo.

\begin{tabular}{|c|c|c|}
\hline CASO & Iniciais & Diagnóstico \\
\hline 01 & J.P.A. $\dagger$ & $\begin{array}{l}\text { RN PT PIG MBP sepse neonatal tardia } \\
\text { marcenscens) choque séptico refratário }\end{array}$ \\
\hline 02 & B.X.N.† & $\begin{array}{l}\text { RN PT AIG sepse choque séptico refratário e cardiogênico } \\
\text { sepse neonatal tardia }(\mathrm{IH})\end{array}$ \\
\hline 03 & S.O.A. & $\begin{array}{l}\text { RN T AIG BCP PCR pregressa sepse fúngica endocardite } \\
\text { fúngica }\end{array}$ \\
\hline 04 & A.B.S. $\dagger$ & $\begin{array}{l}\text { RN PT AIG MBP sepse neonatal precoce com meningite } \\
\text { choque séptico refratário }\end{array}$ \\
\hline 05 & W.G.B.S. & RN PT AIG BCP por Streptococcus choque séptico refratário \\
\hline 07 & C.R.S.O.† & RN PT AIG BP sepse com urocultura (Serratia marcencens) \\
\hline 08 & M.P.S. & RN TAIG sepse fúngica e choque séptico \\
\hline 09 & D.S.A. & $\begin{array}{l}\mathrm{RN} \text { PT PIG BP sepse neonatal tardia choque séptico } \\
\text { refratário }\end{array}$ \\
\hline 10 & T.L.S. & $\begin{array}{l}\text { RN T AIG sepse neonatal tardia Choque séptico refratário } \\
\text { Pneumonia por Streptococcus do grupo B }\end{array}$ \\
\hline 11 & F.A.S.S. & $\begin{array}{l}\mathrm{RN} \text { PT AIG MBP sepse neonatal tardia choque séptico } \\
\text { refratário (Pseudomonas aeruginosa) NEC II }\end{array}$ \\
\hline 12 & C.R.L. & RN T AIG sepse neonatal precoce e tardia \\
\hline 13 & R.C.V. & $\begin{array}{l}\text { RN PT AIG MBP SDR sepse precoce (Streptococcus } \\
\text { agalactie) }\end{array}$ \\
\hline 14 & L.C.V. & $\begin{array}{l}\text { RN PT AIG MBP sepse precoce choque séptico refratário } \\
\text { coagulopatia FMOS }\end{array}$ \\
\hline 16 & C.C.R. & RN TAIG sepse neonatal precoce \\
\hline 18 & L.C.V. & RN PT AIG MBP sepse tardia choque séptico refratário BCP \\
\hline 19 & G.A.S.S. & RN TAIG sepse neonatal tardia ITU (Klebsiella pneumoniae) \\
\hline 20 & R.B.S. & RN PT AIG BP sepse neonatal precoce BCP \\
\hline 21 & N.L.F. & $\begin{array}{l}\text { RN PT AIG MBP sepse neonatal tardia com meningite (HMC } \\
\text { e LCR + Staphylococcus aureus) choque séptico refratário } \\
\text { abscessos em joelhos e braço esquerdo }\end{array}$ \\
\hline 23 & A.F.A.S. & RN T GIG sepse neonatal precoce choque séptico BCP \\
\hline 24 & S.G.S. & RN T AIG sepse neonatal precoce \\
\hline 25 & G.C.S. & RN T AIG sepse neonatal precoce choque séptico \\
\hline 26 & M.M.B. & $\begin{array}{l}\text { RN TAIG sepse neonatal precoce choque séptico BCP HMC+ } \\
\text { Streptococcus do grupo B }\end{array}$ \\
\hline 27 & J.C.S. & RN T PIG sepse neonatal precoce com meningite \\
\hline 28 & M.S.R.R. & RN T PIG sepse neonatal precoce \\
\hline 29 & A.L.S. & RN T AIG sepse neonatal precoce HPP \\
\hline 30 & A.G. & RN PT AIG sepse neonatal precoce \\
\hline 31 & K.C.S. & RN T AIG sepse neonatal precoce \\
\hline 32 & E.N.M.S. & RN T AIG sepse neonatal precoce \\
\hline 33 & I.M.D.V. & RN TAIG sepse neonatal precoce \\
\hline 34 & G.J.S. & RN PT AIG BP sepse neonatal precoce \\
\hline 35 & A.L.D.M. & RN PT AIG sepse neonatal tardia e sepse fúngica \\
\hline
\end{tabular}

Obs: 1) Em verde: Grupo Sepse

2) Em vermelho: Grupo Sepse Grave

3) Casos no 6 ; 15; 17 e 22 excluídos do estudo. 
Anexo D: Valores séricos individuais de TNF-a (pg/ml) com 0, 3 e 7 dias de evolução da sepse dos RN incluídos no estudo.

\begin{tabular}{rrrrr}
\hline CASO & Iniciais & \multicolumn{1}{c}{$0^{\circ}$ dia } & \multicolumn{1}{c}{$3^{\circ}$ dia } & \multicolumn{1}{c}{$7^{\circ}$ dia } \\
\hline 01 & J.P.A. $\dagger$ & 1316,00 & \multicolumn{1}{c}{-} \\
\hline 02 & B.X.N. $\dagger$ & 1,60 & 1,60 & 1,60 \\
\hline 03 & S.O.A. & 1,60 & 1,60 & 1,60 \\
\hline 04 & A.B.S. $\dagger$ & 1,60 & 1,60 & 248,80 \\
\hline 05 & W.G.B.S. & 1,60 & 1,60 & 1,60 \\
\hline 07 & C.R.S.O. & 1,60 & 1,60 & 1,60 \\
\hline 08 & M.P.S. & 1,60 & 1,60 & 1,60 \\
\hline 09 & D.S.A. & 1,60 & 1,60 & 1,60 \\
\hline 10 & T.L.S. & 1,60 & 1,60 & 1,60 \\
\hline 11 & F.A.S.S. & 1,60 & 706,90 & 1,60 \\
\hline 12 & C.R.L. & 1,60 & 1,60 & 1,60 \\
\hline 13 & R.C.V. & 1,60 & 1,60 & 1,60 \\
\hline 14 & L.C.V. & 951,00 & 766,50 & 1,60 \\
\hline 16 & C.C.R. & 1,60 & 1,60 & 1,60 \\
\hline 18 & L.C.V. & 1,60 & 352,80 & 1,60 \\
\hline 19 & G.A.S.S. & 1,60 & 1,60 & 1,60 \\
\hline 20 & R.B.S. & 1,60 & 1,60 & 1,60 \\
\hline 21 & N.L.F. & 1,60 & 1,60 & 152,80 \\
\hline 23 & A.F.A.S. & 1,60 & 1,60 & 1,60 \\
\hline 24 & S.G.S. & 1,60 & 1,60 & 1,60 \\
\hline 25 & G.C.S. & 1,60 & 1,60 & 1,60 \\
\hline 26 & M.M.B. & 1,60 & 1,60 & 1,60 \\
\hline 27 & J.C.S. & 1,60 & 1,60 & 1,60 \\
\hline 28 & M.S.R.R. & 1,60 & 1,60 & 1,60 \\
\hline 29 & A.L.S. & 1,60 & 1,60 & 1,60 \\
\hline 30 & A.G. & 1,60 & 1,60 & 1,60 \\
\hline 31 & K.C.S. & 1,60 & 1,60 & 1,60 \\
\hline 32 & E.N.M.S. & 1,60 & 1,60 & 1,60 \\
\hline 33 & I.M.D.V. & 1,60 & 1,60 & 1,60 \\
\hline 34 & G.J.S. & 1,60 & 1,60 & 1,60 \\
\hline 35 & A.L.D.M. & 290,20 & 1,60 & 1,60 \\
\hline & & & &
\end{tabular}

Obs: 1) Em verde: Grupo Sepse

2) Em vermelho: Grupo Sepse grave

3) Casos no 6 ; 15; 17 e 22 excluídos do estudo. 
Anexo E: Valores séricos individuais de IL-1 1 (pg/ml) com 0, 3 e 7 dias de evolução da sepse dos RN incluídos no estudo.

\begin{tabular}{rrrrc}
\hline CASO & Iniciais & $0^{\circ}$ dia & \multicolumn{1}{c}{$3^{\circ}$ dia } & \multicolumn{1}{c}{$7^{\circ}$ dia } \\
\hline 01 & J.P.A. $\dagger$ & 204,50 & \multicolumn{1}{c}{-} \\
\hline 02 & B.X.N. $\dagger$ & 1,00 & 1,00 & 1,00 \\
\hline 03 & S.O.A. & 1,00 & 1,00 & 1,00 \\
\hline 04 & A.B.S. $\dagger$ & 1,00 & 1,00 & 1,00 \\
\hline 05 & W.G.B.S. & 1,00 & 1,00 & 1,00 \\
\hline 07 & C.R.S.O. & 1,00 & 1,00 & 1,00 \\
\hline 08 & M.P.S. & 1,00 & 1,00 & 1,00 \\
\hline 09 & D.S.A. & 1,00 & 1,00 & 1,00 \\
\hline 10 & T.L.S. & 1,00 & 1,00 & 1,00 \\
\hline 11 & F.A.S.S. & 1,00 & 17,10 & 1,00 \\
\hline 12 & C.R.L. & 1,00 & 1,00 & 1,00 \\
\hline 13 & R.C.V. & 1,00 & 1,00 & 8,00 \\
\hline 14 & L.C.V. & 1,00 & 1,00 & 1,00 \\
\hline 16 & C.C.R. & 1,00 & 1,00 & 1,00 \\
\hline 18 & L.C.V. & 1,00 & 1,00 & 1,00 \\
\hline 19 & G.A.S.S. & 1,00 & 1,00 & 1,00 \\
\hline 20 & R.B.S. & 1,00 & 1,00 & 1,00 \\
\hline 21 & N.L.F. & 1,00 & 1,00 & 9,20 \\
\hline 23 & A.F.A.S. & 1,00 & 1,00 & 1,00 \\
\hline 24 & S.G.S. & 1,00 & 1,00 & 1,00 \\
\hline 25 & G.C.S. & 1,00 & 1,00 & 1,00 \\
\hline 26 & M.M.B. & 1,00 & 1,00 & 1,00 \\
\hline 27 & J.C.S. & 6,60 & 1,00 & 1,00 \\
\hline 28 & M.S.R.R. & 1,00 & 1,00 & 1,00 \\
\hline 29 & A.L.S. & 1,00 & 1,00 & 1,00 \\
\hline 30 & A.G. & 1,00 & 1,00 & 1,00 \\
\hline 31 & K.C.S. & 1,00 & 1,00 & 1,00 \\
\hline 32 & E.N.M.S. & 4,90 & 1,00 & 1,00 \\
\hline 33 & I.M.D.V. & 1,00 & 1,00 & 1,00 \\
\hline 34 & G.J.S. & 1,00 & 1,00 & 1,00 \\
\hline 35 & A.L.D.M. & 8,20 & 1,00 & 1,00 \\
\hline & & & &
\end{tabular}

Obs: 1) Em verde: Grupo Sepse

2) Em vermelho: Grupo Sepse Grave

3) Casos no 6 ; 15; 17 e 22 excluídos do estudo. 
Anexo F: Valores séricos individuais de IL-6 (pg/ml) com 0, 3 e 7 dias de evolução da sepse dos RN incluídos no estudo.

\begin{tabular}{rrrrr}
\hline CASO & Iniciais & \multicolumn{1}{c}{$0^{\circ}$ dia } & \multicolumn{1}{c}{$3^{\circ}$ dia } & \multicolumn{1}{c}{$7^{\circ}$ dia } \\
\hline 01 & J.P.A. $\dagger$ & 9887,80 & \multicolumn{1}{c}{-} \\
\hline 02 & B.X.N. $\dagger$ & 179,20 & 424,70 & \multicolumn{1}{c}{96,10} \\
\hline 03 & S.O.A. & 1621,00 & 94,50 & 121,20 \\
\hline 04 & A.B.S. $\dagger$ & 93,80 & 131,20 & 1797,10 \\
\hline 05 & W.G.B.S. & 4678,60 & 212,70 & 51,10 \\
\hline 07 & C.R.S.O. & 118,70 & 0,70 & 0,70 \\
\hline 08 & M.P.S. & 226,00 & 600,80 & 0,70 \\
\hline 09 & D.S.A. & 77,80 & 82,40 & 910,40 \\
\hline 10 & T.L.S. & 0,70 & 62,50 & 0,70 \\
\hline 11 & F.A.S.S. & 487,90 & 4484,10 & 394,20 \\
\hline 12 & C.R.L. & 500,90 & 0,70 & 59,50 \\
\hline 13 & R.C.V. & 306,50 & 190,60 & 131,90 \\
\hline 14 & L.C.V. & 7325,80 & 7493,60 & 642,80 \\
\hline 16 & C.C.R. & 4166,20 & 112,80 & 0,70 \\
\hline 18 & L.C.V. & 1459,40 & 128,10 & 82,40 \\
\hline 19 & G.A.S.S. & 348,00 & 0,70 & 0,70 \\
\hline 20 & R.B.S. & 2677,80 & 279,80 & 22,20 \\
\hline 21 & N.L.F. & 829,60 & 1308,40 & 1526,50 \\
\hline 23 & A.F.A.S. & 724,40 & 61,00 & 0,70 \\
\hline 24 & S.G.S. & 1526,50 & 0,70 & 0,70 \\
\hline 25 & G.C.S. & 784,60 & 0,70 & 0,70 \\
\hline 26 & M.M.B. & 7069,60 & 58,70 & 0,70 \\
\hline 27 & J.C.S. & 89,20 & 0,70 & 0,70 \\
\hline 28 & M.S.R.R. & 377,40 & 64,80 & 79,30 \\
\hline 29 & A.L.S. & 2970,60 & 134,90 & 103,70 \\
\hline 30 & A.G. & 0,70 & 0,70 & 0,70 \\
\hline 31 & K.C.S. & 253,10 & 44,50 & 0,70 \\
\hline 32 & E.N.M.S. & 1055,80 & 73,30 & 36,10 \\
\hline 33 & I.M.D.V. & 763,90 & 57,80 & 20,40 \\
\hline 34 & G.J.S. & 1631,80 & 82,50 & 64,10 \\
\hline 35 & A.L.D.M. & 995,10 & 351,40 & 134,20 \\
\hline & & & &
\end{tabular}

Obs: 1) Em verde: Grupo Sepse

2) Em vermelho: Grupo Sepse Grave

3) Casos no 6 ; 15; 17 e 22 excluídos do estudo. 
Anexo G: Valores séricos individuais de IL-1Ra (pg/ml) com 0, 3 e 7 dias de evolução da sepse dos RN incluídos no estudo.

\begin{tabular}{rrrrr}
\hline CASO & Iniciais & \multicolumn{1}{c}{$0^{0}$ dia } & \multicolumn{1}{c}{$3^{\circ}$ dia } & \multicolumn{1}{c}{$7^{0}$ dia } \\
\hline 01 & J.P.A. $\dagger$ & 2983,70 & \multicolumn{1}{c}{-} \\
\hline 02 & B.X.N. $\dagger$ & 996,90 & 357,60 & 367,50 \\
\hline 03 & S.O.A. & 2111,40 & 198,90 & 414,80 \\
\hline 04 & A.B.S. $\dagger$ & 667,50 & 412,80 & 2855,90 \\
\hline 05 & W.G.B.S. & 3131,10 & 2422,00 & 262,90 \\
\hline 07 & C.R.S.O. & 227,70 & 500,80 & 277,10 \\
\hline 08 & M.P.S. & 93,20 & 612,60 & 4742,70 \\
\hline 09 & D.S.A. & 416,90 & 169,70 & 2829,50 \\
\hline 10 & T.L.S. & 213,10 & 105,00 & 287,90 \\
\hline 11 & F.A.S.S. & 4548,80 & 6491,60 & 1446,20 \\
\hline 12 & C.R.L. & 720,50 & 117,40 & 140,00 \\
\hline 13 & R.C.V. & 3014,30 & 233,20 & 312,60 \\
\hline 14 & L.C.V. & 507,40 & 511,80 & 2393,20 \\
\hline 16 & C.C.R. & 373,00 & 674,30 & 108,20 \\
\hline 18 & L.C.V. & 3115,60 & 3170,70 & 646,20 \\
\hline 19 & G.A.S.S. & 1675,00 & 146,80 & 56,80 \\
\hline 20 & R.B.S. & 1490,00 & 552,60 & 281,60 \\
\hline 21 & N.L.F. & 557,80 & 3018,90 & 3314,10 \\
\hline 23 & A.F.A.S. & 550,90 & 145,10 & 266,30 \\
\hline 24 & S.G.S. & 540,00 & 407,20 & 27,90 \\
\hline 25 & G.C.S. & 422,50 & 181,30 & 87,10 \\
\hline 26 & M.M.B. & 4350,60 & 111,10 & 106,00 \\
\hline 27 & J.C.S. & 453,30 & 71,70 & 83,50 \\
\hline 28 & M.S.R.R. & 1862,30 & 162,80 & 160,90 \\
\hline 29 & A.L.S. & 842,20 & 655,00 & 167,80 \\
\hline 30 & A.G. & 542,70 & 163,20 & 293,40 \\
\hline 31 & K.C.S. & 380,30 & 112,50 & 104,50 \\
\hline 32 & E.N.M.S. & 884,40 & 247,70 & 145,80 \\
\hline 33 & I.M.D.V. & 902,20 & 285,00 & 173,40 \\
\hline 34 & G.J.S. & 1465,40 & 477,70 & 238,50 \\
\hline 35 & A.L.D.M. & 953,70 & 615,90 & 563,20 \\
\hline & & & & \\
\hline & & & & \\
\hline
\end{tabular}

Obs: 1) Em verde: Grupo Sepse

2) Em vermelho: Grupo Sepse Grave

3) Casos no 6 ; 15; 17 e 22 excluídos do estudo. 
Anexo H: Valores séricos individuais de IL-10 (pg/ml) com 0, 3 e 7 dias de evolução da sepse dos $31 \mathrm{RN}$ incluídos no estudo.

\begin{tabular}{rrrrr}
\hline CASO & Iniciais & \multicolumn{1}{c}{$0^{0}$ dia } & \multicolumn{1}{c}{$3^{\circ}$ dia } & \multicolumn{1}{c}{$7^{\circ}$ dia } \\
\hline 01 & J.P.A. $\dagger$ & 1732,60 & \multicolumn{1}{c}{-} \\
\hline 02 & B.X.N. $\dagger$ & 3,90 & 3,90 & 4,10 \\
\hline 03 & S.O.A. & 3,90 & 3,90 & 3,90 \\
\hline 04 & A.B.S. $\dagger$ & 3,90 & 3,90 & 55,80 \\
\hline 05 & W.G.B.S. & 9,80 & 3,90 & 3,90 \\
\hline 07 & C.R.S.O. & 3,90 & 3,90 & 3,90 \\
\hline 08 & M.P.S. & 3,90 & 3,90 & 22,40 \\
\hline 09 & D.S.A. & 3,90 & 3,90 & 3,90 \\
\hline 10 & T.L.S. & 3,90 & 3,90 & 3,90 \\
\hline 11 & F.A.S.S. & 6,40 & 569,00 & 9,80 \\
\hline 12 & C.R.L. & 3,90 & 3,90 & 3,90 \\
\hline 13 & R.C.V. & 3,90 & 3,90 & 3,90 \\
\hline 14 & L.C.V. & 3,90 & 3,90 & 3,90 \\
\hline 16 & C.C.R. & 3,90 & 3,90 & 3,90 \\
\hline 18 & L.C.V. & 448,00 & 540,50 & 4,30 \\
\hline 19 & G.A.S.S. & 3,90 & 3,90 & 3,90 \\
\hline 20 & R.B.S. & 3,90 & 3,90 & 3,90 \\
\hline 21 & N.L.F. & 3,90 & 3,90 & 7,30 \\
\hline 23 & A.F.A.S. & 3,90 & 3,90 & 3,90 \\
\hline 24 & S.G.S. & 3,90 & 3,90 & 3,90 \\
\hline 25 & G.C.S. & 3,90 & 3,90 & 3,90 \\
\hline 26 & M.M.B. & 3,90 & 3,90 & 3,90 \\
\hline 27 & J.C.S. & 3,90 & 3,90 & 3,90 \\
\hline 28 & M.S.R.R. & 3,90 & 3,90 & 3,90 \\
\hline 29 & A.L.S. & 3,90 & 3,90 & 3,90 \\
\hline 30 & A.G. & 3,90 & 3,90 & 3,90 \\
\hline 31 & K.C.S. & 3,90 & 3,90 & 3,90 \\
\hline 32 & E.N.M.S. & 3,90 & 3,90 & 3,90 \\
\hline 33 & I.M.D.V. & 3,90 & 3,90 & 3,90 \\
\hline 34 & G.J.S. & 3,90 & 3,90 & 3,90 \\
\hline 35 & A.L.D.M. & 81,80 & 46,30 & 7,10 \\
\hline & & & & \\
\hline & & & & \\
\hline
\end{tabular}

Obs: 1) Em verde: Grupo Sepse

2) Em vermelho:Grupo Sepse Grave

3) Casos no 6 ; 15; 17 e 22 excluídos do estudo. 
Anexo I: Valores séricos individuais da PCR (mg/L) com 0, 3 e 7 dias de evolução da sepse dos RN incluídos no estudo.

\begin{tabular}{rrrrr}
\hline CASO & Iniciais & $0^{\circ}$ dia & $3^{\circ}$ dia & $7^{\circ}$ dia \\
\hline 01 & J.P.A. $\dagger$ & 117,0 & - & - \\
\hline 02 & B.X.N. $\dagger$ & $<3,2$ & 5,4 & $<3,2$ \\
\hline 03 & S.O.A. & 9,7 & 17,9 & 24,6 \\
\hline 04 & A.B.S. $\dagger$ & $<3,2$ & $<3,2$ & 24,5 \\
\hline 05 & W.G.B.S. & $<3,2$ & 48,2 & 6,8 \\
\hline 07 & C.R.S.O. & 12,1 & 10,1 & 8,4 \\
\hline 08 & M.P.S. & 5,4 & 194,0 & 126,4 \\
\hline 09 & D.S.A. & 24,3 & 13,5 & $<3,2$ \\
\hline 10 & T.L.S. & 15,8 & 23,3 & 4,3 \\
\hline 11 & F.A.S.S. & 30,8 & 115,2 & 147,6 \\
\hline 12 & C.R.L. & 33,0 & 110,0 & $<5,0$ \\
\hline 13 & R.C.V. & 19,0 & 8,0 & $<5,0$ \\
\hline 14 & L.C.V. & $<5,0$ & $<5,0$ & $<5,0$ \\
\hline 16 & C.C.R. & 8,0 & 100,0 & 13,0 \\
\hline 18 & L.C.V. & 91,0 & 188,0 & 86,5 \\
\hline 19 & G.A.S.S. & 171,0 & 85,0 & $<5,0$ \\
\hline 20 & R.B.S. & 68,0 & 17,0 & 13,0 \\
\hline 21 & N.L.F. & 189,6 & 91,9 & 108,1 \\
\hline 23 & A.F.A.S. & 134,0 & 39,0 & 6,0 \\
\hline 24 & S.G.S. & 24,0 & 24,0 & 6,0 \\
\hline 25 & G.C.S. & 7,0 & 6,0 & $<5,0$ \\
\hline 26 & M.M.B. & 30,0 & 23,0 & $<5,0$ \\
\hline 27 & J.C.S. & $<5,0$ & $<5,0$ & $<5,0$ \\
\hline 28 & M.S.R.R. & 128,0 & 18,0 & $<5,0$ \\
\hline 29 & A.L.S. & 180,0 & 49,0 & 10,0 \\
\hline 30 & A.G. & 45,0 & 5,8 & $<5,0$ \\
\hline 31 & K.C.S. & 107,0 & Nc & $<5,0$ \\
\hline 32 & E.N.M.S. & 33,0 & 16,0 & 8,0 \\
\hline 33 & I.M.D.V. & 43,0 & 17,0 & 7,0 \\
\hline 34 & G.J.S. & 37,0 & 15,0 & 6,0 \\
\hline 35 & A.L.D.M. & 47,6 & 67,6 & 39,8 \\
\hline & & & &
\end{tabular}

Obs: 1) Em verde: Grupo Sepse

2) Em vermelho:Grupo Sepse Grave

3) Casos no 6 ; 15; 17 e 22 excluídos do estudo.

4) Nc: não coletado 
Anexo J: Valores séricos individuais de $\mathrm{Hb}(\mathrm{g} \%), \mathrm{HT}(\%)$, № de leucócitos por $\mathrm{mm}^{3}, \mathrm{n}^{\circ}$ de neutrófilos por $\mathrm{mm}^{3}$, Índice neutrofílico (IN), e plaquetas por $\mathrm{mm}^{3}$ no dia 0 do diagnóstico de sepse dos $\mathrm{RN}$ incluídos no estudo.

\begin{tabular}{rrrrrrrr}
\hline CASO & Iniciais & \multicolumn{1}{c}{$\mathrm{Hb}$} & \multicolumn{1}{c}{ HT } & \multicolumn{1}{l}{ Leucócitos } & Neutrófilos & \multicolumn{1}{c}{ IN } & plaquetas \\
\hline 01 & J.P.A. $\dagger$ & 7,0 & 20,5 & 3.850 & 2.772 & \multicolumn{1}{c}{0} & 48.000 \\
\hline 02 & B.X.N. $\dagger$ & 11,0 & 32,0 & 11.270 & 7.100 & 0,11 & 214.000 \\
\hline 03 & S.O.A. & 6,5 & 20,0 & 22.350 & 11.622 & 0,21 & 225.000 \\
\hline 04 & A.B.S. $\dagger$ & 8,5 & 24,7 & 22.620 & 1.176 & 0,07 & 183.000 \\
\hline 05 & W.G.B.S & 14,6 & 43,0 & 15.240 & 11.582 & 0,14 & 273.000 \\
\hline 07 & C.R.SO & 7,5 & 24,0 & 17.400 & 10.440 & 0,25 & 440.000 \\
\hline 08 & M.P.S. & 11,4 & 33,0 & 29.700 & 15.236 & 0,13 & 332.000 \\
\hline 09 & D.S.A. & 17,2 & 48,0 & 16.000 & 9.920 & 0,04 & 217.000 \\
\hline 10 & T.L.S. & 15,0 & 43,0 & 20.900 & 13.585 & 0,01 & 197.000 \\
\hline 11 & F.A.S.S. & 11,7 & 34,0 & 5.800 & 2.950 & 0 & 89.000 \\
\hline 12 & C.R.L. & 16,6 & 47,0 & 13.000 & 10.010 & 0,06 & 267.000 \\
\hline 13 & R.C.V. & 15,0 & 44,0 & 4.100 & 3.034 & 0,23 & 108.000 \\
\hline 14 & L.C.V. & 15,4 & 45,0 & 6.300 & 2.898 & 0,26 & 115.000 \\
\hline 16 & C.C.R. & 14,5 & 43,0 & 2.700 & 918 & 0,82 & 264.000 \\
\hline 18 & L.C.V. & 10,4 & 33,0 & 11.200 & 8.512 & 0,26 & 33.000 \\
\hline 19 & G.A.S.S. & 16,6 & 50,0 & 8.600 & 5.762 & 0,01 & 260.000 \\
\hline 20 & R.B.S. & 14,0 & 42,0 & 4.400 & 2.244 & 0,80 & NR \\
\hline 21 & N.L.F. & 11,9 & 35,9 & 19.000 & 14.250 & 0,16 & 309.000 \\
\hline 23 & A.F.A.S. & 15,0 & 45,0 & 3.000 & 1.440 & 0,60 & NR \\
\hline 24 & S.G.S. & 17,9 & 56,0 & 8.700 & 6.786 & 0,26 & 138.000 \\
\hline 25 & G.C.S. & 14,3 & 43,0 & 24.100 & 21.449 & 0,40 & 206.000 \\
\hline 26 & M.M.B. & 13,4 & 39,0 & 16.200 & 12.798 & 0,40 & 153.000 \\
\hline 27 & J.C.S. & 17,7 & 53,0 & 23600 & 19.588 & 0,18 & 344.000 \\
\hline 28 & M.S.R.R. & 12,3 & 40,0 & 6.700 & 4.891 & 0,68 & 276.000 \\
\hline 29 & A.L.S. & 15,1 & 46,0 & 7.100 & 4.899 & 0,45 & 164.000 \\
\hline 30 & A.G. & 16,2 & 46,0 & 9.900 & 6.336 & 0,34 & 208.000 \\
\hline 31 & K.C.S. & 14,7 & 43,0 & 17.900 & 11.993 & 0,15 & 250.000 \\
\hline 32 & E.N.M.S. & 15,9 & 46,0 & 13.200 & 8.712 & 0,40 & NR \\
\hline 33 & I.M.D.V. & 14,8 & 43,0 & 15.200 & 7.296 & 0,25 & 214.000 \\
\hline 34 & G.J.S. & 14,3 & 41,0 & 7.600 & 4.712 & 0,16 & 180,000 \\
\hline 35 & A.L.D.M. & 20,3 & 60,0 & 3.900 & 2.145 & 0 & 120.000 \\
\hline & & & & & & & \\
\hline
\end{tabular}

Obs: 1) Em verde: Grupo Sepse

2) Em vermelho:Grupo Sepse Grave

3) Casos no 6 ; 15; 17 e 22 excluídos do estudo.

4) NR: Não realizado 
Anexo L: Microorganismos isolados em culturas

\begin{tabular}{cccc}
\hline CASO & Iniciais & Microorganismos & Local \\
\hline 01 & J.P.A. $\dagger$ & Serratia marcescens & Hemocultura \\
\hline 02 & B.X.N. $\dagger$ & Staphylococcus epidermidis & Hemocultura \\
\cline { 3 - 4 } & Klebsiella pneumoniae & Urocultura \\
\hline 03 & S.O.A. & Cândida albicans & Hemocultura e Urocultura \\
\hline 04 & A.B.S. $\dagger$ & Candida albicans (7 ${ }^{\circ}$ dia) & hemocultura \\
\hline 05 & W.G.B.S. & & \\
\hline 07 & C.R.S.O. $\dagger$ & & \\
\hline 08 & M.P.S. & Cândida albicans (3o dia) & Hemocultura \\
\hline 09 & D.S.A. & Staphylococcus epidermidis & Hemocultura \\
\hline 10 & T.L.S. & & \\
\hline 11 & F.A.S.S. & Pseudomonas aeruginosa & Hemocultura \\
\hline 12 & C.R.L. & & \\
\hline 13 & R.C.V. & Streptococcus agalactie & Hemocultura \\
\hline 14 & L.C.V. & & \\
\hline 16 & C.C.R. & & Hemocultura \\
\hline 18 & L.C.V. & Acinetobacter baumanni & \\
\hline 19 & G.A.S.S. & & \\
\hline 20 & R.B.S. & & \\
\hline 21 & N.L.F. & Staphylococcus aureus & Hemocultura e LCR \\
\hline 23 & A.F.A.S. & & \\
\hline 24 & S.G.S. & & \\
\hline 25 & G.C.S. & & \\
\hline 26 & M.M.B. & Streptococcus agalactie & \\
\hline 27 & J.C.S. & & \\
\hline 28 & M.S.R.R. & & \\
\hline 29 & A.L.S. & & \\
\hline 30 & A.G. & & \\
\hline 31 & K.C.S. & & \\
\hline 32 & E.N.M.S. & & \\
\hline 33 & I.M.D.V. & & \\
\hline 34 & G.J.S. & & \\
\hline 35 & A.L.D.M. & & \\
\hline & & & \\
\hline
\end{tabular}

Obs: 1) Em verde: Grupo Sepse

2) Em vermelho:Grupo Sepse Grave

3) Casos no 6 ; 15; 17 e 22 excluídos do estudo. 
Anexo M: RN com sepse neonatal e meningite e TNF- $\alpha$ nos dias 0,3 e 7 de evolução

\begin{tabular}{ccccccr}
\hline \multirow{2}{*}{ CASO } & \multirow{2}{*}{ Iniciais } & \multirow{2}{*}{ Gênero } & \multirow{2}{*}{ Peso $(\mathrm{g})$} & \multicolumn{3}{c}{ TNF- $\alpha$} \\
\cline { 5 - 7 } & & & Dia 0 & Dia 3 & Dia 7 \\
\hline 04 & A.B.S. $\dagger$ & $\mathrm{M}$ & 1270 & 1,60 & 1,60 & 248,80 \\
\hline 08 & M.P.S. & $\mathrm{F}$ & 2885 & 1,60 & 1,60 & 1,60 \\
\hline 21 & N.L.F. & $\mathrm{M}$ & 1120 & 1,60 & 1,60 & 152,80 \\
\hline
\end{tabular}

Anexo N: RN com sepse neonatal e meningite e IL-1 $\beta$ nos dias 0,3 e 7 de evolução

\begin{tabular}{ccccccc}
\hline \multirow{2}{*}{ CASO } & \multirow{2}{*}{ Iniciais } & \multirow{2}{*}{ Gênero } & \multirow{2}{*}{ Peso $(\mathrm{g})$} & \multicolumn{3}{c}{ IL-1 } \\
\cline { 5 - 7 } & & & & Dia 0 & Dia 3 & Dia 7 \\
\hline 04 & A.B.S. $\dagger$ & $\mathrm{M}$ & 1270 & 1,00 & 1,00 & 1,00 \\
08 & M.P.S. & $\mathrm{F}$ & 2885 & 1,00 & 1,00 & 1,00 \\
\hline 21 & N.L.F. & $\mathrm{M}$ & 1120 & 1,00 & 1,00 & 9,20 \\
\hline
\end{tabular}

Anexo 0: RN com sepse neonatal e meningite e IL-6 nos dias 0, 3 e 7 de evolução

\begin{tabular}{ccccrrr}
\hline \multirow{2}{*}{ CASO } & \multirow{2}{*}{ Iniciais } & \multirow{2}{*}{ Gênero } & \multirow{2}{*}{ Peso $(\mathrm{g})$} & \multicolumn{3}{c}{ IL-6 } \\
\cline { 5 - 7 } & & & Dia 0 & Dia 3 & \multicolumn{1}{c}{ Dia 7 } \\
\hline 04 & A.B.S. $\dagger$ & M & 1270 & 93,80 & 131,20 & 1797,10 \\
\hline 08 & M.P.S. & $\mathrm{F}$ & 2885 & 226,00 & 600,80 & 0,70 \\
\hline 21 & N.L.F. & $\mathrm{M}$ & 1120 & 829,60 & 1308,40 & 1526,50 \\
\hline
\end{tabular}

Anexo P: RN com sepse neonatal e meningite e IL-1Ra nos dias 0, 3 e 7 de evolução

\begin{tabular}{cccrrrr}
\hline \multirow{2}{*}{ CASO } & \multirow{2}{*}{ Iniciais } & \multirow{2}{*}{ Gênero } & \multirow{2}{*}{ Peso $(\mathrm{g})$} & \multicolumn{3}{c}{ IL-1Ra } \\
\cline { 5 - 7 } & & & Dia 0 & \multicolumn{1}{c}{ Dia 3 } & \multicolumn{1}{c}{ Dia 7 } \\
\hline 04 & A.B.S. $\dagger$ & M & 1270 & 667,50 & 412,80 & 2855,90 \\
\hline 08 & M.P.S. & F & 2885 & 93,20 & 612,60 & 4742,70 \\
\hline 21 & N.L.F. & M & 1120 & 557,80 & 3018,90 & 3314,10 \\
\hline
\end{tabular}


Anexo Q: RN com sepse neonatal e meningite e IL-10 nos dias 0 , 3 e 7 de evolução

\begin{tabular}{ccccccc}
\hline \multirow{2}{*}{ CASO } & \multirow{2}{*}{ Iniciais } & \multirow{2}{*}{ Gênero } & \multirow{2}{*}{ Peso $(\mathrm{g})$} & \multicolumn{3}{c}{ IL-10 } \\
\cline { 5 - 7 } & & & Dia 0 & Dia 3 & Dia 7 \\
\hline 04 & A.B.S. $\dagger$ & M & 1270 & 3,90 & 3,90 & 55,80 \\
\hline 08 & M.P.S. & F & 2885 & 3,90 & 3,90 & 22,40 \\
\hline 21 & N.L.F. & M & 1120 & 3,90 & 3,90 & 7,30 \\
\hline
\end{tabular}

Anexo R: RN com sepse neonatal e meningite e PCR nos dias 0 , 3 e 7 de evolução

\begin{tabular}{cccrrrr}
\hline \multirow{2}{*}{ CASO } & \multirow{2}{*}{ Iniciais } & \multirow{2}{*}{ Gênero } & \multirow{2}{*}{ Peso $(\mathrm{g})$} & \multicolumn{3}{c}{ PCR } \\
\cline { 5 - 7 } & & & & Dia 0 & Dia 3 & Dia 7 \\
\hline 04 & A.B.S. $\dagger$ & M & 1270 & $<3,2$ & $<3,2$ & 24,5 \\
\hline 08 & M.P.S. & $\mathrm{F}$ & 2885 & 5,4 & 194,0 & 126,4 \\
\hline 21 & N.L.F. & M & 1120 & 189,6 & 91,9 & 108,1 \\
\hline
\end{tabular}

Anexo S: RN com sepse neonatal e meningite e relação IL-6/IL-1Ra nos dias 0,3 e 7 de evolução

\begin{tabular}{ccccccc}
\hline \multirow{2}{*}{ CASO } & \multirow{2}{*}{ Iniciais } & \multirow{2}{*}{ Gênero } & \multirow{2}{*}{ Peso $(\mathrm{g})$} & \multicolumn{3}{c}{ IL-6/L-1Ra } \\
\cline { 5 - 7 } & & & Dia 0 & Dia 3 & Dia 7 \\
\hline 04 & A.B.S. $\dagger$ & $\mathrm{M}$ & 1270 & 0,14 & 0,31 & 0,62 \\
\hline 08 & M.P.S. & $\mathrm{F}$ & 2885 & 2,42 & 0,98 & - \\
\hline 21 & N.L.F. & $\mathrm{M}$ & 1120 & 1,48 & 0,43 & 0,46 \\
\hline
\end{tabular}

Anexo T: RN com sepse neonatal e meningite e relação IL-6 / (IL-6 + IL1Ra) nos dias 0 , 3 e 7 de evolução

\begin{tabular}{ccccccc}
\hline \multirow{2}{*}{ CASO } & \multirow{2}{*}{ Iniciais } & \multirow{2}{*}{ Gênero } & \multirow{2}{*}{ Peso $(\mathrm{g})$} & \multicolumn{3}{c}{ IL-6/(IL-6 + IL-1Ra) } \\
\cline { 5 - 7 } & & & Dia 0 & Dia 3 & Dia 7 \\
\hline 04 & A.B.S. $†$ & M & 1270 & 0,12 & 0,24 & 0,39 \\
\hline 08 & M.P.S. & F & 2885 & 0,71 & 0,49 & - \\
\hline 21 & N.L.F. & M & 1120 & 0,60 & 0,30 & 0,31 \\
\hline
\end{tabular}

Anexo U: RN com sepse neonatal e meningite valores liquóricos

\begin{tabular}{c|l|c|c|c|c|c}
\hline CASO & Iniciais & $\begin{array}{c}\text { Leucócitos } \\
/ \mathrm{mm}^{3}\end{array}$ & $\begin{array}{c}\text { Neutrófilos } \\
(\%)\end{array}$ & $\begin{array}{c}\text { Proteínas } \\
(\mathrm{mg} \%)\end{array}$ & Glicose & Cultura \\
\hline 04 & A.B.S. $\dagger$ & 38 & 59 & $\mathrm{Ml}$ & 41 & Negativa \\
\hline 08 & M.P.S. & 65 & 12 & 66 & 56 & Negativa \\
\hline 21 & N.L.F. & 93 & 76 & 108 & 42 & Positiva $^{*}$ \\
\hline * Staphylococcus aureus (concomitante a hemocultura) &
\end{tabular}


09

REFERÊNCIAS BIBLIOGRÁFICAS 


\section{REFERÊNCIAS BIBLIOGRÁFICAS}

Abbas AK, Lichtman AH. Cytokines. In: Abbas AK, Lichtman AH. Cellular and molecular immunology. 5th ed. Philadelphia: Elsevier; 2005. p.243-74.

American Academy of Pediatrics. Guidelines for perinatal care. 4th ed. Elk Grove Village: American Academy of Pediatrics; 1997. p.93-125: Intrapartum care.

American College of Chest Physicians Society of Critical Care Medicine Consensus Conference Committee. Definitions for sepsis and organ failure and guidelines for the use of innovate therapies in sepsis. Crit Care Med. 1992;20:864-74.

Anderson MR, Blumer JL. Advances in the therapy for sepsis in children. Pediatr Clin North Am. 1997;44:179-205.

Anderson KV, Jurgens G, Nuslein-Volhard C. Establishment of dorsal-ventral polarity in the Drosophila embryo: genetic studies on the role of the Toll gene product. Cell. 1985a;42:779-89. 
Anderson KV, Jurgens G, Nuslein-Volhard C. Establishment of dorsal-ventral polarity in the drosophila embryo: the induction of polarity by the Toll gene product Cell. 1985b;42:791-98.

Ashare A, Powers LS, Butler NS, Doerschug KC, Monick MM, Hunninghake GW. Anti-inflammatory response is associated with mortality and severity of infection in sepsis. Am J Physiol Lung Cell Mol Physiol. 2004;288:633-40.

Ayala A, Chung CS, Grutkoski PS, Song GY. Mechanisms of immune resolution. Crit Care Med. 2003;31(suppl 8):S558-S571.

Balagtus RC, Bell CE, Edwards LD, Levin S. Risk of local and systemic infections associated with umbilical catheterization. A prospective study in 86 newborn patients. Pediatrics. 1971;48:39-67.

Baltimore RS. Neonatal nosocomial infection. Semin Perinatol. 1998;22:2532.

Bellanti JA, Kadlec JV, Escobar-Gutierrez A. Cytokines and the immune response. Pediatr Clin North Am. 1994;41:597-621.

Beutler B, Cerami A. Cachectin: more than a tumor necrosis factor. $N$ Engl J Med. 1987;316:379-85. 
Beutler B, Poltorak A. Sepsis and evolution of the innate immune response. Crit Care Med. 2001;29;(Suppl. 7):S2-S6.

Beutler B, Trang MNL, Pekala P, Cerami A. Purification of cachectin, a lipoprotein lipase-suppressing hormone secreted by endotoxin-induced raw 264,7 cells. J Exp Med.1985;161:984-95.

Bochud PY, Calandra T. Pathogenesis of sepsis: new concepts and implications for future treatment. BMJ. 2003;326:262-6.

Bone RC. The pathogenesis of sepsis. Ann Intern Med. 1991;115:457-69.

Bone RC. Toward a theory regarding the pathogenesis of the systemic inflammatory response syndrome: what we do and do not know about cytokines regulation. Crit Care Med. 1996;24:163-72.

Bone RC, Grodzin CJ, Balk RA. Sepsis: a new hypothesis for pathogenesis of the disease process. Chest. 1997;112:235-43.

Borish LC, Steinke JW. Cytokines and Chemokines. J Allergy Clin Immunol. 2003;111(Suppl.):S460-S475. 
Brandtzaeg P, Van Deuren M. Current concepts in the role of the host response in Neisseria meningitides septic shock. Curr Opin Infect Dis. 2002;15:247-52.

Brightbill HD, Modlin RL. Toll-like receptors: molecular mechanisms of the mammalian immune response. Immunology. 2000;101:1-10.

Brown E, Atkinson JP, Fearon DT. Innate immunity: 50 ways to kill a microbe. Curr Opin Immunol. 1994;6:73-4.

Calandra T, Gerain J, Heumann D, Baumgartner JD, Glauser MP. High circulating levels of interleukin-6 in patients with septic shock: evolution during sepsis, prognostic value and interplay with other cytokines. Am J Med. 1991;91:23-9.

Carrigan SD, Scott G, Tabrizian M. Toward resolving the challenges of sepsis diagnosis. Clinl Chem. 2004;50:1301-14.

Casey LC. Immunologic response to infection and its role in septic shock. Crit Care Clin. 2000;16:193-213.

Casey LC, Balk RA, Bone RC. Plasma cytokine and endotoxin levels correlate with survival in patients with sepsis syndrome. Ann Intern Med. 1993;119:771-8. 
Ceccon MEJR. Análise do uso das interleucinas 6 e 8 e proteína $C$ reativa para diagnóstico e seguimento terapêutico de recém-nascido com sepse tardia internados na Unidade de Cuidados Intensivos Neonatal [Livre Docência]. São Paulo: Faculdade de Medicina da Universidade de São Paulo; 2002

Ceccon MEJR. Marcadores imunológicos (imunoglobulinas: IgG, $\lg M, \lg A$, Complemento total, proteínas reguladoras do complement, Proteína $C$ reativa) em recém-nascidos com fatores de risco para infecção precoce. [Tese]. São Paulo: Faculdade de Medicina da Universidade de São Paulo; 1995.

Chiesa C, Pellegrini G, Panero A, Osborn JF, Signore F, Assumma M, Pacifico L. C-reactive protein, interleukin-6, and procalcitonin in the immediate postnatal period: influence of illness severity, risk status, antenatal and perinatal complications, and infection. Clin Chem. 2003;49:60-8.

Cohen J. The immunopathogenesis of sepsis. Nature. 2002;420:885-91.

Colotta F, Ghezzi P, Mantovani A. Interleukin-1. In: Mire-Sluis A, Thorpe R. Cytokines. San Diego: Academic Press; 1998. p.1-18.

Cook JA. The toll of sepsis: Altered innate immunity in polymicrobial sepsis. Crit Care Med. 2003;31:1880-2. 
Crowder MJ, Hand DJ. Analysis of repeated measures. 1st. ed. London: Chapman and Hall; 1990. 257p.

Cunneen J, Cartwright M. The puzzle of sepsis. Fitting the pieces of the inflammatory Response with treatment. AACN Clinical Issues. 2004;15:1844.

Damas $\mathrm{P}$, Ledoux D, Nys M, Vrindts $\mathrm{Y}$, De Groote D, Franchimont $\mathrm{P}$, Lamy M. Cytokines serum level during severe sepsis in human IL-6 as a marker of severity. Ann Surg. 1992;215:356-42.

De Bont ESJM, De Leij LHFM, Okken A, Baarsma R, Kimpen JLL. Increased plasma concentrations of interleukin-1 receptor antagonist in neonatal sepsis. Pediatr Res. 1995;37:626-9.

Del Vecchio A, Laforgia N, Capasso M, Lolascon A, Latini G. The role of molecular genetics in the pathogenesis and diagnosis of neonatal sepsis. Clin Perinatol. 2004;31:53-67.

Derkx B, Marchant A, Goldman M, Bijlmer R, Van Deventer S. High levels of interleukin-10 during the initial phase of fulminant meningococcal septic shock. J Infect Dis. 1995;171:229-32.

Dinarello CA. Impact of basic research on tomorrow's medicine. Proinflammatory cytokines. Chest. 2000;118:503-8. 
Dinarello CA. Proinflammatory and anti-inflammatory cytokines as mediators in the pathogenesis of septic shock. Chest. 1997;112:321-9.

Dinarello CA. The proinflammatory cytokines interleukin-1 and tumor necrosis factor and treatment of septic shock syndrome. J Infect Dis. 1991;163:1174-94.

Dinarello CA, Wolff SM. The role of interleukin-1 in disease. N Engl J Med. 1993;328:106-13.

Dollner H, Vatten L, Linnebo I, Zanussi GF, Laerdal A, Austgulen R. Inflammatory mediators in umbilical plasma from neonates who develop early onset sepsis. Biol Neonate. 2001;80:41-7.

Doughty L, Carcillo JA, Kaplan S, Janosky J. The compensatory antiinflammatory cytokine interleukin10 response in pediatric sepsis induced multiple organ failure. Chest.1998;113:1625-31.

Ertel W, Keel M, Neidhart R, Steckholzer U, Kremer JP, Ungethuem U, Trentz O. Inhibition of the defense system stimulating interleukin-12 interferon-gamma pathway during critical illness. Blood. 1997; 89:1612-20.

Fearon DT, Locksley RM. The instructive role of innate immunity in the acquired immune response. Science. 1996;272:50-3. 
Fischer E, Van Zee KJ, Marano MA, Rock CS, Kenney JS, Poutsiaka DD, Dinarello CA, Lowry SF, Moldawer LL. Interleukin-1 receptor antagonist circulates in experimental inflammation and in human disease. Blood. 1992;79:2196-200.

Fischer JE, Seifarth FG, Baenziger O, Fanconi S, Nadal D. Hindsight judgment on ambiguous episodes of suspected infection in critically ill children. Eur J Pediatr. 2003;162:840-3.

Gabay C, Kushner I. Mechanism of disease: acute-phase proteins and other systemic responses to inflammation. N Engl J Med. 1999;340:448-54.

Gallou S, Kushner I. C reactive protein and acute phase response. Adv Intern Med. 1992;37:313-36.

Gea-Banacloche JC, Opal SM, Jorgensen J, Carcillo JA, Sepkowitz KA, Cordonnier C. Sepsis associated with immunosuppressive medications: an evidence-based review. Crit Care Med. 2004;32;(Suppl. 11):S578-S590.

Gerdes JS. Diagnosis and management of bacterial infections in the neonate. Pediatr Clin North Am. 2004;51:939-59.

Giroir BP. Mediators of septic shock: new approaches for interrupting the endogenous inflammatory cascade. Crit Care Med. 1993;21:780-9. 
Gogos CA, Drosou E, Bassaris HP, Skoutelis A. Pro- versus antiinflammatory cytokine profile in patients with severe sepsis: a marker for prognosis and future therapeutic options. J Infect Dis. 2000;181:176-80.

Goldie AS, Fearon KCH, Ross JA, Barclay GR, Jackson RE, Grant IS, Ramsay G, Blyth AS, Howie JC. Natural cytokine antagonists and endogenous antiendotoxin core antibodies in sepsis syndrome. JAMA. 1995;274:172- 7 .

Goldstein B, Giroir B, Randolph A, The Members of the International Consensus Conference on Pediatric Sepsis. International pediatric sepsis consensus conference: Definition for sepsis and organ dysfunction in pediatrics. Pediatr Crit Care Med. 2005;6:2-8.

Goldman S, Ellis R, Dhar V, Cairo MS. Rationale and potential use of cytokines in the prevention and treatment of neonatal sepsis. Clin Perinatol. 1998;25:699-710.

Gonzalez BE, Mercado CK, Johnson L, Brodsky NL, Bhandari V. Early markers of late onset sepsis in premature neonates: clinical, hematological and cytokine profile. J Perinat Med. 2003;31:60-8.

Hageman JR, Caplan MS. Introduction the structure and function of inflammatory mediators for clinician. Clin Perinatol. 1995;22:251-61. 
Hack CE, De Grott ER, Felt-Bersma RJF, Nuijens JH, Strack Van Schinjndel RJMS, Eerenberg-Belmer AJM, Thisjs LG, Aarden LA. Increased plasm levels of interleukin-6 in sepsis. Blood. 1989;74:1704-10.

Hallman M, Rämet M, Ezekowitz RA. Toll-like receptors as sensors of pathogens. Pediatr Res. 2001;50:315-21.

Harris H, Wirtschafter D, Cassidy G. Endotracheal intubation and its relationship to bacterial colonization and systemic infection of newborn infants. Pediatrics. 1976;58:816-23.

Heeg K, Dalpke A. TLR-induced negative regulatory circuits: Role of suppressor of cytokine signaling (SOCs) proteins in innate immunity. Vaccine. 2003;21(Suppl 2):S61-S67.

Henneke P, Berner R. SIRS and group-B streptococcal sepsis in newborn: pathogenesis and perspectives in adjunctive therapy. Semin Fetal Neonatal Med. 2006;11:333-42.

Hotchkiss RS, Karl IE. The pathophysiology and treatment of sepsis. N Engl J Med. 2003;348:138- 50.

Howard M, O'garra A, Ishida H, Malefyt RW, Vries J. Biological properties of interleukin 10. J Clin Immunol. 1992;12:239-47. 
Jafari HS, McCraken GH. Sepsis and septic shock: a review for clinicians. Pediatr Infect Dis J. 1992;11:739-49.

Janeway CA Jr, Travers P, Walport M, Shlomhik M. Imunobiologia: o sistema immune na saúde e na doença. 5a ed. Porto Alegre: Artmed Editora; 2002. p.55-111: Imunidade inata.

Jurges ES, Henderson DC. Inflammatory and immunological markers in preterm infants: correlation with disease. Clin Exp Immunol. 1996;105:551-9.

Kaisho T, Akira S. Toll-like receptors as adjuvant receptors. Biochim Biophys Acta. 2002;1589:1-13.

Kilpatrick L, Harris MC. Cytokines and the inflammatory response. In: Polin RA, Fox WW. Fetal and neonatal physiology. 2nd ed. Philadelphia: Saunders; 1998. p.1967-79.

Klein JO, Marcy SM. Bacterial sepsis and meningitis. In: Remington JS, Klein JO. Infection diseases of the fetus and newborn infant. Philadelphia: Saunders; 1990. p.601-56

Klein JO, Marcy SM. Bacterial. sepsis and meningitis. In: Remington JS, Klein JO. Infection diseases of the fetus and newborn infant. 4th ed. Philadelphia: Saunders; 1995. p.835-90. 
Koch T. Origin and mediators involved in sepsis and the systemic inflammatory response syndrome. Kidney Int Suppl. 1998;53;(Suppl. 64):669.

Küster H, Weiss M, Willeitner AE, Detlefsen S, Jeremias I, Zbojan J, Geiger R, Lipowsky G. Simbruner G. Interleukin-1 receptor antagonist and interleukin-6 for early diagnosis of neonatal sepsis 2 days before clinical manifestation. Lancet. 1998;352:1271-7.

Lawn JE, Cousens S, Zupan J, for the Lancet Neonatal Survival Steering Team. 4 million neonatal deaths: when? Where? Why? Lancet. 2005;365:891-900.

Lakhani SA, Bogue CW. Toll-like receptor signaling in sepsis. [Emergency and critical care pediatrics]. Curr Opin Pediatr. 2003;15:278-82.

Lemaitre B, Nicolas E, Michaut L, Reichhart JM, Hoffman JA. The dorsalventral regulatory gene cassette spatzle, Toll/cactus control the potent antifungal response in Drosophila adults. Cell. 1996;86:973-83.

Levy MM, Fink MP, Marshal JC, Abraham E, Angus D, Cook D, Cohen J, Opal SM, Vincent JL, Ramsay G, for the international sepsis definitions conference. 2001 SCCM / ESICM / ACCP / ATS / SIS International sepsis definitions conference. Crit Care Med. 2003;31:1250-6. 
Lien E, Ingalls RR. Toll-like receptors. Crit Care Med. 2002;30:S1-S11.

Loisa P, Rinne T, Laine S, Hurme M, Kaukinen S. Anti-inflammatory cytokine response and the development of multiple organ failure in severe sepsis. Acta Anaesthesiol Scand. 2003;47:319-25.

Lowry SF. Cytokines mediators of immunity and inflammation. Arch Surg. 1993;128:1235-41.

Manroe BL, Weinbwerg AG, Resenfeld CR, Browne R. The neonatal blood count in health and disease. Reference values for neutrophilic cells. $J$ Pediatr. 1979;75:89-98.

Martin C, Saux P, Mege JL, Perrin G, Papazian L, Gouin F. Prognostic value of serum cytokines in septic shock. Intensive Care Med. 1994;20:272-7.

McKay F. Tumor necrosis factor- $\alpha$ (TNF- $\alpha$ ) induced cell adhesion to human endothelial cells is under dominant control of one TNF receptor cell type TNF-R55. J Exp Med. 1993;177:1277-80.

Meadow W, Rudinsky B. Inflammatory mediators and neonatal sepsis. Rarely has so little been known by so many about so much. Clin Perinatol. 1995;22:519-36. 
Medzhitov R, Preston-Hurlburt P, Janeway Jr CA. A human homologue of the Drosophila Toll protein signals activation of adaptive immunity. Nature. 1997;388:394-7.

Mire-Sluis AR, Thorpe R. Cytokines. San Diego: Academic Press; 1998. p.525-46: Summary tables.

Mishra UK, Jacobs SE, Doyle LW, Garland S. Newer approaches to the diagnosis of early onset neonatal sepsis. Arch Dis Child Fetal Neonatal. 2006;91:F208-F212.

Modlin RL, Brightbill HD, Godowski PJ. The Toll of innate immunity on microbial pathogens. N Engl J Med. 1999;340:1834-5.

Nasraway SA. The problems and challenges of immunotherapy in sepsis. Chest. 2003;123;(Suppl 5):451S- 459S.

Netea MG, Van Der Meer JWM, Van Deuren M, Kullberg BJ. Proinflammatory cytokines and sepsis syndrome: not enough, or too much of a good thing? Trends immunol. 2003;24:254-8.

Ng PC. Diagnostic markers of infection in neonates. Arch Dis Child Fetal Neonatal. 2004;89:F229-F235. 
Ng PC, Li K, Wong RPO, Chui K, Wong E, Li G, Fok TF. Proinflammatory and anti-inflammatory cytokine responses in preterm infants with systemic infections. Arch Dis Child Fetal Neonatal. 2003;88:F209-F213.

Nomura N, Miyagima N, Sozuka T, Tanaka A, Kawarabayasi Y, Sato S, Nagase T, Seki N, Isshikawa K, Tabata S. Prediction of the coding sequences of 40 new genes (KIAA0001 - KIAA0040) deduced by analysis of randomly sampled cDNA clones from human immature myeloid cell line K61. DNA Res. 1994;1:27-35.

Oberholzer A, Oberholzer C, Moldawer LL. Cytokine signaling: regulation of the immune response in normal and critically ill states. Crit Care Med. 2000;28:3-12.

Oberholzer A, Oberholzer C, Moldawer LL. Interleukin 10: A complex role in the pathogenesis of sepsis syndromes and its potential as an antiinflamatory drugs Crit Care Med. 2002;30:S58-S63.

Okusawa S, Gelfand JA, Ikejima T, Connolly RJ, Dinarello CA. Interleukin-1 induces a shock like state in rabbits: synergism with tumor necrosis factor and effect of cyclooxygenase inhibition. J Clin Invest. 1988;81:1162-72. 
Opal SM, Esmosn CT. Bench-to-bedside review: functional relationships between coagulation and the innate immune response and their respective roles in the pathogens of sepsis. Crit Care. 2003;7:23-38.

Overall Jr JC. Neonatal bacterial meningitis: analysis of predisposing factor and outcome compared with matched control subjects. $J$ Pediatr. 1970;76:499-511.

Palazzi DL, Klein JO, Baker CJ. Bacterial sepsis and meningitis. In: Remington JS, Klein JO, Wilson CB, Baker CJ. Infections diseases of the fetus and newborn infant. 6th ed. Philadelphia: Saunders; 2006. p.247-95.

Pinsky MR. Pro- and antiinflammatory balance in sepsis [Renal system]. Curr Opin Crit Care. 2000;6:411-5.

Pinsky MR, Vincent JL, Deviere J, Alegre M, Kahn RJ, Dupont E. Serum cytokines levels in human septic shock. Relation to multiple-system organ failure and mortality. Chest. 1993;103:565-75.

Polin RA, St Geme JW 3rd. Neonatal. sepsis. Adv Pediatr Infect Dis. 1992;7:25-61. 
Ramos JLA. Avaliação do crescimento intra-uterino por medidas antropométricas do recém-nascido [Tese]. São Paulo: Faculdade de Medicina da Universidade de São Paulo; 1983.

Reyes CS, García-Muñoz Reyes DF, González G, Dominguez C, Domenech, E. Role of cytokines (interleukin-1 $\beta ; 6$; 8 ; tumour necrosis factor- $\alpha$, and soluble receptor of interleukin-2) and C-reactive protein in the diagnosis of neonatal sepsis. Acta Paediatr; 2003;92:221-7.

Sakamoto K, Arakawa H, Mitas S, Ishiko T, Ikei S, Egami H, Hisano S, Ogawa M. Elevation of circulating interleukin-6 after surgery: factor influencing the serum level. Cytokine. 1994;6:181-6.

Senftleben U, Karin M. The IKK/NF [kappa] B pathway. Crit Care Med. 2002;30:S18-S26.

Sikora JP, Chlebna-Sokol D, Krzyzanskna-Oberbek A. Proinflammatory cytokines (IL-6, IL-8); cytokines inhibitors (IL-6sR, sTNFRII) and antiinflammatory cytokines (IL-10, IL-13) in the pathogenesis of sepsis in newborn and infants. Arch Immunol Ther Exp (Warsz). 2001;49:399-404.

Silveira RC, Procianoy RS. Evaluation of interleukin-6, tumour necrosis factor- $\alpha$ and interleukin $1 \beta$ for early diagnosis of neonatal sepsis. Acta Paediatr. 1999;88:647-50. 
Singer JM, Andrade DF. Analysis of Longitudinal data. In: Sen PK, Rao CR. Handbook of statistics: bio-environmental and public health statistics. Amsterdam: North Holland; 2000. v.18. p.115-60.

Stein D, Roth S, Vogelsang E, Nusslein-Volhard C. The polarity of dorsal ventral axis in the Drosophila embryo is defined by an extracellular signal. Cell. 1991;65:725- 5 .

Stoll BJ. The global impact of neonatal infection. Clin Perinatol. 1997;24:121.

Stoll BJ, Hansen NI, Higgins RD, Fanaroff AA, Duara S, Goldberg R, Laptook A, Walsh M, Oh W, Hale E, for the National Institute of Child Health and Human Development. Very low birth weight preterm infants with early onset neonatal sepsis. The predominance of gram-negative infections continues in the National Institute of Child Health and Human Development Neonatal Research Network, 2002-2003. Pediatr Infect Dis J. 2005;24:635-9.

Storm W. Transient bacteremia following endotracheal suctioning in ventilated newborns. Pediatrics. 1980;65:487-90.

Strieter RM, Kunkel SL, Bone RC. Role of tumor necrosis factor a in disease status and inflammation Crit Care Med. 1993;21:S447-S463. 
Taniguchi T, Koido Y, Aiboshi J, Yamashita T, Suzaki S, Kurokawa A. Change in the ratio of interleukin- 6 to interleukin-10 predicts a poor outcome in patients with systemic inflammatory response syndrome. Crit Care Med. $1999 ; 27: 1262-4$.

Tracey KJ. The inflammatory reflex. Nature. 2002;420:853-9.

Tracey KJ, Cerami A. Tumor necrosis factor, others cytokines and disease. ANNU Rev Cell Bio. 1993;9:317-43.

Tracey KJ, Cerami A. Tumor necrosis factor: a pleiotropic cytokine and therapeutic target. ANNU Rev Med. 1994;45:491-503.

Ulloa L, Tracey KJ. The ' cytokine profile': a code for sepsis. Trens Mol Med. 2005;11:56-63.

Van Der Poll T. Immunotherapy of sepsis. Lancet Infect Dis. 2001;1:165-74.

Van Deventer SJ, Buller HR, Ten Cate JW, Aarden LA, Hack CE, Sturk A. Experimental endotoxemia in humans: analysis of cytokine release and coagulation, fibrinolitic and complement pathways. Blood. 1990;76:2520-6 
Van Dissel JY, Van Lange Velde P, Westendorp RG, Kwappenberg K, Frölich M. Anti-inflammatory cytokines profile and mortality in febrile patients . Lancet. 1998;351:950-3.

Vaz FAC, Ceccon MEJ, Diniz EMA, Valdetaro F. Marcadores imunológicos (IgM e protein $\mathrm{C}$ reativa) nas infecções neonatais. Rev Ass Med Bras. 1998;44:185-5.

Waage A, Halstensen A, Espevik T. Association between tumour necrosis factor in serum and fatal outcome in patients with meningococcal disease. Lancet. 1987;1:355-7.

Werling D, Jungi TW. Toll-like receptors linking innate and adaptive immune response. Vet Immunol Immunopathol. 2003;91:1-12

Wiswell JE, Hachey J. Multiple site blood cultures in the initial evaluation for neonatal sepsis during the first week of life. Pediatr Infect Dis. 1991;10:3659.

World Health Organization. Perinatal mortality: a listing of available information. Geneva: World Health Organization; 1996. 
Wright JG, Christman JW. The role of nuclear factor kappa $B$ in the pathogenesis of pulmonary diseases: implications for therapy. Am J Respir Med. 2003;2:211-9.

Zivot JB, Hoffman WD. Pathogenic effects of endotoxina. New Horiz. 1995;3:267-5.

Zupan J, Aahman E. Perinatal mortality for the year 2000: estimates developed by WHO. Geneva: World Health Organization; 2005. 